University of Windsor

Scholarship at UWindsor

8-22-1966

\title{
Kinetics of catalytic oxidation of methane application of initial rate technique for mechanism determination.
}

Om Parkash Ahuja

University of Windsor

Follow this and additional works at: https://scholar.uwindsor.ca/etd

\section{Recommended Citation}

Ahuja, Om Parkash, "Kinetics of catalytic oxidation of methane application of initial rate technique for mechanism determination." (1966). Electronic Theses and Dissertations. 6411.

https://scholar.uwindsor.ca/etd/6411

This online database contains the full-text of PhD dissertations and Masters' theses of University of Windsor students from 1954 forward. These documents are made available for personal study and research purposes only, in accordance with the Canadian Copyright Act and the Creative Commons license-CC BY-NC-ND (Attribution, Non-Commercial, No Derivative Works). Under this license, works must always be attributed to the copyright holder (original author), cannot be used for any commercial purposes, and may not be altered. Any other use would require the permission of the copyright holder. Students may inquire about withdrawing their dissertation and/or thesis from this database. For additional inquiries, please contact the repository administrator via email (scholarship@uwindsor.ca) or by telephone at 519-253-3000ext. 3208. 


\title{
KINETICS OF CATAIYTIC OXIDATION OF METHANE \\ APPLICATION OF INITIAI RATE TECHNIQUE \\ FOR MECHANISM DETERMINATION
}

\begin{abstract}
A THESIS
Submitted to the Faculty of Graduate Studies through the Department of Chemical Engineering in Partial Fulfilment of the requirements for the degree of Master of Applied Science at University of windsor
\end{abstract}

by

Om Parkash Ahuja

$$
\begin{gathered}
\text { Windsor, Ontario, Canada } \\
\text { April, } 1966
\end{gathered}
$$


UMI Number: EC52592

\section{INFORMATION TO USERS}

The quality of this reproduction is dependent upon the quality of the copy submitted. Broken or indistinct print, colored or poor quality illustrations and photographs, print bleed-through, substandard margins, and improper alignment can adversely affect reproduction.

In the unlikely event that the author did not send a complete manuscript and there are missing pages, these will be noted. Also, if unauthorized copyright material had to be removed, a note will indicate the deletion.

(B)

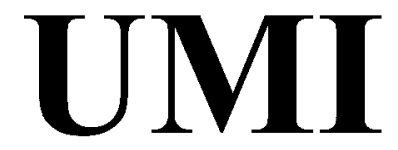

UMI Microform EC52592

Copyright 2008 by ProQuest LLC.

All rights reserved. This microform edition is protected against unauthorized copying under Title 17, United States Code.

ProQuest LLC

789 E. Eisenhower Parkway PO Box 1346

Ann Arbor, MI 48106-1346 


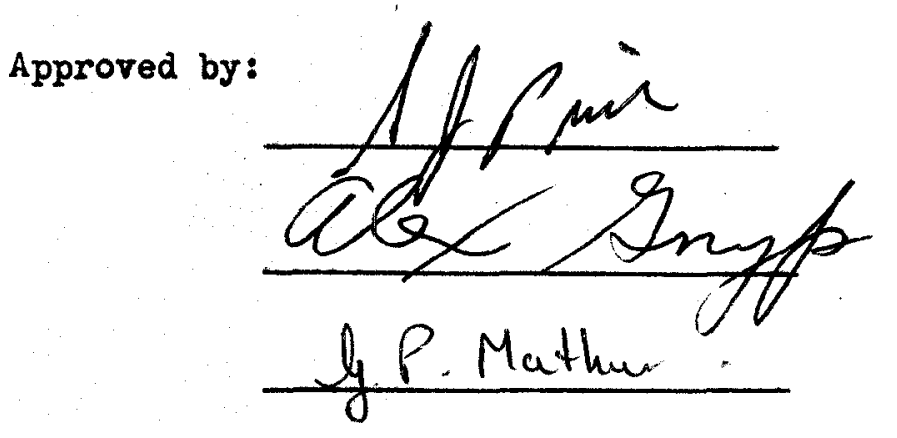

\section{7}




\section{ABSTRACT}

A kinetic investigation on the oxidation of methane using a palladium catalyst was conducted. A differential bed reactor was used, and the conversions of methane were limited to about $10 \%$. The small conversions facilitated the use of the initial rate approach to find the reaction mechanism. Plots of initial rate against total pressure were used to interpret the data qualitatively. Iinearised rate equations were used to find the regression coefficients for various plausible mechanisms. The criteria of best fit to experimental data eliminated many improbable mechanisms.

Data on the variation of initial rate with feed composition were very helpful in arriving at a definite mechanism for the oxidation reaction. The experimental results indicated that the reaction rate was controlled by surface reaction in which the adsorbed oxygen and adsorbed methane react to produce adsorbed carbon dioxide and adsorbed water. The corresponding rate equation has the form:

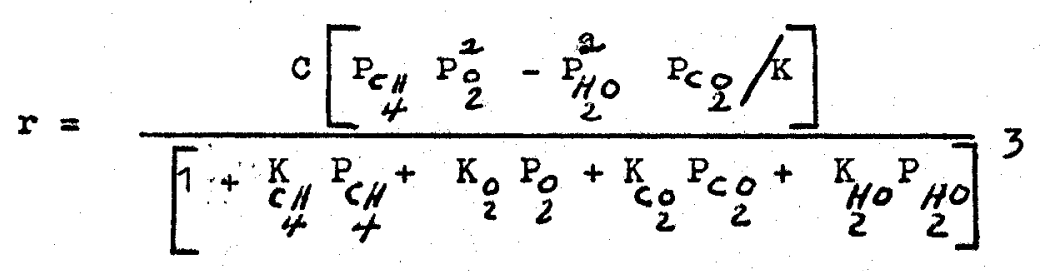




\section{ACKNOWLEDGEMENTS}

The author wishes to express his sincere gratitude to Dr. G.P. Mathur for his able guidance, valuable suggestions and constructive criticism, to Dr. A.W. Gnyp for his guidance and direction, to Dr. S.J.W. Price, who provided his valuable time and guidance for operation of the gas chromatograph.

The financial assistance offered by National Research Council of Canada, in gratefully acknowledged. 
TABLE OF CONTENTS

ABSTRACT

ACKNOWLEDGEMENTS

TABIE OF CONTENTS

IIST OF TABLES

(v)

LIST OF FIGURES

(vi)

CHAPTER

Page

INTRODUCTION - - - - - - - - - - -

1

II LITERATURE REVIEW -................

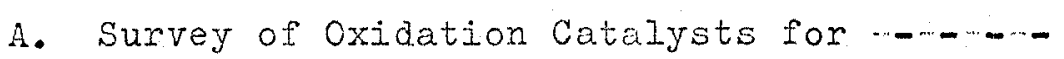

Exhaust Gases

B. Kinetic Studies of Oxidation of $\cdots \cdots \cdots$

Hydrocarbons

C. Important Considerations for Design of - -

Catalytic Converter

III THEORETICAI CONSIDERATIONS - - - - - - - 10

IV EXPERIMENTAL EQUTPMENT AND MATERIAL - - - - 15

A. Reactor, Preheater and Accessories - - - I 15

B. Flow Measurement Devices _ - . . . . 19

C. Analytical set-up - - - . - - - 19

D. Catalyst Choice _ - . . - . - - 19

E. Selection of Gases - - - - - - - - 20

$V$ OPERATIOMAL DETAILS AND RESULTS - - - - - 21

A. Calibration Procedures - - - - - - - 21.

B. Operations Procedure - - - - - - - 24

C. Results - . . - . . . . . . - 25

VI AMALYSIS OF RESULIS - - - - - - - - 29

VII CONCLUSIONS $\ldots \ldots-\ldots$

(iii) 


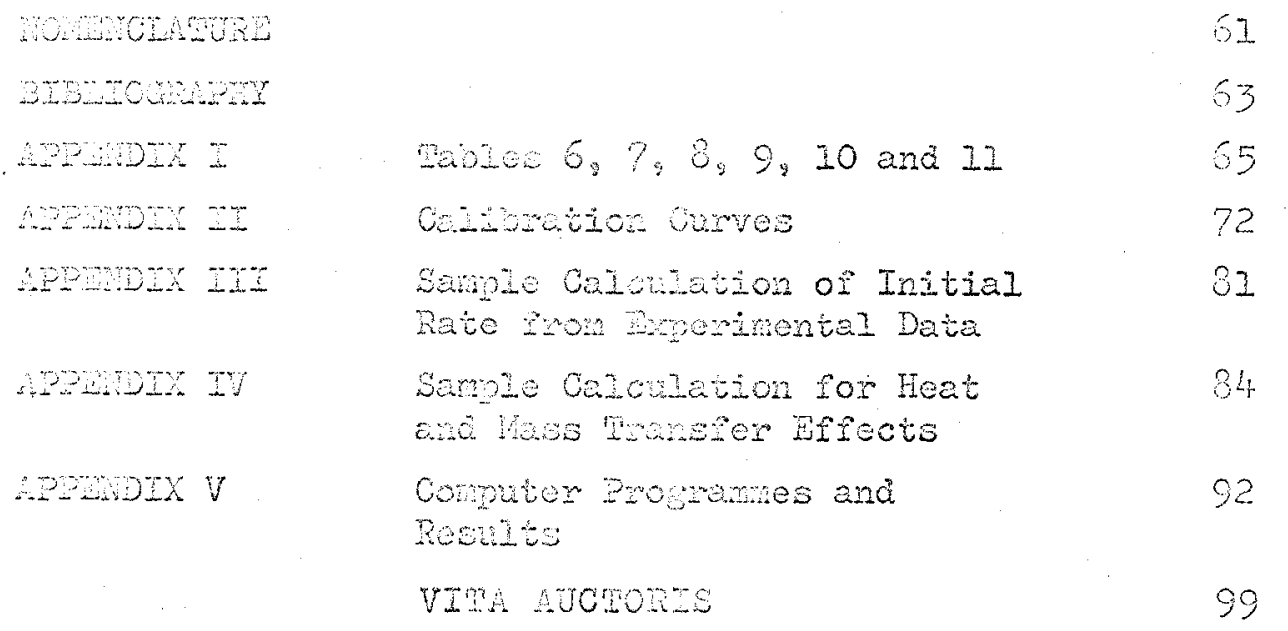




\section{LISE OR NABES}

\begin{tabular}{|c|c|}
\hline & Eperbinental results of cxidation Runs \\
\hline 3 & 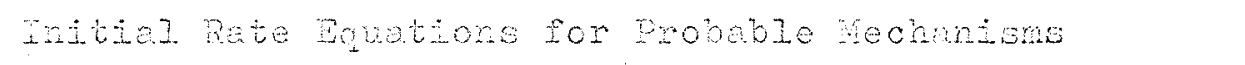 \\
\hline , & Regresuton Coepsctonds for Hirearised Rate Rquations \\
\hline 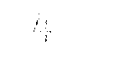 & Mechantotic Rave Taution mo \\
\hline $3 a$ & 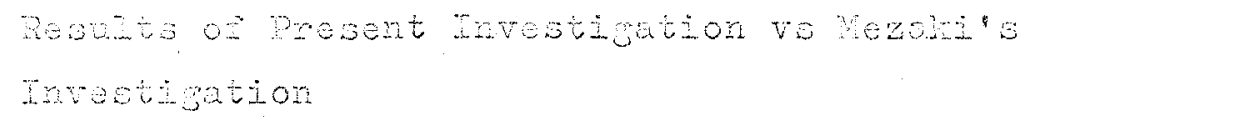 \\
\hline 5 & Dotrical Rate Equation Deta \\
\hline 6 & 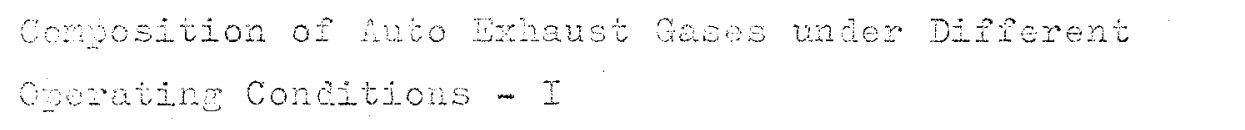 \\
\hline$?$ & $\begin{array}{l}\text { Conposition of Aut Exhave Gases unces Diflenent } \\
\text { Openating Conditions - II }\end{array}$ \\
\hline 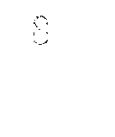 & $\begin{array}{l}\text { omposition of Auto Txhaust Gases under Difperent } \\
\text { oporting Conditione - InI }\end{array}$ \\
\hline 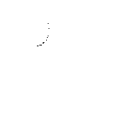 & $\begin{array}{l}\text { Corelation botwecn Space Velocity and Conversion } \\
\text { g Wothene }\end{array}$ \\
\hline & ne tratysis of C.P. Grade Methene \\
\hline & Operating Data Por Chromatographio Analysis \\
\hline
\end{tabular}

(v) 
6 Initial Rate of Reaction Vs Feed Composition $300^{\circ} \mathrm{C}, 1.817 \mathrm{Atm}$.

7 Initial Rate of Reaction Vs Feed Composition $320^{\circ} \mathrm{C}, 1.817 \mathrm{Atm}$.

8 Initial Rate of Reaction Vs Feed Composition $340^{\circ} \mathrm{C}, 1.817 \mathrm{Atm}$.

11 Initial Rate of Reaction from Mechanistic

Equation $340^{\circ} \mathrm{C}$

12 Initial Rate of Reaction from Impirical

Equation $300^{\circ} \mathrm{C}$

13. Initial kate of Reaction from Empirical Equation $320^{\circ} \mathrm{C}$

14 Initial Race of Reaction from Empirical

15 Calibration Curves for Oxygen Rotameter 
LIST OF FUORES (Cont'd)

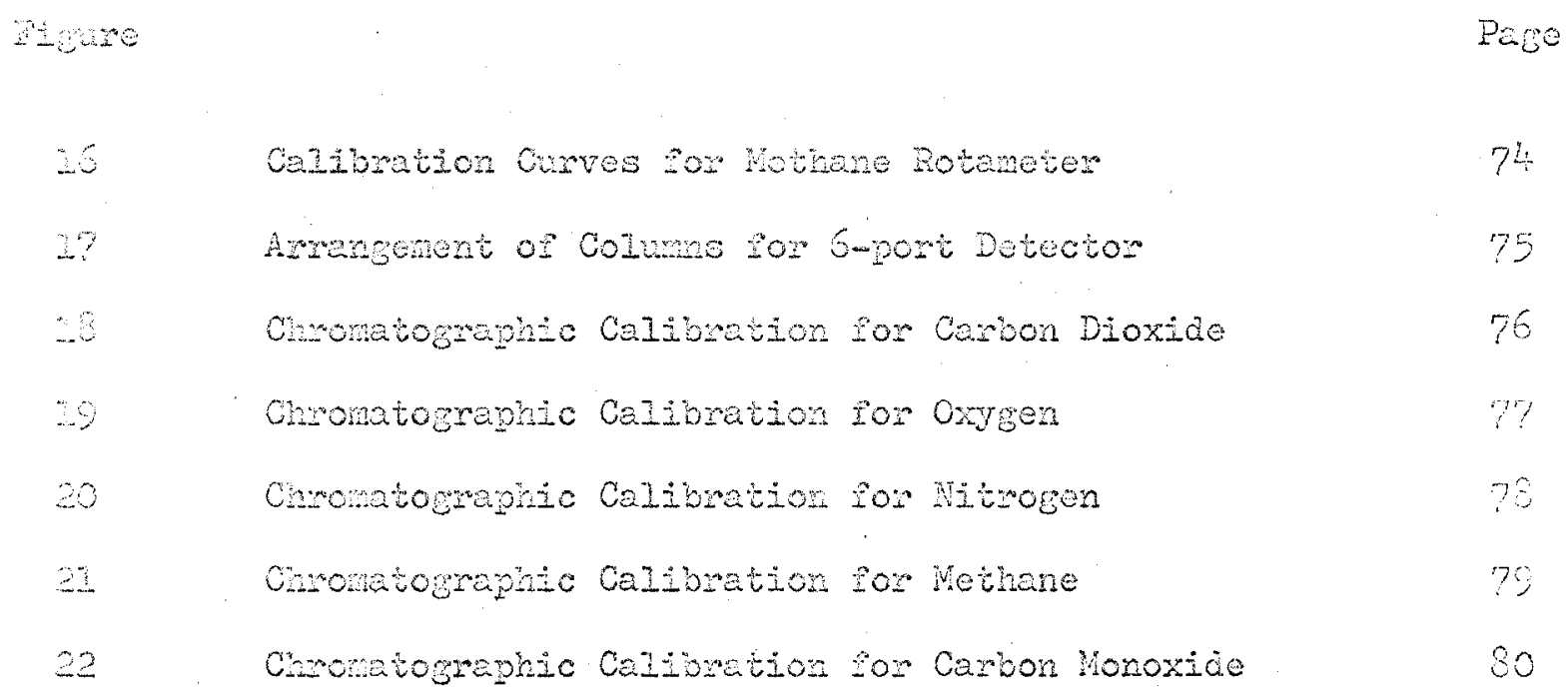


Air pollution, in general, is a direct result of smoke, dust or fumes from a variety of sources. Processes like combustion, roasting, mining and quarying contribute greatly to air pollution.

The objectionable components from incomplete combustion of fuels in industry and automobiles are the hydrocarbons and oxides of nitrogen. Hydrocarbons and nitrogen oxides are present in such small concentrations that they probably have no direct effect on health. But, as reported by Yocom (1), the hydrocarbons react photochemically with nitrogen oxides to produce unstable peroxides which act as a nuclei in smog production. In major industrial cities, high concentrations of carbon monoxide, coming from combustion processes and automobiles, can cause toxic efiect on humans.

At present the world's use of fuels is rising rapialy because of industrialisation and development. As a result the pollution hazard is growing. Reduction of smog forming components and carbon monoxide in tail gases would be a necessary step towards reducing air pollution.

Many devices ${ }^{(2)}$ have been advanced so far for the prevention of these undesirable components in tail gases of automobiles. The following devices have been examined critically from a commercial point of view: 
1. After burners

2. Isiquid washing devices

3. Adsorption units

4. Catalytic converters

The major problem in the design of after burners is maintenance of a flame which will allow auto-ignition of hydrocarbons under all conditions. Liquid washing devices and adsorption with porous solids have not been very succecsful so far, because of the unwieldy size of such devices. Catalytic conversion is a promising alternative to other devices.

Extensive investigations on catalytic converters for carbon monoxide and hydrocarbons, were made by Lamb and coworkers towards the end of World war I. The investigations of lumb and co-workers and of Yant and Hawk ${ }^{(4)}$ showed that the catalysts effective for carbon monoxide oxidation are also effective for hydrocarbons oxidation. Recently reported laboratory evaluations of catalysts for the automotive exhausts by Camon and Welling (5) confirm the earlier results.

Table 6,7 and $8^{(6)}$ in Appendix 1 show typical compositions of automotive exhaust gases under different operating conditions. These tables show that methane constitutes 25 to $40 \%$ of the total hydrocarbons in tail gases. Furthermore, Anderson and co-workers (7). have reported that, in the light hydrocarbons family, methane is the most difficult gas to oxidise.

The data obtained from the catalytic oxidation of methane should be helpful in the design of a suitable catalytic reactor for automobile exhaust control. In adaition to this, a kinetic investigation of the methane oxidation should be very interesting from a scientific point of view. 
In the present investifation the objective was to establish the mechanism of catalytic oxidation of methane by usine an initial rate approach. Obviously, the initial rate technique limited to low conversion experiments, does not provide data for design of catalytic converters for auto exhausts. Experiments at nearly complete conversion would be necessary to provide such information. However, integral rate data are difficult to evaluate from a mechanistic point of view.

For a study of a catalytic reaction, a two step process is recommended

(i) Initial rate analysis to establish the mechanistic equation.

(ii) High conversion study to fit the mechanistic equation in the desired conversion range.

The assumption that is inherent in the above scheme is that the adsorption characteristics of the components do not change over the range of conversion. This is considered a reasonable assumption for most catalytic reactions. The equilibrium quantities being function of temperature only, do not change with composition.

This investigation is concerned with the first stage of the scheme discussed above. Data at low conversion and varying pressure would be employed to establish the mechanistic equation. The rate equation obtained by initial rate approach, after addition of the proper product terms should be applicable for high conversion range. 


\section{A. Survey of Oxidation Catolysts for Exhaust Gases}

Many investigations ( 8 ) have been reported on the partial oxidation of hydrocarbons to valuable organic substances as acids, aldehydes, alcohols, esters and ketones. In addition to this, a large amount of work has been done on the catalytic oxidation of exhaust gases and individual hydrocarbon constituents.

As early as 1825, the effect of platinum on the combustion of methane at $290^{\circ} \mathrm{C}$ was investigated by Henry (9). Yant and Hawk ${ }^{(4)}$ found that platinum had a catalytic effect at temperatures between 150 to $300^{\circ} \mathrm{C}$ for approximately $4 \%$ methane in air. Conversion was less than $10 \%$ in this temperature range.

The catalytic activity of copper oxide for methane oxidation has been studied by CampbeII (10), Wheeler ${ }^{(11)}$ and Araki ${ }^{(13)}$. According to them, copper oxide has a catalytic activity at rather elevated temperatures, in the range of $400-700^{\circ} \mathrm{C}$.

Yant and Hawk ${ }^{(4)}$, Thompson ${ }^{(14)}$, and Anderson and co-workers (7) found oxides of $\mathrm{Ni}, \mathrm{Cr}, \mathrm{Mn}, \mathrm{V}$ and Co quite effective for methane oxidation. In particular, $\mathrm{Co}_{3} \mathrm{O}_{4}$ gave promising results with respect to conversion and catalyst life. According to recent experiments of Kazarnovskya and Dykhno(15), the most effective catalyst for oxidation of methane is manganic ore enriched with silver. The complete combustion of $0.10-0.15 \%$ methane in oxygen was observed at $300^{\circ} \mathrm{C}$. The detailed description of this catalyst is not given. 
Towards the end of Vorld War I, a commercial material called Fopcalite was discovered for carbon monoxide gas masks. Hopcalite is a registered trade name with the Mine Safety Appliance Company, and is really a mixture of compounds which indlude, among others, manganese dioxide and cuprous oxide. After extensive investigations, lamb and co-workers $(3)$ found that the mixture of oxides of copper, manganese, silver and cobalt was most effective for oxidation of carbon monoxide. Yant and Hawk ${ }^{(4)}$ have reported that commercial Hopcalite could oxidise $4 \%$ methane in air to carbon dioxide and water with $10-60 \%$ conversion over the temperature range $200-350^{\circ} \mathrm{C}$. This catalyst is quite effective for dry gas, but poisoned very rapidly in presence of water vapour. It also loses activity on prolonged heating at temperatures above $250^{\circ} \mathrm{C}$, due to sintering.

$$
\text { Anderson and co-workers ( } 7 \text { ) have concluded that the }
$$
catalytic activity of metals and their oxides, decreases in the following order: Pd, Pt, $\mathrm{Cr}, \mathrm{Mn}, \mathrm{Cu}, \mathrm{Ce}, \mathrm{Co}, \mathrm{Fe}, \mathrm{Ni}$, and Ag. This order of effectiveness was the same as previously reported by Cohn and Haley $(16)$.

\section{B. Kinetic Studies on the Oxidation of Hydrocarbons}

Anderson and co-workers ${ }^{(7)}$ did a kinetic study on the oxidation of methane. The catalyst bed was 7 to $7.5 \mathrm{cc}$. deep with a cross section of $2.435 \mathrm{sq}$. cm., methane concentration was $1 \%$ and air flow 2 liters/min. at room temperature. Thirty kinds of catalysts were tested over the temperature range $450-800^{\circ} \mathrm{K}$, using a constant value of space velocity. The experimental data were approximated by an empirical equation with respect to methane concentration. 


\begin{abstract}
Roserbaum (17) worked on the oxidation of very dilute methane ( 51 ppm in air) at $1075^{\circ}$ F by using the pelletized catalyst supplied by Ingelhard Industries. The relationship between space velocity and conversion is given in Table 9 in Appendix I. The volume of catalyst used was $0.0005 \mathrm{cu}$. ft. No details were given for the size and composition of the catalyst.

Mezaki (18) used vanadia, cobalt, copper-chromite, chrome alumina, hopcalite and palladium catalysts for methane oxidation. He found palladium to be the most effective catalyst from the stand point of ignition temperature, stability, freedom from side reactions, and good conversion. However, palladium is not necessarily free from objectionable features. It has a reported tendency of poisoning by lead compounds.
\end{abstract}

Mezaki studied the catalytic oxidation of methane using $0.5 \%$ palladium on alunina catalyst. Methane concentrations in feed were $I$ to $2 \%$. The reaction temperature was varied between 320 to $380^{\circ} \mathrm{C}$ and the pressure was kept atmospheric. The feed in addition to reactants containea reaction products as well. In this connection, Mezaki has correctly pointed out that when the feed to reactor contains the reaction products, one cannot use the initial rate - total pressure correlation to screen the postulated mechanisms.

In an initial survey, Mezaki (19) used 84 models in which adsorption of reactants or desorption of products was the postulated rate-controlining step. The linearised models were fitted to the experimental rate-data by least square. technique, but this fitting resulted in two or more negative constants. This led to the rejection of these models. 
Then, assuming that surface reaction is the rate controlling step, Mezaki used integral kinetic equations for fitting the experimental data to postulated models. He eventually concluded that the controlling step in the oxidation of methane is surface reaction between adsorbed oxygen and gaseous methane to give adsorbed carbon dioxide and water. There is no apriori reason to suspect that in a catalytic reaction, at different temperatures, the same step is rate controlling. Recent applications of the initial rate technique have established that for the same catalytic reaction at different temperatures, different steps could be rate controlling. Thaller and Thodos (20) and Mathur (21) have reported changes in controlling step at different temperatures for two quite different types of catalytic reactions. In view of this, Mezaki's treatment of kinetic data appears to be somewhat empirical.

c. Important Considerations in the design of a Catalytic Converter

Many factors have to be considered for the design of a catalytic converter for auto exhausts. Different makes and life of automobiles, fuels and wide range of operating conditions lead to great variation in physical and chemical properties of exhaust gases. A brief review of the current situation follows.

\section{(i) Exhaust Gas Temperature}

Exhaust gas temperatures are changed by operating conditions. Temperatures from 150 to $1500^{\circ} \mathrm{F}$ have been observed depending on engine operation and location of measurement in tail gas pipe. Therefore, it is essential to determine the lowest temperature at which the 
catalytic conversion starts and highest working temperature of catalyst.

\section{(ii) Exhaust Gas Flow Rate}

From measured air intakes of passenger cars, computed exhaust volumes, at $1 \mathrm{Atm}$. and $70^{\circ} \mathrm{F}$, range from 6 to $10 \mathrm{cfm}$. at idle, to $50 \mathrm{cfm}$. at $50 \mathrm{mph}$. The flow rate at accelration might reach $250 \mathrm{cfm}$.

\section{(iii) Exhaust Gas Composition}

Hydrocarbons, hydrogen and carbon monoxide are the major combustible components in the exhaust gases. The concentrations of these components vary greatly depending on operating conditions and air-fuel ratio. Tables 6,7 and $8^{(6)}$ in Appendix I show some typical compositions of automobile exhaust gases under different operating conditions.

If automobiles were running at fairly constant rates, the kinetics of exhaust gas oxidation could be solved for a steady state condition. When an automobile starts to run, the oxidation process gives a complicated unsteady state problem. Generally, an automobile starts in a residential area, goes through more.populated zones at variable engine conditions, and runs through sparsely populated areas at rather constant conditions. When the engine starts, it stays at a rather low temperature and the exhaust contains a large amount of carbon monoxide and hydrocarbons. Therefore, the oxidation catalyst needs to be specially active at low temperature. 
It should also have good conversion, good life, and inertness to lead compounts.

The pressure drop through the catalytic converter should be low to reduce power cost for compression of gases. The converter should also be compact in construction. 


\section{THEORETICAL CONSIDERATIONS}

In a solid catalyzed reaction the physical steps are the transfer of the fluid reactants upto the catalyst surface, diffusion of reactants into the interior of the pellet, diffusion of products back to the surface and transfer of products from the exterior surface to the main stream. To simplify the kinetic interpretation of the experimental data, these physical steps have to be minimised.

The chemical steps involve activated adsorption of reactants with or without dissociation, surface reaction on active sites and activated desorption of products. From an absolute theory point of view, the adsorption process is a bimolecular reaction involving a molecule or an atom from the gas phase and an active point on the catalyst surface.

In order to determine the mechanism of a catalytic reaction on the basis of the Hougen Model(21), various possible reaction schemes are investigated. The acceptability criteria for any, rate equation is that all equilibrium constants have to be positive.

As an illustration, consider a scheme in which the surface reaction is between an adsorbed methane molecule and two oxygen molecules dissociated and adsorbed on dual sites. The rate equations for adsorption, surface reaction and desorption steps are deduced from the treatment given by Hougen $(21)$ 


\section{ADSORPTION STEPS}

(i) Adsorption of oxygen:-

$$
\begin{aligned}
& 2 \mathrm{O}_{2}+2 \mathrm{I}_{2} \rightleftharpoons 2 \mathrm{O}_{2} I_{2} \\
& 2 \mathrm{O}_{2} I_{2}+4 \mathrm{I} \rightleftharpoons 401+2 I_{2}
\end{aligned}
$$

Eq. (1) is rate controling and equilibrium maintained

in (2), net rate of adsorption of oxygen

$R$ ads. $=k_{\mathrm{O}_{2}} \mathrm{a}^{2} \mathrm{O}_{2} \mathrm{C}^{2}{ }_{2}-\mathrm{ko}_{2} \frac{\left[\mathrm{C}_{\mathrm{O}}\right]^{4}\left[\mathrm{C}_{12}\right]^{2}}{\mathrm{~K}^{\prime} \mathrm{O}_{2}\left[\mathrm{C}_{2}\right]^{4}}-(3)$

(ii) Adsorption of methane:-

$$
\mathrm{CH}_{4}+\mathrm{I} \rightleftharpoons \mathrm{CH}_{4} \mathrm{I}
$$

net rate of adsorption of methane

$$
r=k_{\mathrm{CH}_{4}} \quad{ }^{a_{\mathrm{CH}}} \mathrm{C}_{1}-k^{\prime} \mathrm{CH}_{4} \quad{ }_{\mathrm{CH}_{4} \mathrm{I}}
$$

\section{SURFACE REACTION}

Surface reaction between four adsorbed oxygen atoms

and adsorbed methane molecule to give activated complex

involving one carbon dioxide molecule and two water molecules and two active centres

$$
4 \mathrm{OI}+\mathrm{CH}_{4} \mathrm{I} \rightleftharpoons \mathrm{CO}_{2} \mathrm{I}+2 \mathrm{H}_{2} \mathrm{OI}+2 \mathrm{I}
$$

net rate of surface reaction

$R$ s.r. $=\frac{s(s-1) \mathrm{ks.r.}}{I^{2}}\left[\mathrm{C}_{\mathrm{CH}_{4} I} \mathrm{C}^{4} \mathrm{OI}-\frac{{ }_{\mathrm{CO}_{2} I} \mathrm{C}^{2} \mathrm{H}_{2} \mathrm{OI} \mathrm{C}_{I}^{2}}{\mathrm{~K}^{\prime} \mathrm{s.r} .}\right]$ 
DESORPTION STEPS

(i) Desorption of Carbon dioxide

$$
\mathrm{CO}_{2} \mathrm{I} \rightleftharpoons \mathrm{CO}_{2}+\mathrm{I}
$$

net rate of desorption of $\mathrm{CO}_{2}$

$r$ des. $=k^{\prime}{ }_{\mathrm{Co}_{2}}{\stackrel{C}{\mathrm{co}_{2} I}-k_{\mathrm{CO}_{2}}}_{\mathrm{aco}_{2}} \mathrm{C}_{1}$

(ii) Desorption of water

$$
2 \mathrm{H}_{2} \mathrm{OI} \rightleftharpoons 2 \mathrm{H}_{2} \mathrm{O}+2 \mathrm{I}
$$

net rate of desorption of $\mathrm{H}_{2} \mathrm{O}$

$r$ des. $=k^{\prime}{ }_{\mathrm{H}_{2} \mathrm{O}} \quad \mathrm{C}^{2} \mathrm{H}_{2} \mathrm{OI} \quad-k_{\mathrm{H}_{2} \mathrm{O}} \quad a^{2} \mathrm{H}_{2} \mathrm{O} \quad \mathrm{C}^{2}$

If the adsorption of oxycen is rate controlling step and the adsorption of methane, the surface reaction, the desorption of $\mathrm{CO}_{2}$ and $\mathrm{H}_{2} \mathrm{O}$ are equilibrium steps. The rate of reaction

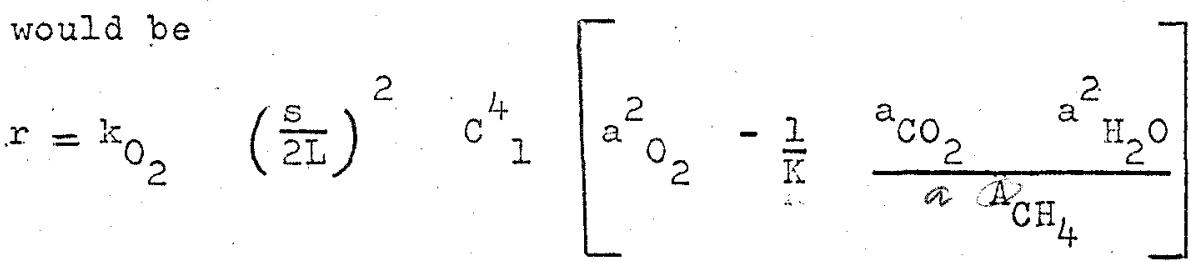

$C_{1}$, total concentrations of vacant active centres, is given by

$$
\begin{aligned}
& \mathrm{C}_{\mathrm{I}}=\mathrm{I}-\mathrm{C}_{\mathrm{CH}_{4} \mathrm{I}}+\mathrm{C}_{\mathrm{CO}_{2} \mathrm{I}}+\mathrm{C}_{\mathrm{H}_{2} \mathrm{OI}}+\mathrm{C}_{\mathrm{OI}}
\end{aligned}
$$

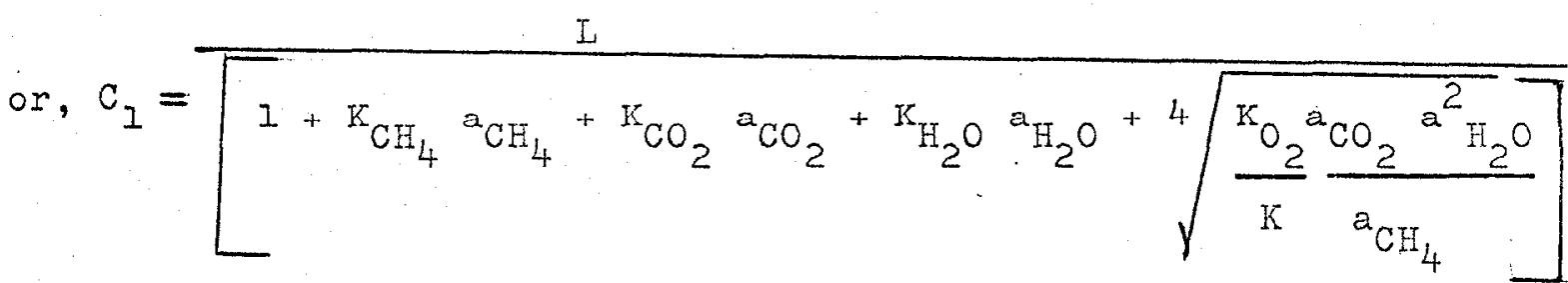


from (12) and (14)

$$
\begin{aligned}
& \mathrm{ko}_{2} s^{2} L^{2}\left[\mathrm{a}^{2} \mathrm{O}_{2}-\frac{1}{\mathrm{~K}} \quad \frac{{ }_{\mathrm{CO}_{2}} a^{2} \mathrm{H}_{2} \mathrm{O}}{a_{\mathrm{CH}_{4}}}\right]
\end{aligned}
$$

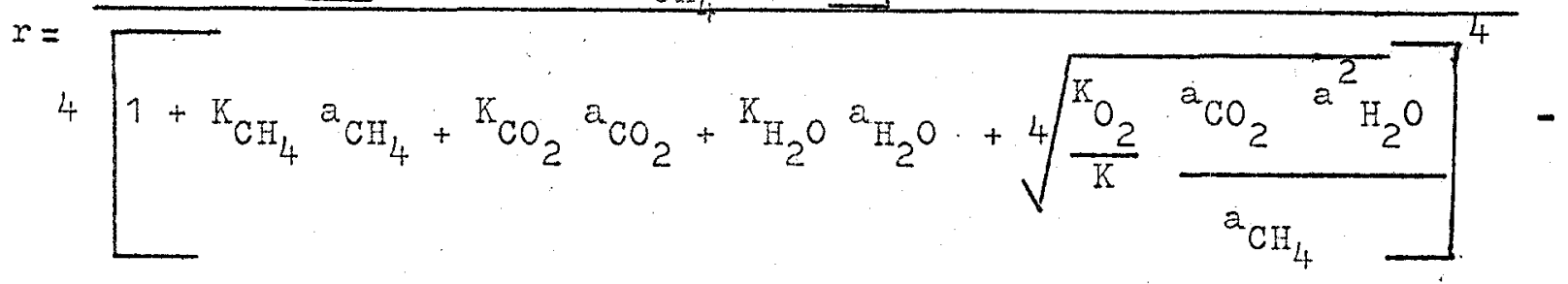

If product concentrations are very small as compared to reactant concentrations, the rate of reaction can be written, as,

$r=K\left[\begin{array}{ll}a^{2} & \\ & 0_{2}\end{array}\right] /\left[\begin{array}{lll}1 & \mathrm{~K}_{\mathrm{CH}_{4}} & \mathrm{a}_{\mathrm{CH}_{4}}\end{array}\right]^{4}$

For a constant ratio of methane to oxygen, and assuming ideal gas law condition, equation (16) can be written in terms of total pressure, $\pi$, as follows

$$
r o=a \pi^{2} /[1+b]^{4}
$$

The simplicity and directness of the initial rate equation (17), as compared to the complete rate expression, equation (15), is obvious.

Iang and Hougen (22) pointed out that initial rate analysis is one of the best techniques to establish the mechanism of a catalytic reaction. They have discussed in detail the type of results that are to be anticipated when the initial rates are plotted against total pressure and feed composition. 
By systenatic and independent variations in total pressure and feed composition, the plots of initial rates acainst total pressure and feed composition are obtained. Through an interpretation of these plots, it is possible to establish the rate controlling step or steps of the catalytic reaction with assurance. Moreover, initial rate approach does not assume that the same controlljng step or steps are operative at all temperatures.

As pointed out in the introduction the initial rate equations are not complete rate equations for a catalytic reaction. The initial rate approach nevertheless provides for a much more direct determination of the mechanism of a catalytic reaction.

In this investigation the objective is to establish the mechanism of methane oxidation at different temperatures. The overwhelming advantages of the initial rate technique, as apposed to the conventional approaches, recommended for this investigation. 


\section{EXPERIMENTAI EQUIPMENT AND MATERIALS}

The reaction rate data for the oxidation of methane was obtained using a differential bed reactor confined in a cylinderical tube. A schematic diagram of the set up is shown in Figure 1. The details of the equipment and materials used are given below:-

\section{(A) Reactor, Preheater and Accessoriès}

The reactor tube and the differential bed are shown in Figure 2. The reactor tube was made of $1 / 1 / 2$ inch I.D., schedule 40, 304 stainless steel tubing, The ends of the tube were fitted with 300 psig. welding neck flanges and matching blind flanges. Copper gaskets of $1 / 8$ inch thickness were used for leakproof closure of the tube. Thermowells were welded to top and bottom flanges. To facilitate insertion of $1 / 4 "$ berl saddles, 3/8" O.D.S.S. tube was also welded to top and bottom flanges.

The differential bed consisted of a $13 / 8 " 0 . D ., 1 / 8 "$ thick, $51 / 2$ " long S.S. cartridge. Its ends were closed by screens and washers. The screens fitted snugly with the inside of the reactor tube with little clearance. Catalyst mixed with ceramic berl saddles was charged into the cartridge. This minimised the non-uniformity of bed and channeling effects. The catalyst bed occupled the space between the ends of the thermowells, rest of reactor space was packed with $1 / 4$ " ceramic berl saddles. 


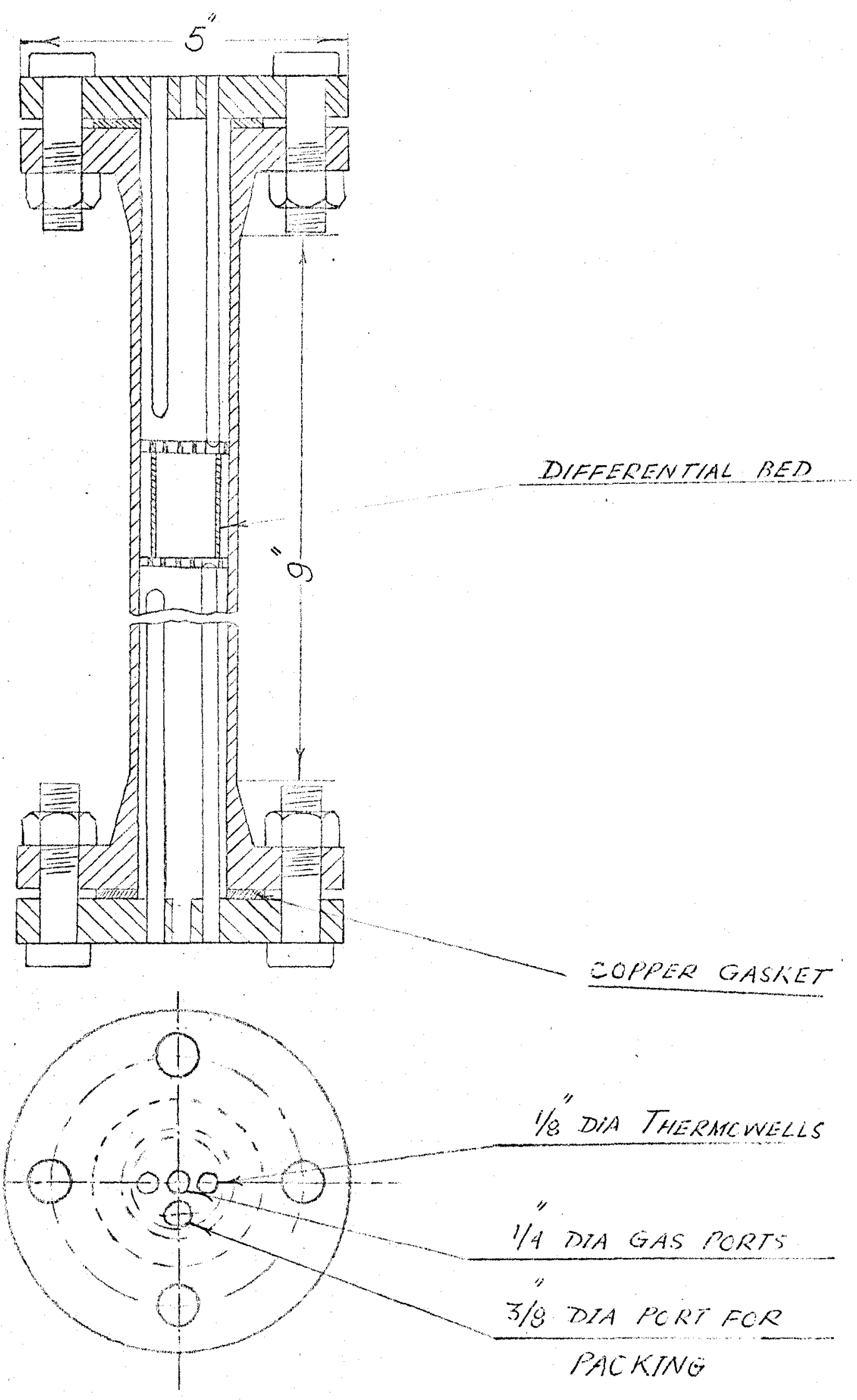

FIG.2 SECTIONAL VIEW OF REACTOR TUBE AND DIFEERENTIAL BED 
The preheater construction was basically identical to that of the reactor. A minor difference was that reactor tube was 3 inches shorter than the preheater tube. The preheater was packed with $1 / 4 "$ ceramic berl saddles.

The tubing connecting the gas cylinders to preheater was 1/4" O.D. Copper. From preheater exit to sampling connection, the tubing was 1/4" O.D. S.S. Standard screwed swagelok fittings were used for all connections.

The preheater was heated by $12 "$ long, 1400 watts cylinderical heating units. The reactor had three independently controlled heating sections of lengths $3.1 / 2 "$, $5^{\prime \prime}$ and $31 / 2 "$ rated at 700,1160 and 700 watts respectively. The furnaces were insulated with refractory fibre felt supplied by Johns Manville. To prevent condensation of water vapours in the system, the tubing from preheater exit to sampling connection was heated with electric heating tape.

Chromel-alumel thermocouples in $1 / 16 "$ O.D. stainless steel sheaths were used for temperature measurement.

A pressure gauge of range $0-400$ psig. With valve connections at the inlet and the outlet of the reactor, was used to measure the operating pressure of the system. A spring loaded pressure relief valve set at 500 pounds, was used as the safety device. 
(B) Flow Measurement Devices

Rotameters were used to measure the flow rates of oxygen and methane. These were equipped with dual floats, one of pyrex, the other of stainless steel. The maximum flow ranges with the two floats were 4.4 and $8.8 \mathrm{sCFH}$ of air. The rotameters for oxygen and methane were identical in all respects. These were supplied by Matheson Co.

(C) Analytical Equipment

The analytical equipment for reactants and products was a gas chromatograph. It was a 5000 series selecta system model supplied by Barber Colman Itd. It had dual column bath and six port thermal conductivity detector. The arrangement of the columns connected to the six ports is given in Figure 17 of Appendix II. - The first colurn was a I/4" O.D.; I ft. silica gel type followed by $1 / 4$ " O.D. $7 \mathrm{ft.} \mathrm{molecular} \mathrm{sieve} \mathrm{column.} \mathrm{The} \mathrm{second} \mathrm{column}$ was 1/8" O.D.; $15 \mathrm{ft}$. carbowax 1500 .

Other major parts of the chromatograph were carrier gas supply regulators, injector bath, column bath, detector filaments current supply and the recorder. All syringes were gas tight.

(D) The catalyst, $0.5 \%$ palladium on alumina supplied by . Engelhard Industries Inc., had the following physical properties:-

$$
\begin{array}{ll}
\text { Bulk density } & 56 \text { pounds per cu. ft. } \\
\text { Surface area } & 120 \text { square metres per gram. } \\
\text { Size } & 1 / 8 " \times 1 / 8^{\prime \prime} \text { cylinderical pellets }
\end{array}
$$


(E) Selection of Gases

(i) Oxygen gas was supplied by Iiquid Carbonic Corporation and was of $99.9 \%$ purity.

(ii) Methane gas was of chemically pure grade supplied by Matheson Co. It was of minimum 99\% purity. The typical average composition of the gas in given in Table 10, Appendix $I$.

(iii) Nitrogen and carbon dioxide used for calibration were of $99.9 \%$ purity and supplied by Liquid Carbonic Corporation.

(iv) Carbon monoxide used for calibration was of C.P. grade supplied by Matheson Co. It was of minimum 99. $5 \%$ purity.

(v) The helium gas used as carrier in the chromatograph was of $99.99 \%$ purity. It was supplied by Liquid Carbonic Corporation. An alumina packed filter was used in the helium line to prevent, any trace of water vapour in the helium gas from entering the system. 
The operational procedure for conduction of kinetic runs is summarised in this chapter.

\section{(A) Calibration Procedure}

\section{(i) Calibration of Rotameters}

For rotameters operating under a constant pressure difference but with a constriction of variable area, the mass flow rate is related to the scale reading by the following expression (23)

$$
w=c_{r} A_{0}\left[\frac{2 g \rho\left(\rho_{f}-\rho\right)}{A_{f}}\right]^{1 / 2}
$$

Since the float density is normally an order of magnitude larger than the density of the fluid whose flow is being measured, equation (18) can be approximated to

$$
\frac{W}{\sqrt{p}}=\mathrm{C}_{r} \mathrm{~A}_{0}
$$

The coefficient of discharge $\mathrm{Cr}$ is sensitive to the viscosity and to the flow lines through the constriction. For high flow rates, $\mathrm{Cr}$ tends to assume a constant value, and for this reason it is convenient to calibrate the flow meters according to the procedure suggested by equation (19). 
The calibration of methane and oxygen rotameters was done by measuring actual flow rates with a precision wet-test meter. The upstream pressures and temperatures of the gases were measured by pressure gauges and thermometers installed in the lines before the rotameters inlet. Since neither of the gases is soluble in water, the presaturator of the wet test meter was filled with distilled water. The calibration curves for the rotameters over the complete range of investigation are given by Figures 15 and 16 in Appendix II

\section{(ii) Calibration of Thermocouples}

The chromel-alumel thermocouples used to measure temperatures were calibrated against the boiling point of distilled water and the melting points of chemically pure tin and zinc. The observed temperatures were extremely close to standard temperatures. Therefore, the error involved in measurement of experimental temperatures, is negligible.

\section{(iii) Calibration of Chromatograph}

\section{(a) Princiole}

The carrier gas is introduced into the system at a specified flow rate. The column, injector and detector baths are heated to the required isothermal temperatures. These temperatures are chosen to prevent condensation of any component at any stage of the process. Another operational consideration is that separation of different components should be explicit. A sample mixture is then injected into the 
injector part. As the sample is carried through the columns, the components are separated according to their respective solubilities in the column charge. The components having little affinity for the column material pass through the column rapidly, while those with greater affinities are retained in the column for longer periods.

As each component emerges from the column, it is driven into the sensing side of the detector located immediately after the column exit. The other side of the detector which is the reference side is upstream of the sample injection block and is filled with carrier gas prior to the point at which the sample is injected. Thermistors in each chamber of the detector are connected to a balanced bridge circuit and are cooled by the gases to which they are exposed. When a component enters the sensing chamber, the thermistor bridge circuit is unbalanced and generates a signal. The signal is proportional to the difference in thermal conductivities of the carrier gas and the component. The signal drives a recorder pen to produce, in graphic form, a quantitative and qualitative description of the component.

(B) Calibration

Due to large number of components to be analyzed, the silica gel column, followed by rolecular sieve column, were found to give explicit separation of all the desired components. The silica gel column gave combined peak and peak for carbon dioxide. 
The molecular sieve column gave separation for oxygen, nitrocen, methare and carbon monoxide.

The operating conditions for the analytical set-up are given by Table II, in Appendix I.

The concentration of any component is directly proportional to the peak area. However, in this case, a measurement of peals height gave a reasonably accurate proportionality to component concentration. This relation was valid for pure components as well as for the mixtures used. The calibration curves for different components are given by figures 18 to 22, in Appendix II. The concentration of water was found by difference. Absence of alcohol and aldehydes was established during the trial runs of methane oxidation, thus calibrations for these components were not done.

\section{(B) Operational Procedure}

The preheater and reactor furnaces were switched on and variacs adjusted to heat the system to the desired temperature. Oxygen gas was fed through the rotameter, with the feed rate and reactor exit valve being adjusted for the desired working pressure. After the temperatures had stabilised, methane gas was slowly fed to the system through the rotameter. The flowrates of oxygen and methane, the reactor exit valve and the variacs.were adjusted for desired working pressure and isothermal temperature of the differential bed.

The reaction was allowed to proceed for about one hour, at the desired conditions, before the first sample was taken for analysis. Three samples were taken for each run. The average 
of the three readings was used to calculate the product composition. It took about fifteen minutes for analysis of each product sample. Therefore, each sample was withdrawn at an interval of fifteen to twenty minutes after the attainment of equilibrium conditions.

Preliminary runs confirmed Mezaki's (18) observations that the catalyst achieved uniform activity after twenty hours of service. Therefore, for each series of runs, the catalyst was first allowed to attain uniform activity.

Prior to the start of the runs, with the catalyst, blank runs were made with different oxygen methane ratios within the range of operating temperatures and pressures. These blank runs confirmed that no parts of the equipment contributed to the conversion.

(c) Results

Following the procedure outlined above, two series of runs were made. For both series the catalyst charge was $0.498 \mathrm{gm}$. One series of runs was with about $6 \%$ to $30 \%$ methane, at about 1.8 atmospheres total pressure and at temperatures of 300,320 and $340^{\circ} \mathrm{C}$. The second series of runs was made at almost constant feed composition of about $6.5 \%$ methane. The total pressure was varied from 1.8 to 9.7 atmospheres. The runs were at isothermal temperatures of 300,320 and $340^{\circ} \mathrm{C}$.

\section{7}

\section{UNIVERSITY OF WINDSOR LIBRARY}


The percentage of products was 0.4 to $1.2 \%$, and conversions were 3.69 to $9.10 \%$. For such small conversions, it is accurate enough to consider the reaction to be differential. Initial rates of reaction were computed from the expression

$$
r o=\frac{x_{A O}}{W / F_{A O}}
$$

The method of computation of initial rate from experimental data, is given in Appendix III. The results of the experimental runs are given by Table 1. 


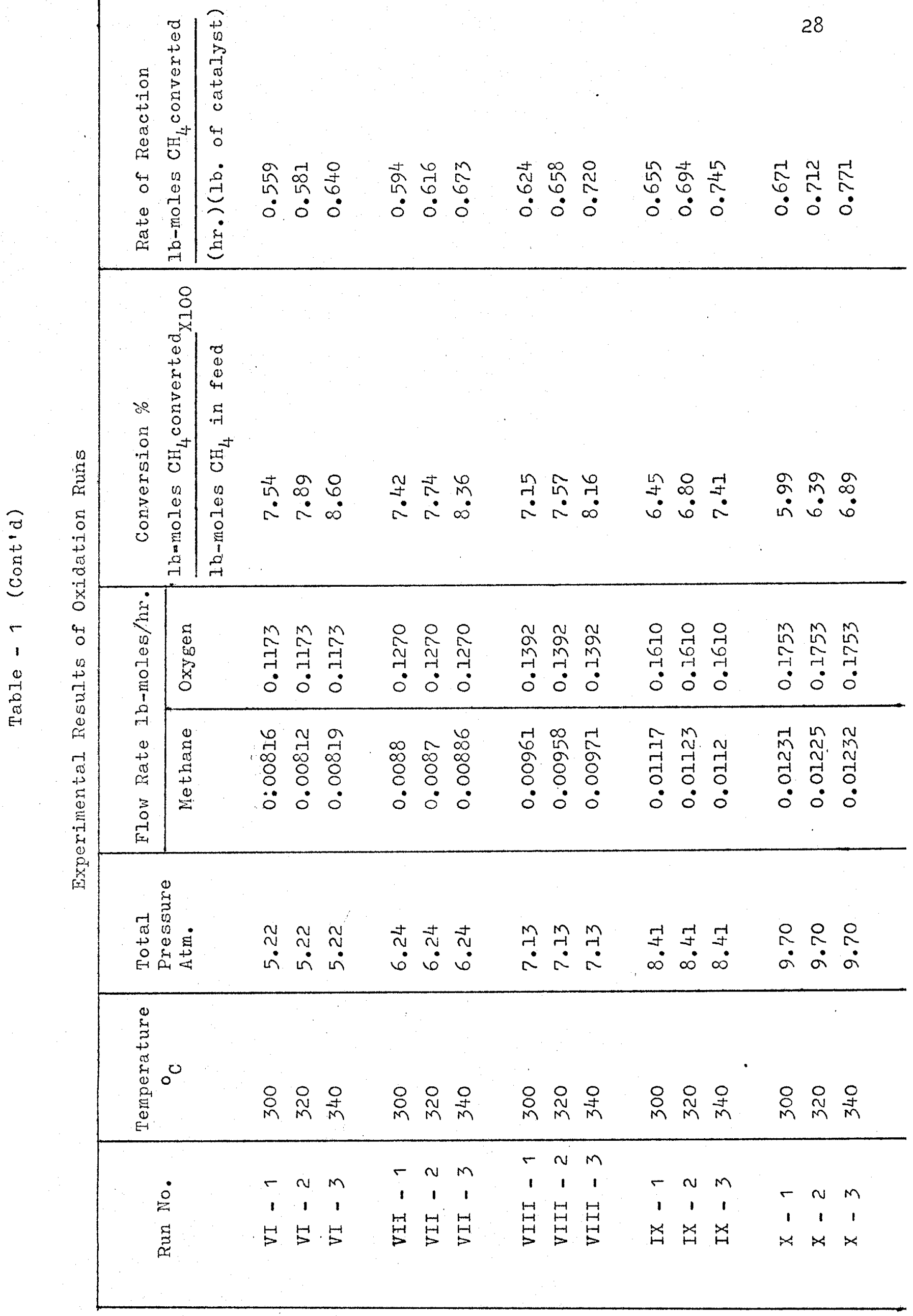




\section{ANAIYSIS OF RESULTS}

In the interpretation of experimental kinetic data, many experimental errors might be encountered. A detailed consideration of the errors that might affect the observed rate of reaction is essential to a valid interpretation of experimental results. Hougen (24) has discussed these errors, arranged below in the order of decreasing importance:

1. Variation in catalyst activity.

2. Departure from unity in effectiveness factor of catalyst.

3. External resistance due to mass and heat transfer.

4. Neglect of pressure arop due to flow. Besides these, the following sources of experimental errors should also be considered.

5. Side reactions.

6. Homogenised reaction and catalyzed reaction by reactor wall.

7. Errors associated with analysis, flow measurement and temperature measurement.

\section{Variation in Catalyst Activity}

Mezaki (18), who used the same catalyst as the one employed in this investigation, reported that catalyst activity decreases considerably during the twenty hour service period. After this period the activity reached a fairly constant value. Therefore for each series of runs, the catalyst was first allowed to attain uniform activity. 
2. Departure from unity in effectiveness factor of Catalyst

The effectiveness factor of a catalyst pellet is defined by Hougen ${ }^{(24)}$ as follows:

"The effectiveness factor of a catalyst pellet is the ratio of the actual reaction rate per unit mass of catalyst when the catalyst is distributed throughout a porous pellet to the rate where the available catalyst is restricted to the exterior surface of the surface." The catalyst used in this investigation consisted of small pellets, $1 / 81 \times 1 / 8 "$. In this catalyst, the penetration of palladium into alumina pallets was only superficial. The most active part of the catalyst was distributed on the surface or located near enough the surface. Therefore, it was assumed that the effectiveness factor was very close to unity.

3. External resistance due to mass and heat transfer

Yang and Hougen (22) have detailed the equations for calculating heat and mass transfer effects for different operating conditions. The calculations for run 1 - I are given in Appendix III.

Results of these calculations indicate that for all runs, the heat and mass transfer effects were negligible.

4. Neglect of pressure drop due to flow

To take into account pressure drop due. to flow, the operating pressure was taken as the mean of reactor inlet and outlet pressures. 
5. Side reactions

In the trial runs over the range of operating conditions, no side products were detected by the chromatographic analysis.

6. Homosenized reaction and catalyzed reaction by reactor walls

In the blank runs over the range of operating conditions, no reaction products were detected by the chromatographic analysis.

7. Errors associated with analysis, flow measurement and temperature measurement

The errors due to analysis of feed streams and product streams were less than $0.5 \%$. The errors due to flow measurement and temperature measurement were negligible.

KINETIC INEERPRETATION OF RESULTS

The interpretation of the initial rate results consists usuaily of two parts, first, a qualitative interpretation based on the nature of results obtained, and second, a statistical interpretation to obtain a quantitative rate expression. The acceptability criteria for statistical interpretation is that for any rate equation, all equilibrium constants have to be positive. The various plausible mechanisms for the reaction are given in Table 2 .

The initial rates obtained in this experimental study were plotted against the total pressure value. The plots for the three temperatures 300,320 and $340^{\circ} \mathrm{C}$ are given in figures 3,4 and 5 . 


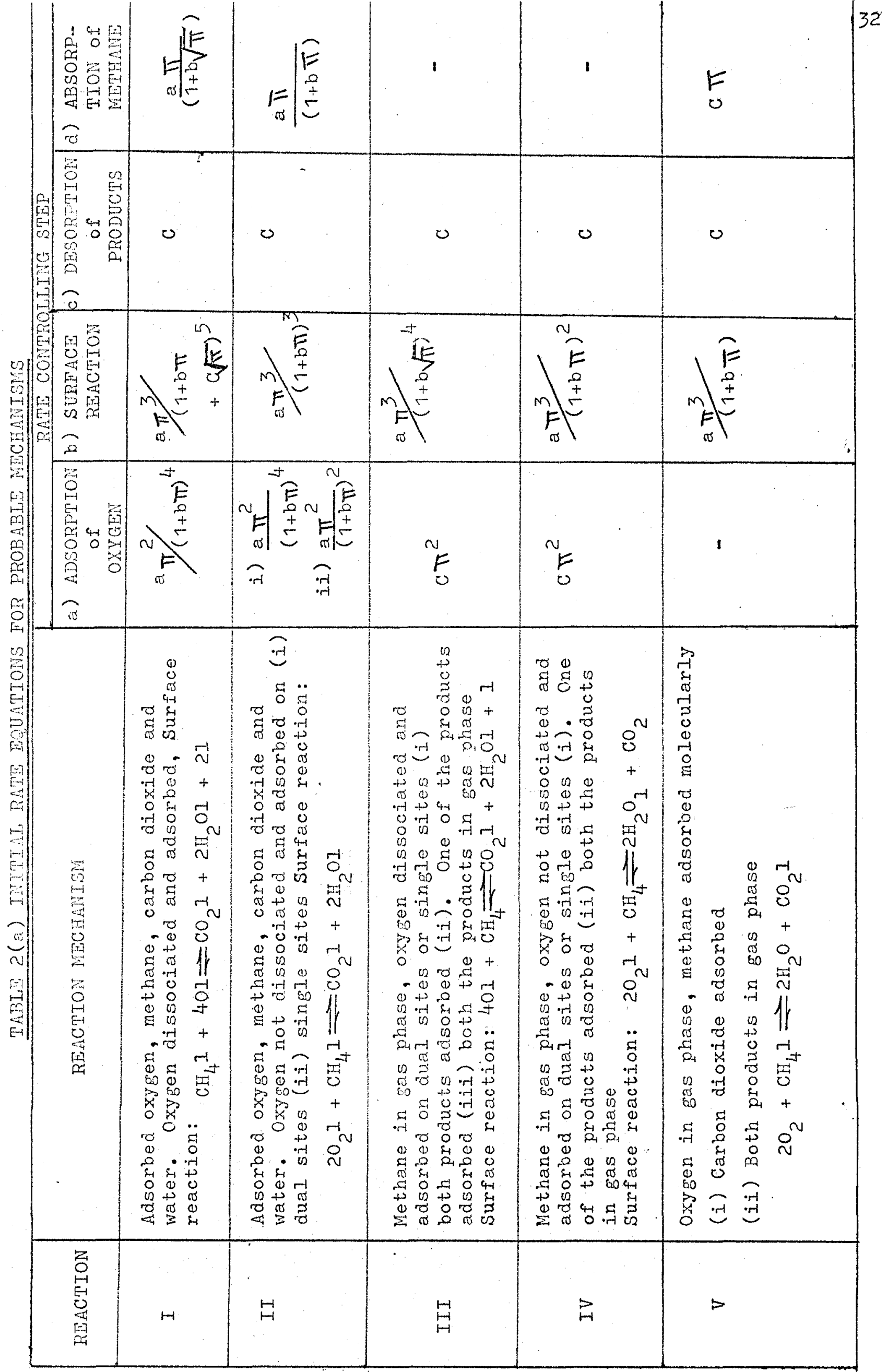


TABLE 2(b) DESIGNATION OF INITIAI RATE EQUATIONS

\begin{tabular}{|c|c|c|}
\hline $\begin{array}{l}\text { INITIAL } \\
\text { RATE } \\
\text { EQUATION } \\
\text { NO. }\end{array}$ & REACTIONS & INITIAL RATE EQUATION \\
\hline$(I)$ & II a (ii) & $a \pi^{2} /(1+b \pi)^{2}$. \\
\hline$(I I)$ & II $b$ & $a \pi^{3} /(1+b \pi)^{3}$ \\
\hline (III) & IV $\mathrm{b}$ & $a \pi^{3} /(1+b \pi)^{2}$ \\
\hline (IV) & $\mathrm{V} b$ & $a \pi^{3} /(1+b \pi)$ \\
\hline$(V)$ & II d & $a \pi /(1+b \pi)$ \\
\hline$(V I)$ & Ia, II a (i) & $a \pi^{2} /(1+b \pi)^{4}$ \\
\hline$(V I I)$ & III b & $a \pi^{3} /(1+b \sqrt{\pi})^{4}$ \\
\hline (VIII) & $I d$ & $a \pi /(1+b \sqrt{\pi})$ \\
\hline$(I X)$ & I b & $a \pi^{3} /(1+b \pi+c \sqrt{\pi})^{5}$ \\
\hline$(X)$ & Ic, IIc, IIIc, IVc, Vc & C \\
\hline$(X I)$ & $v a$ & $\mathrm{c} \pi$ \\
\hline$(X I I)$ & IIIa, IVa & $c \pi^{2}$ \\
\hline
\end{tabular}




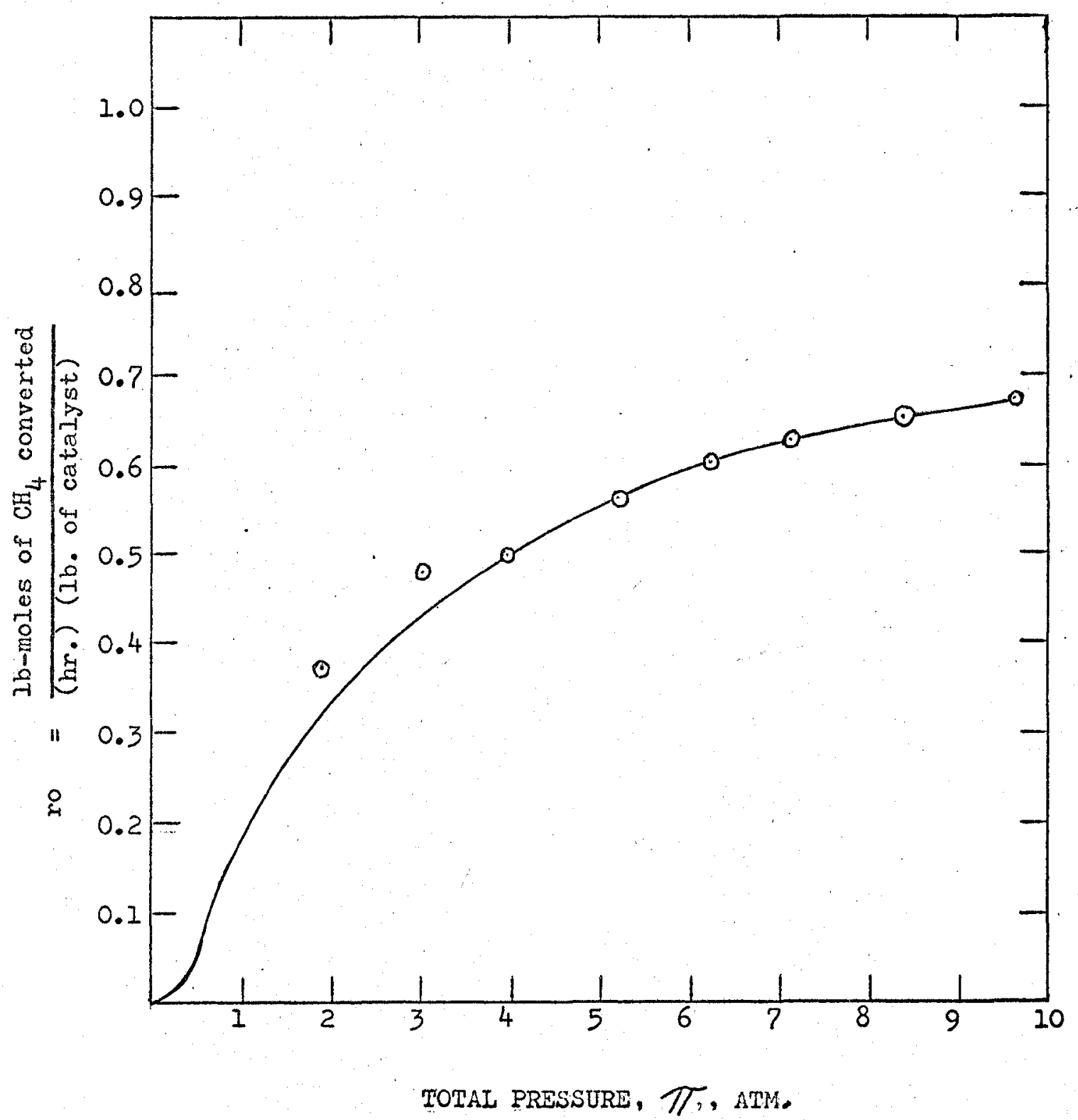

Fig. 3 INITIAL RATE OF REACTION VS TOTAL PRESSURE, $300^{\circ} \mathrm{C}$ 


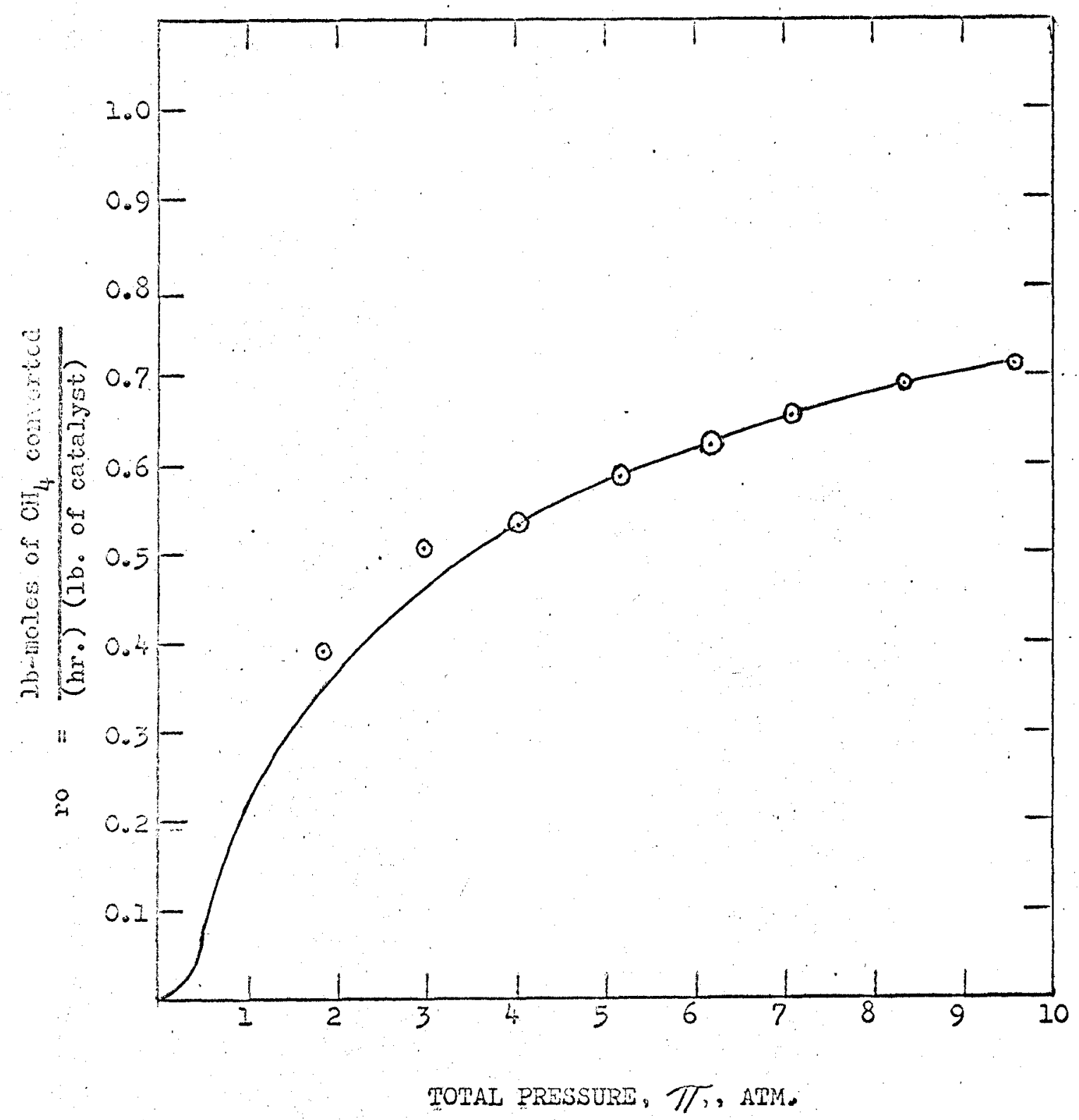

Fig. 4 INITIAL RATE OF REACTIOH VS TOTAL PRESEURE, $320^{\circ} \mathrm{C}$ 


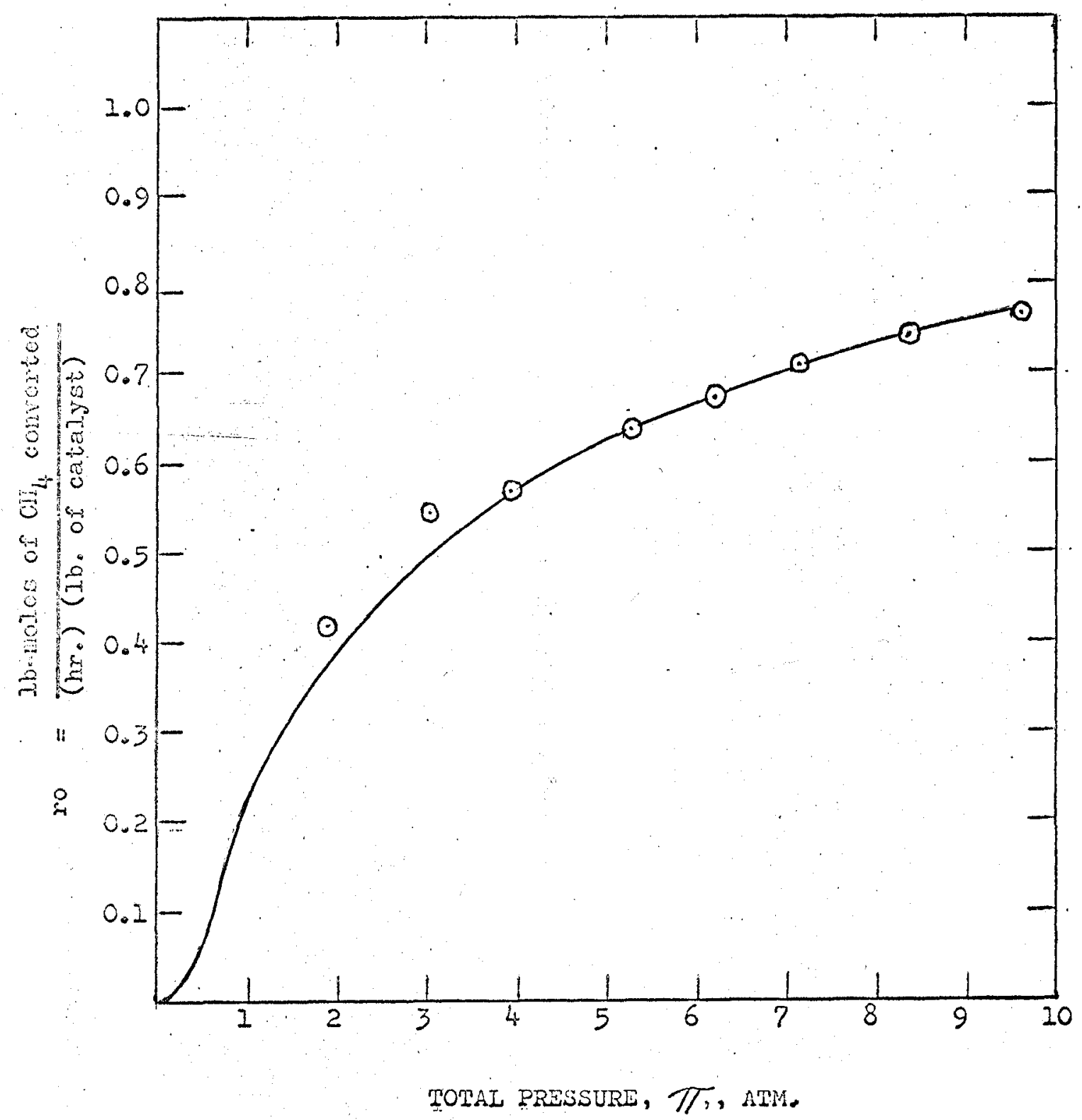

Fig. 5 INITIAL RATE OF REACTION VS TOTAL PRESSURE, $340^{\circ} \mathrm{C}$ 
From these figures, the reaction mechanisms represented by equations ro $c$, ro $=C \pi$ and ro $=c \pi^{2}$ can be rejected, as their plots would be grossly different from the plots of figures 3,4 and 5 .

To examine the validity of other possibilities, coefficients of the remaining nine theoretical rate equations were estimated from the experimental data for three temperatures. The nonlinear rate equations were transformed to linear equations by algebric manipulation. The coefficients of these linearised rate equations were estimated from the statistical methods of linear regression (25) Considering the rate equation (I)

$$
\text { ro }=a \pi^{2} /(1+b \pi)^{2}
$$

Rearranging, this becomes

$$
\frac{\pi}{\left(r_{0}\right)^{1 / 2}}=\frac{1}{(a)^{1 / 2}}+\frac{b}{(a)^{1 / 2}} \pi
$$

or, an expression of the type $Y=A+B X$

The regression coefficients $A$ and $B$ are given by

$$
\begin{aligned}
A= & \frac{\sum X^{2} \sum Y-\sum X \sum X Y}{n \sum X^{2}-\left(\sum X\right)^{2}} \\
B= & \frac{n \geq X Y-\sum X \geq Y}{n \sum X^{2}-\left(\sum X\right)^{2}}
\end{aligned}
$$

For an expresion involving three coefficients, as in case of rate equation (IX)

$$
r_{0}=\frac{a \pi^{3}}{(1+b \pi+c \sqrt{\pi})^{5}}
$$

Rearranging, this becomes

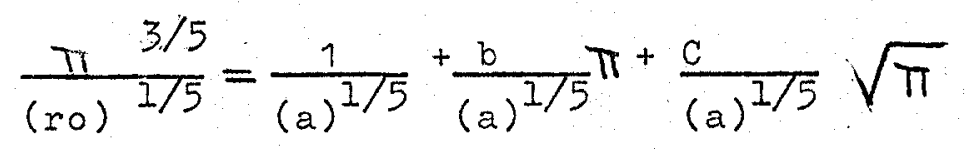


or, an expression of the type $Z=B_{0}+B_{1} X+B_{2} X$

The coefficients $B_{0}, B_{1}$ and $B_{2}$ are given by three Iinear equaitons computed by the method of multiple regression (25)

$$
\begin{aligned}
& \Sigma Z=n_{0}+B_{1} \Sigma X+B_{2} \Sigma Y \\
& \Sigma X Z=B_{0} \Sigma X+B_{1} \Sigma X^{2}+B_{2} \Sigma X Y \\
& \Sigma Y Z=B_{0} \Sigma Y+B_{1} \Sigma X Y+B_{2} \Sigma Y^{2}
\end{aligned}
$$

The coeficients of nine equations were computed on an IBM1620 computer. The programmes and results are given in Appendix $V$. The results are tabulated in Table 3.

From the nature of the plots in figures 3,4 and 5 , no shift in mechanism was noted over the temperature range 300 , 320 and $340^{\circ} \mathrm{C}$. Moreover, none of the figures 3,4 and 5 showed a maxima. Therefore, the possibility of the reaction mechanism given by rate equation (VI), which exhibits a maxima for $\pi \max .=\frac{1}{b}$, was rejected. The rate equations (III) and (IV) depicted negative regression coefficients, so these were also excluded as plausible mechanisms.

Rate equations I, II, V, VII, VIII and IX showed positive values for regression coefficients and remained possible mechanisms. These six possible equations were then subjected to goodness of fit criteria. Equations VII, VIII and IX showed a variation of more than $100 \%$ from experimental values of initial rates, thus eliminating them as possible mechanistic equations. Equations I, II and $V$ showed an average variation of $1 \%$ from experimental data. 
As proposed by Yang and Hougen (22), the effect of feed composition upon rate of reaction was utilised to eliminate further implausible mechanisms. Plots of rate of reaction against methane percent in feed composition are given by figures 6,7 and 8 . Interpretation from these plots, rules out the survival of reaction mechanisms given by equations $I$ and $V$. The plots of equations $I$ and $V$ would be entirely different from the plots of figures 6,7 and 8 .

Further more, as a check, values of initial rates from equations $I$, II and $V$ were computed for the varying feed composition runs, by using the corresponding linear regression coefficients. The experimental data showed a variation of more than 100\% from that predicted by equation I, about $25 \%$ from that predicted by equation $V$, only about $4 \%$ from that obtained by equation II.

Hence, from qualitative view points, equation II is the probable mechanism for methane oxidation. Also, from quantitative interpretations, it is the most accurate fit both for constant feed and varying feed composition runs.

Therefore, it is proposed that following is the rate controlling mechanism for methane oxidation.

"Oxycen and methane adsorbed on the catalyst surface, the surface is:

$$
2 \mathrm{O}_{2} \mathrm{I}+\mathrm{CH}_{4} \mathrm{I} \rightleftharpoons 2 \mathrm{H}_{2} \mathrm{OI}+\mathrm{CO}_{2} \mathrm{I}
$$

surface reaction is rate controlling.". 


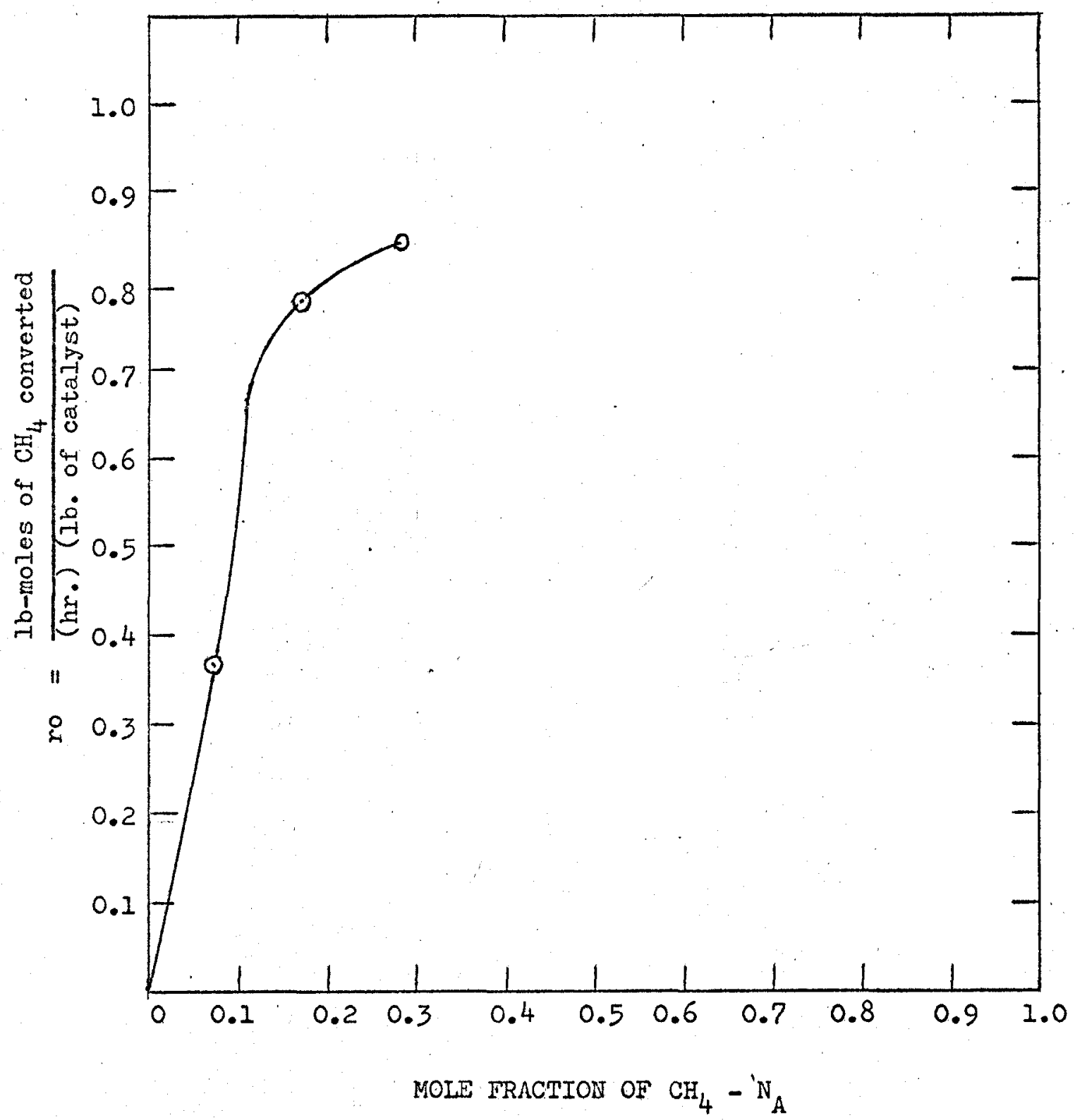

Fig. 6 INITIAI RATE OF RTACTION VS FEED COMPOSITION, $300^{\circ} \mathrm{C}, 1.817 \mathrm{ATM}$. 


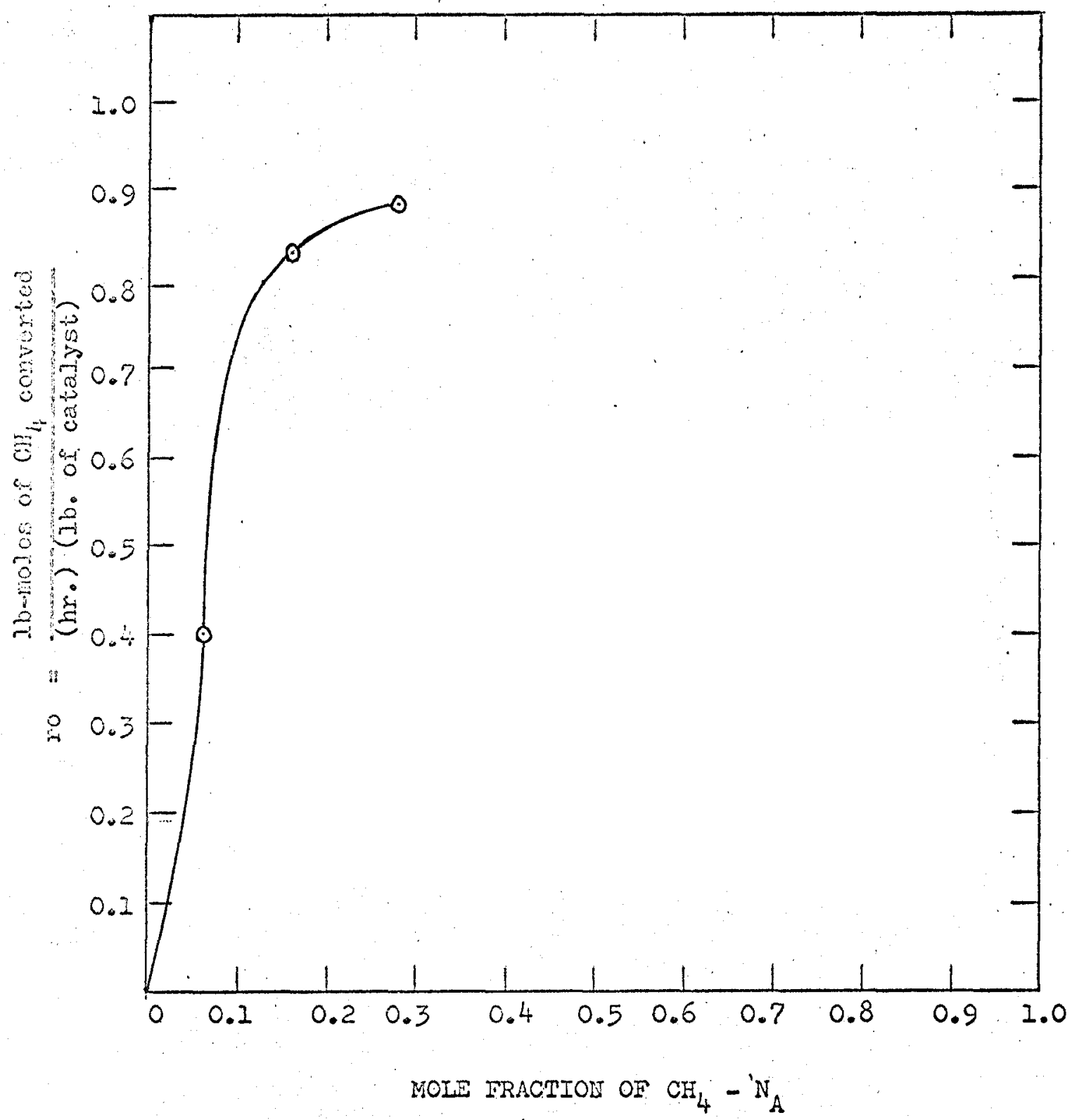

PIE. 7 INITIAL RATE OF REACTION VS FEED COMPOSITION, $320^{\circ} \mathrm{C}, 1.817$ AMM. 


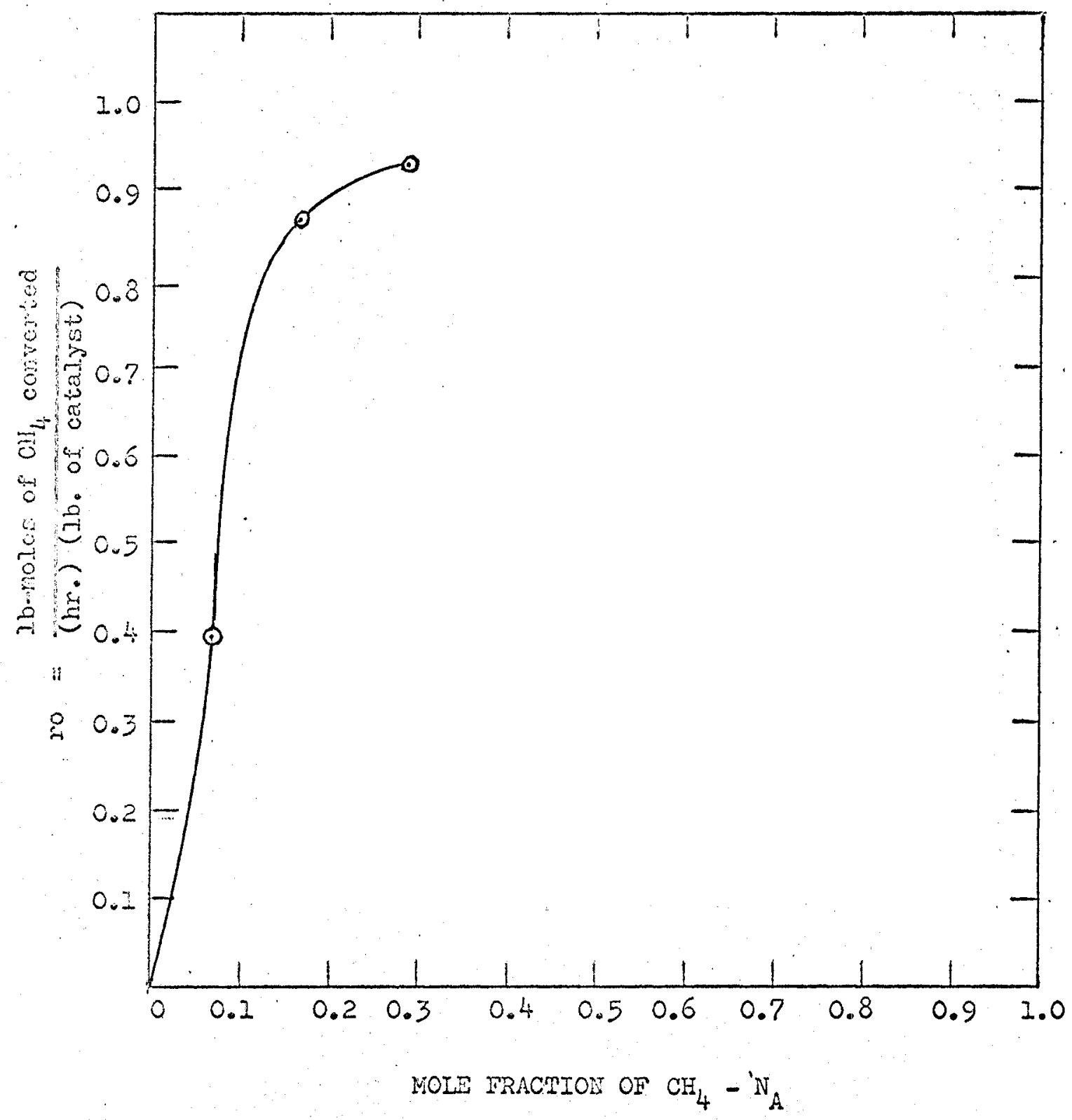

Hig.8 INITIAL RATE OF RTACTION VS FEED COMPOSITION, $340^{\circ} \mathrm{C}, 1.817$ ATM. 
The corresponding rate equation has the form

$$
r=\frac{\mathrm{c}\left[{ }^{p} \mathrm{CH}_{4} p^{2} \mathrm{O}_{2}-\mathrm{p}_{\mathrm{H}_{2} \mathrm{O}}^{2} \mathrm{p}_{\mathrm{CO}} / \mathrm{K}\right]}{\left[1+\mathrm{K}_{\mathrm{CH}}{ }_{4}{ }_{\mathrm{CH}_{4}}+\mathrm{K}_{\mathrm{O}_{2}} \mathrm{p}_{\mathrm{O}_{2}}+\mathrm{K}_{\mathrm{CO}_{2}}{ }_{\mathrm{pO}_{2}}+\mathrm{K}_{\mathrm{H}_{2} \mathrm{O}} \mathrm{p}_{\mathrm{H}_{2} \mathrm{O}}\right]} 3
$$

the corresponding initial rate equation is:

$$
\text { ro }=a \pi^{3} /(1+b \pi)^{3}
$$

at $300^{\circ} \mathrm{C} \quad$ ro $=4.144 \pi^{3} /(1+1.737 \pi)^{3}$

at $320^{\circ} \mathrm{C} \quad$ ro $=4.206 \frac{3}{\pi} /(1+1.714 \pi)^{3}$

at $340^{\circ} \mathrm{C} \quad$ ro $=4.644 \frac{3}{\pi} /(1+1.723 \pi)^{3}$

The initial rates computed from the proposed mechanistic equation and their variation from experimental data are given in Table 4.

Figures 9 , 10 and 11 graphically illustrate the agreement of the computed rates with the observed reaction rate.

Mezaki's rate equation gives a deviation of about 17\%, as compared to the deviation of $4 \%$ based on the equation arrived at in this investigation. Table 4-a gives the results based on proposed mechanistic equation as compared to results based on Mezaki's investigation. 


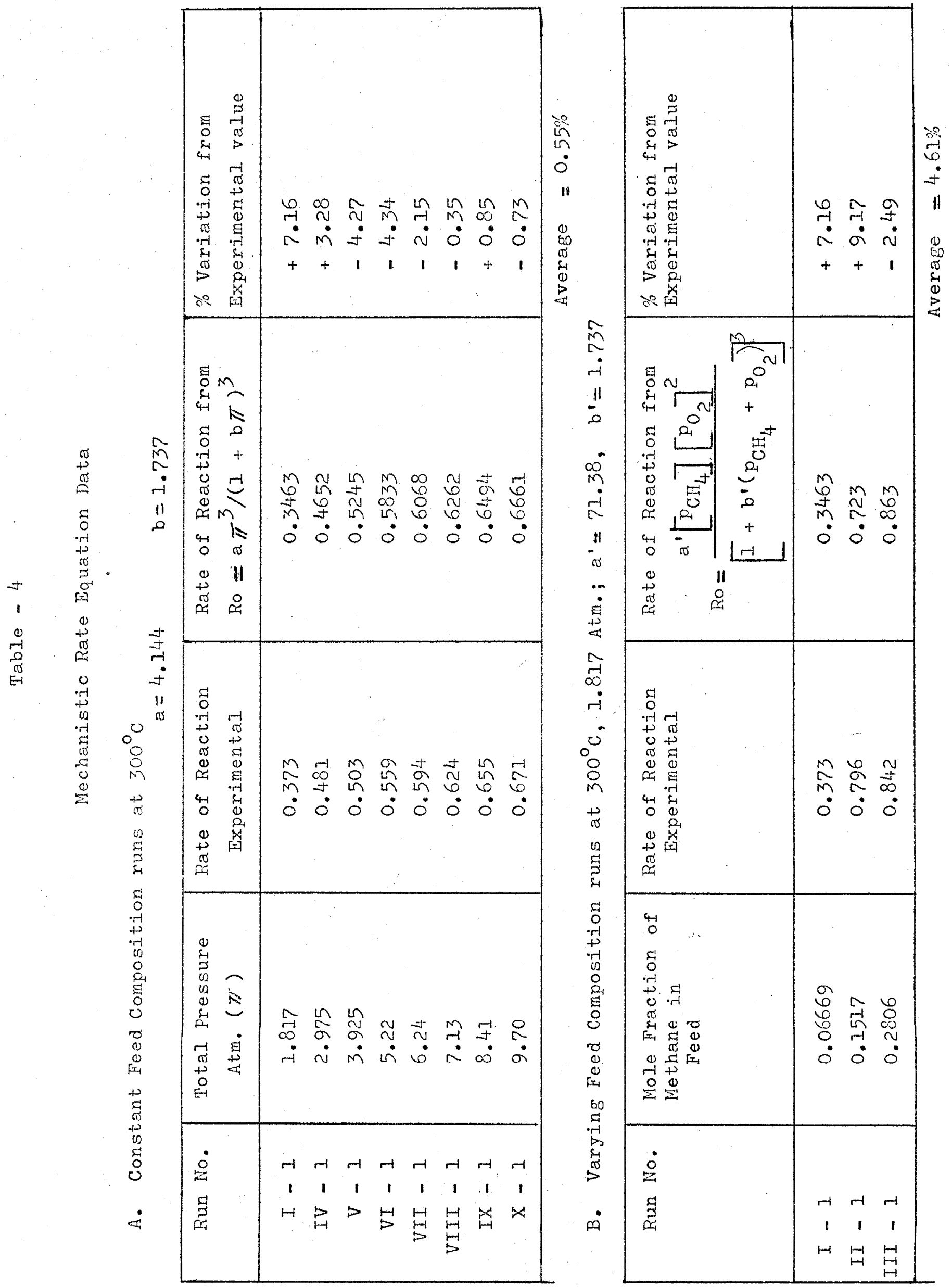




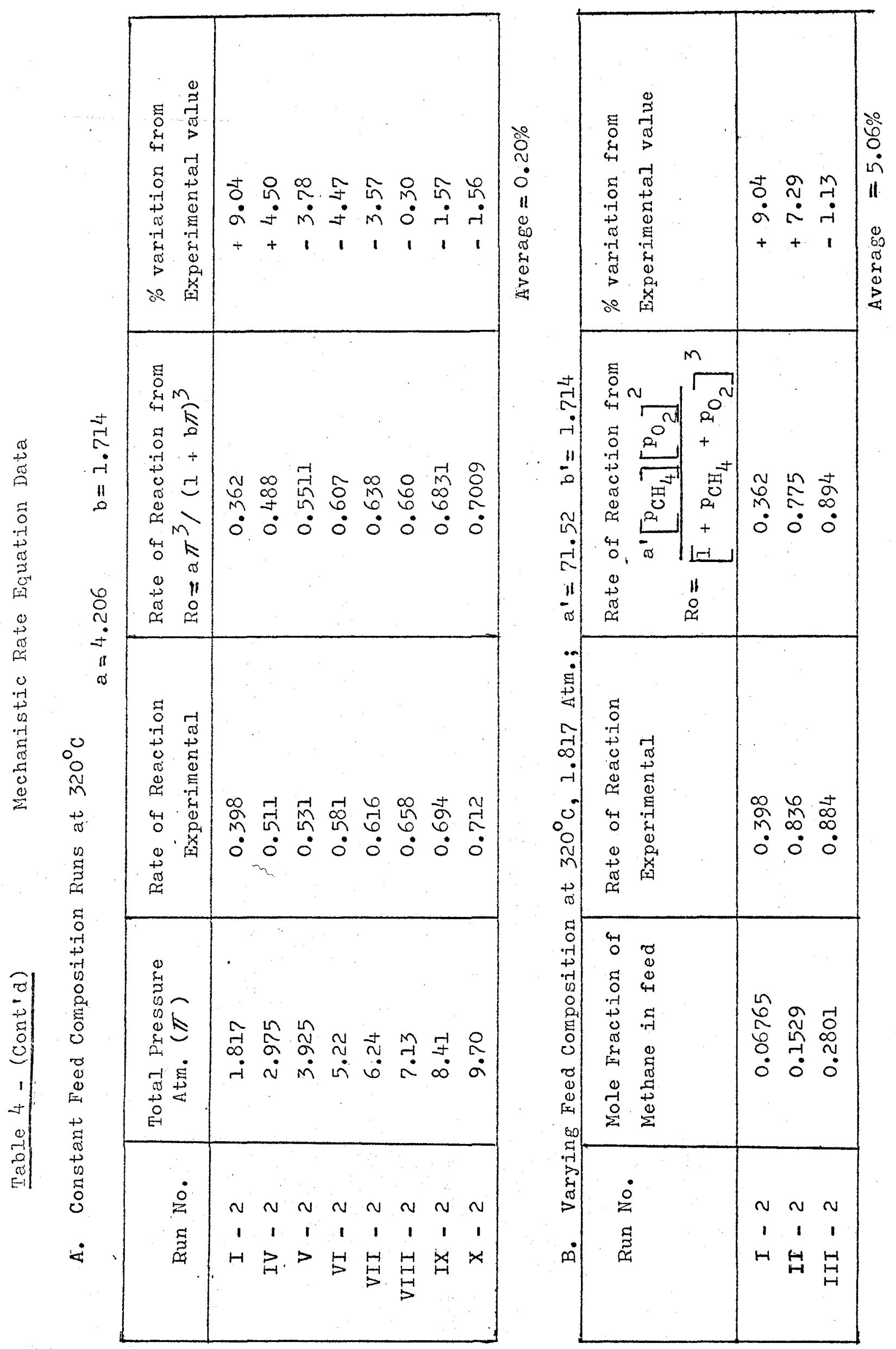




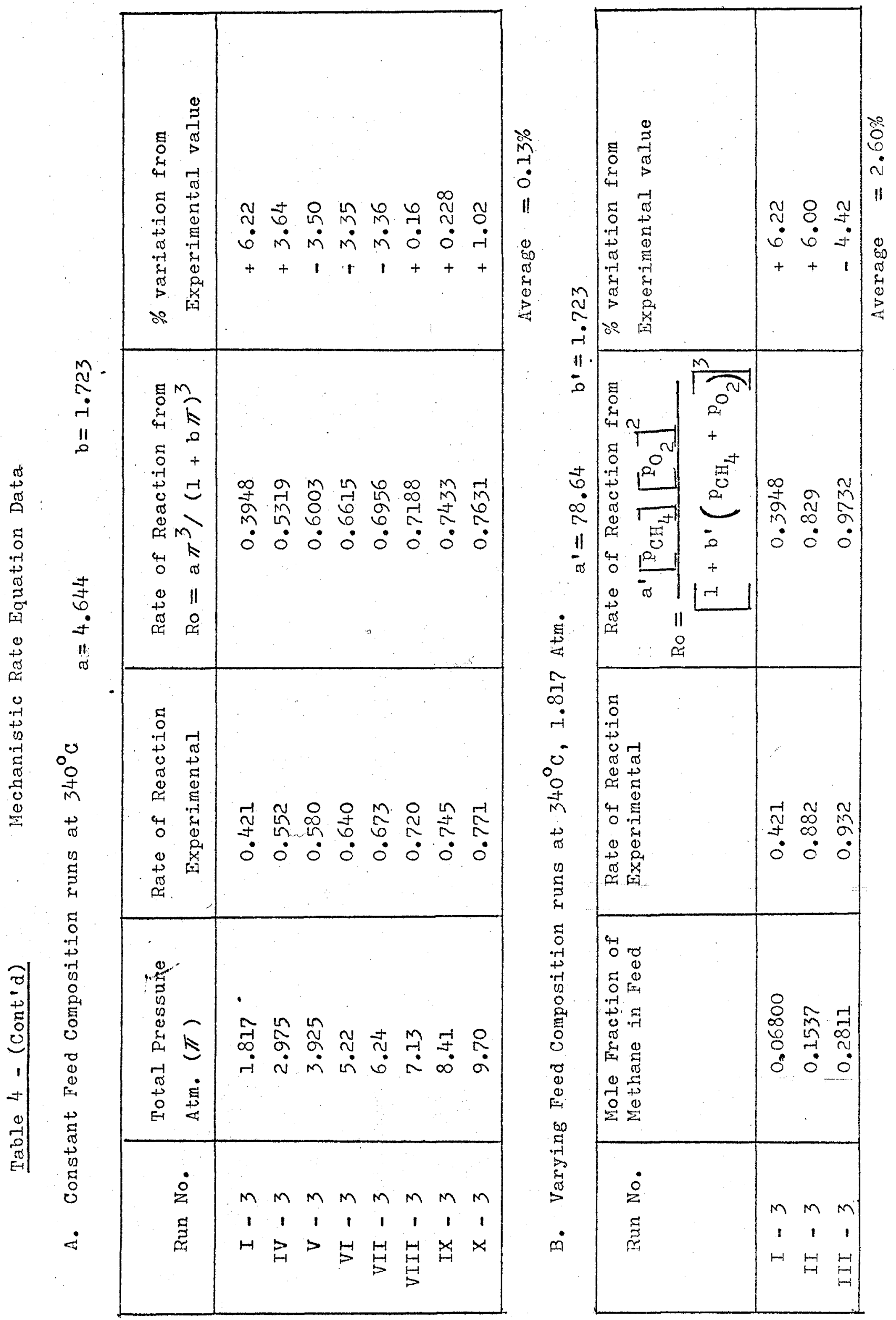




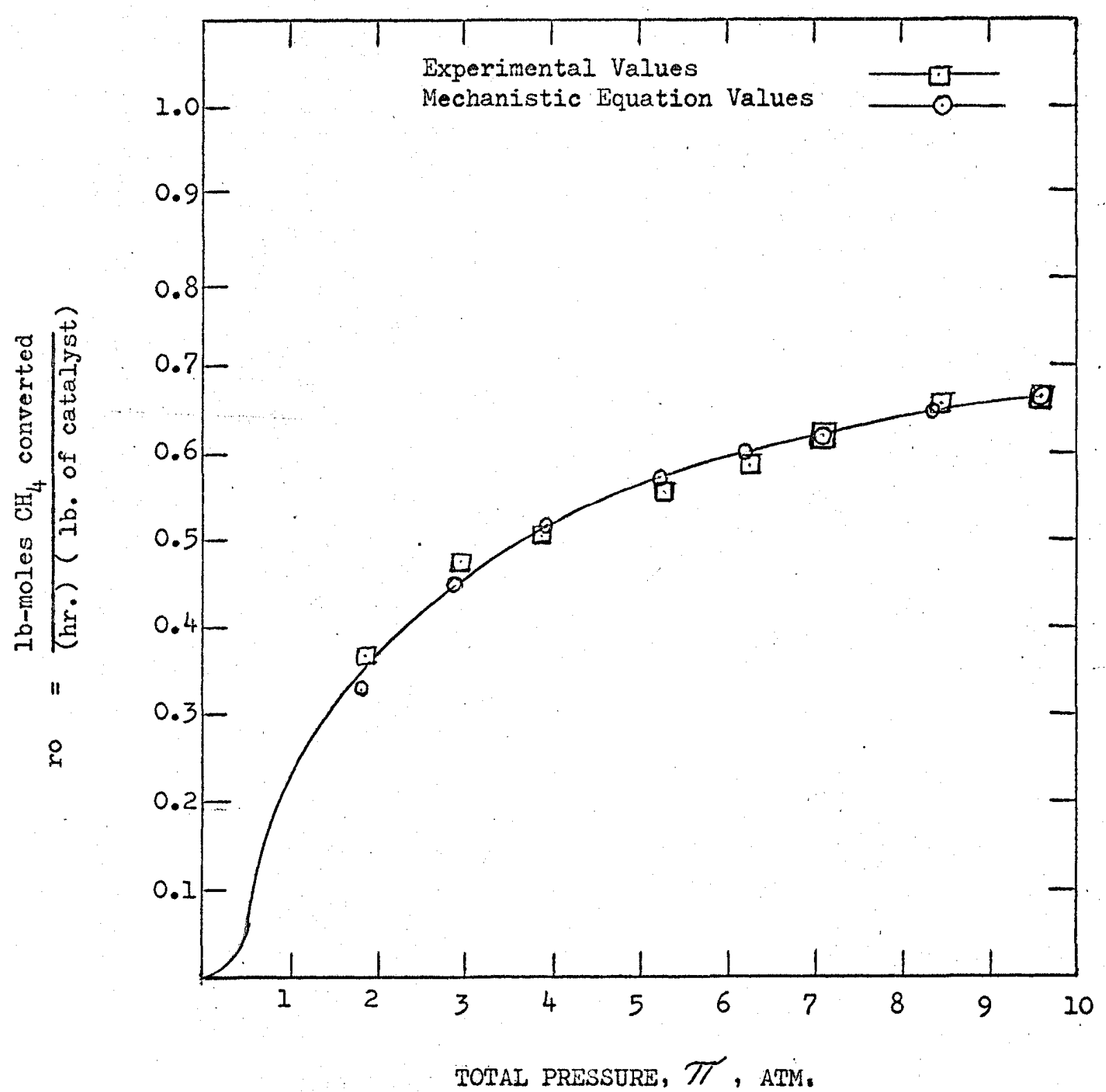

Fig. 9 INITIAL RATE OF REACTION FROM MECHANISTIC EQUATION, $300^{\circ} \mathrm{C}$ 


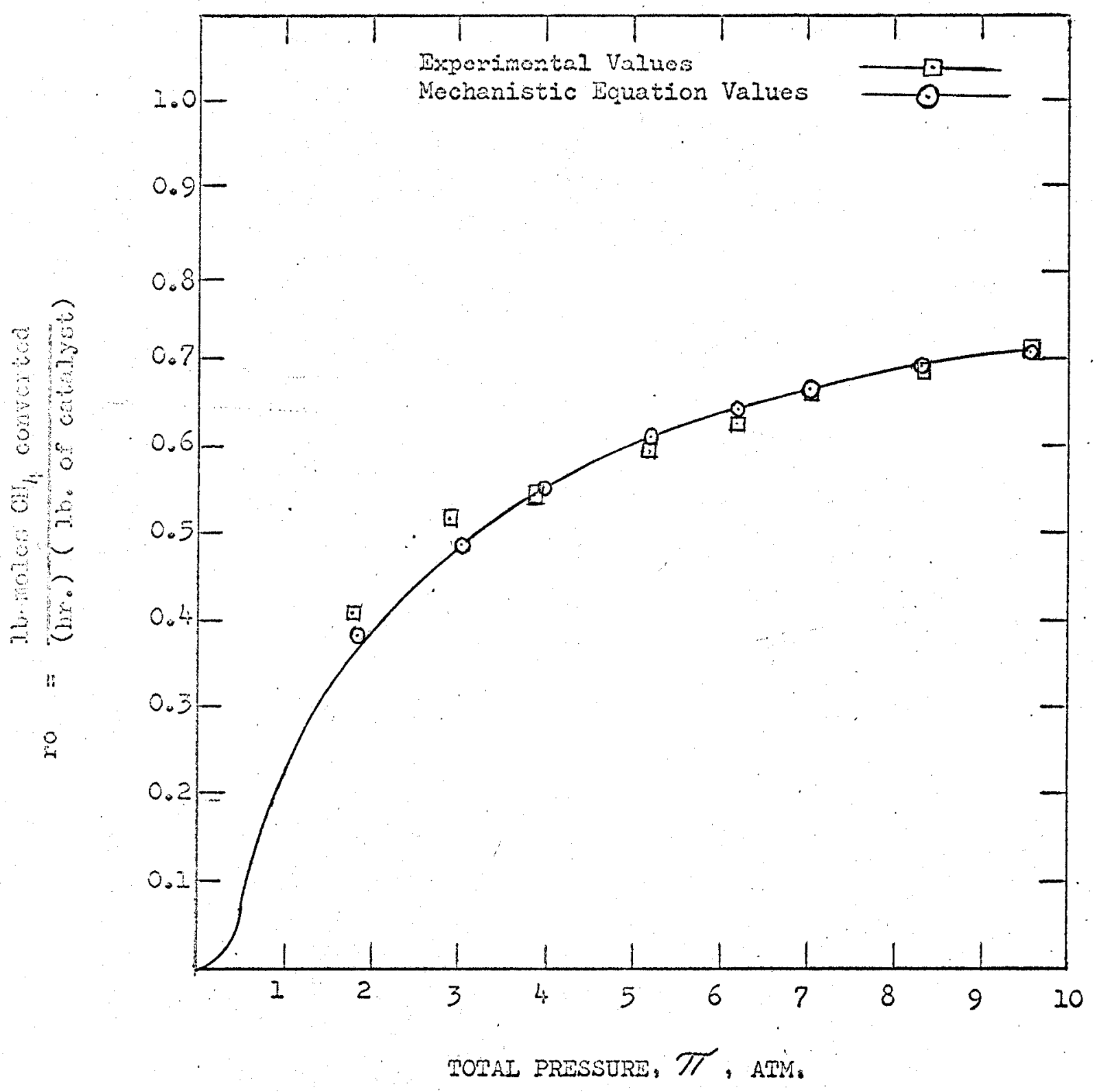

Fig. 10 INITIAL RATE OF RTACTION FROM MECHANISTIC EQUATION, $320^{\circ} \mathrm{C}$ 


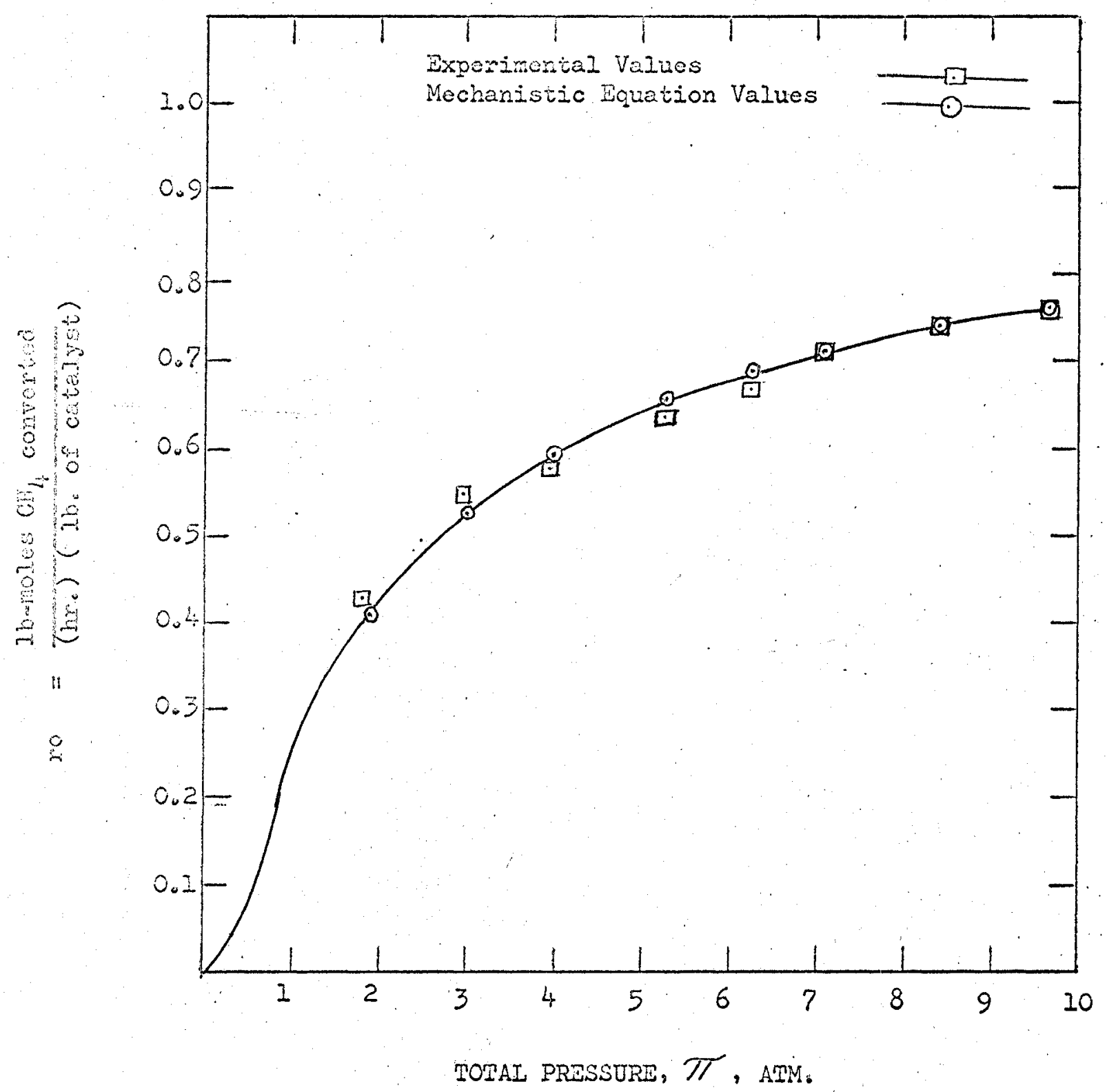

Fig. 11 INITIAI RATE OF REACTION FROM MECHANISTIC RQUATION, $340^{\circ} \mathrm{C}$ 


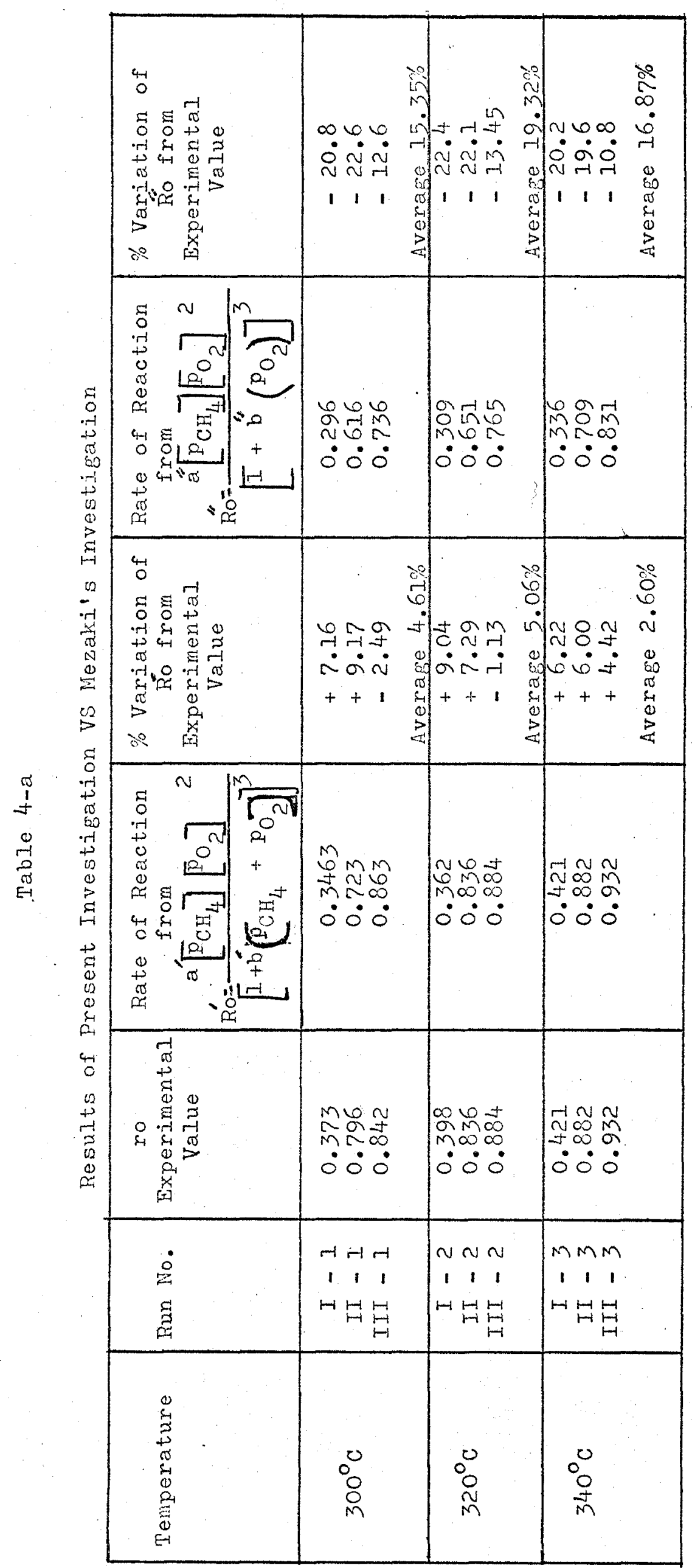


EMPIRICAI APPROACH

From the reactor design point of view, it is of interest to subject the oxidation data to a power law model. The following rate equation was used to find the empirical power law coefficients.

$$
\text { Rate }=k\left[{ }^{\mathrm{C}_{\mathrm{CH}_{4}}}\right]^{\mathrm{m}}\left[\mathrm{C}_{2}\right]^{\mathrm{n}}
$$

Empirical coefficients for equation (21) were found by multiple regression technique ${ }^{(25)}$. The computer programme and results are given in Appendix $V$. The values of empirical coefficients are given in table 5. The average order of reaction was found to be 0.62 .

The initial rates computed from the empirical equation (21), and their variation from experimental data, are given in table 5 . The average deviation was found to be less than 1\%. Figures 12, 13 and 14 graphically illustrate the agreement of computed rates with the observed reaction rates.

The proposed empirical rate equations have the form:

$$
\begin{aligned}
& \text { at } 300^{\circ} \mathrm{C}, \quad \mathrm{ro}=2.528\left[\mathrm{C}_{\mathrm{CH}_{4}}\right]^{0.0763}\left[\mathrm{C}_{\mathrm{O}_{2}}\right]^{-0.5429} \\
& \text { at } 320^{\circ} \mathrm{C} \text {, ro }=2.635\left[{ }^{\mathrm{C}} \mathrm{CH}_{4}\right]^{0.06726}\left[\mathrm{C}_{2}\right]^{0.5518} \\
& \text { at } 340^{\circ} \mathrm{C}, \quad \text { ro }=2.772\left[{ }^{\mathrm{C}_{\mathrm{CH}}}\right]^{0.05932}\left[\dot{\mathrm{C}}_{\mathrm{O}_{2}}\right]^{0.5613}
\end{aligned}
$$

\section{UNIVERSITY OF WINDSOR LIBRARY}




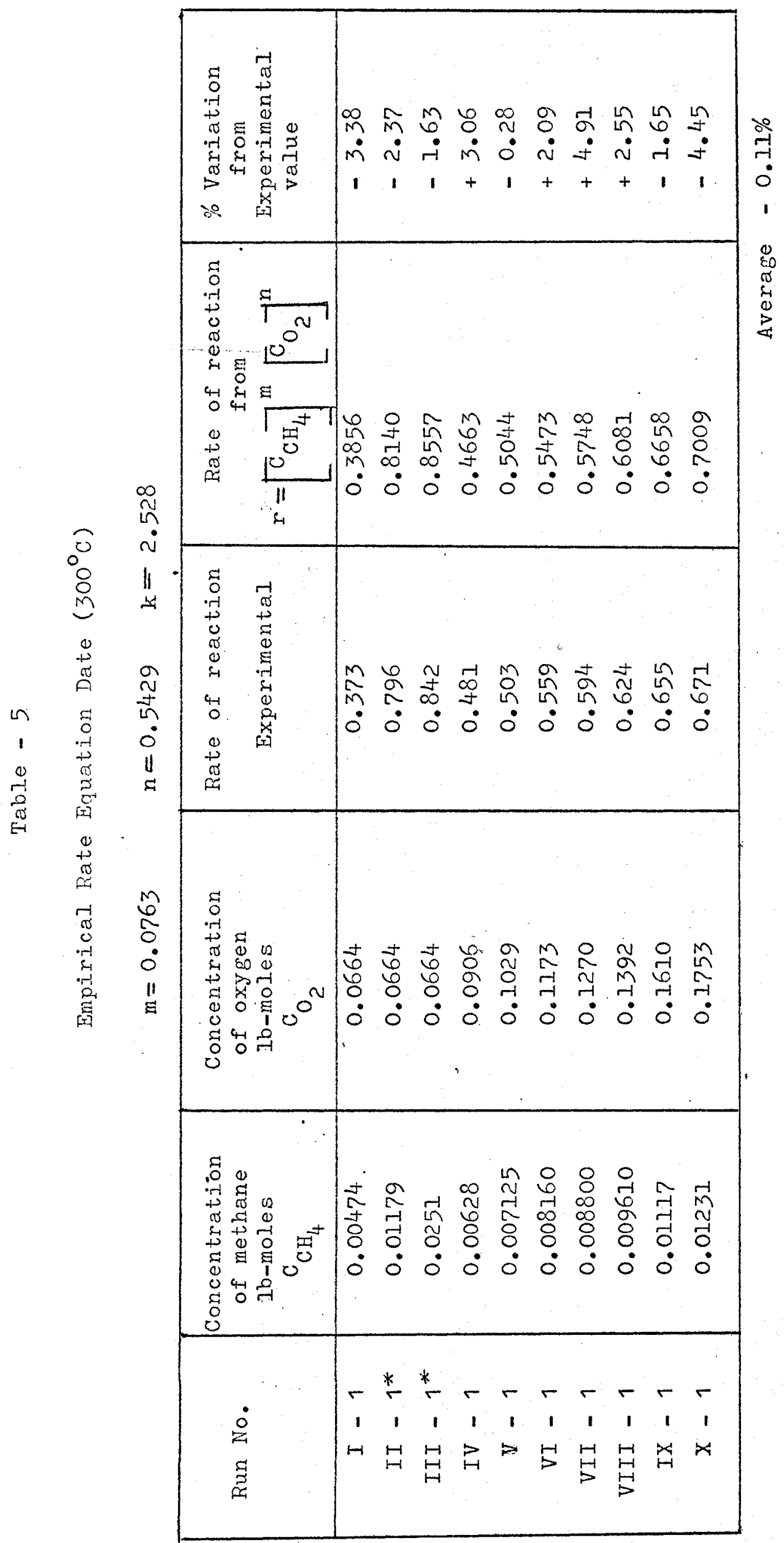




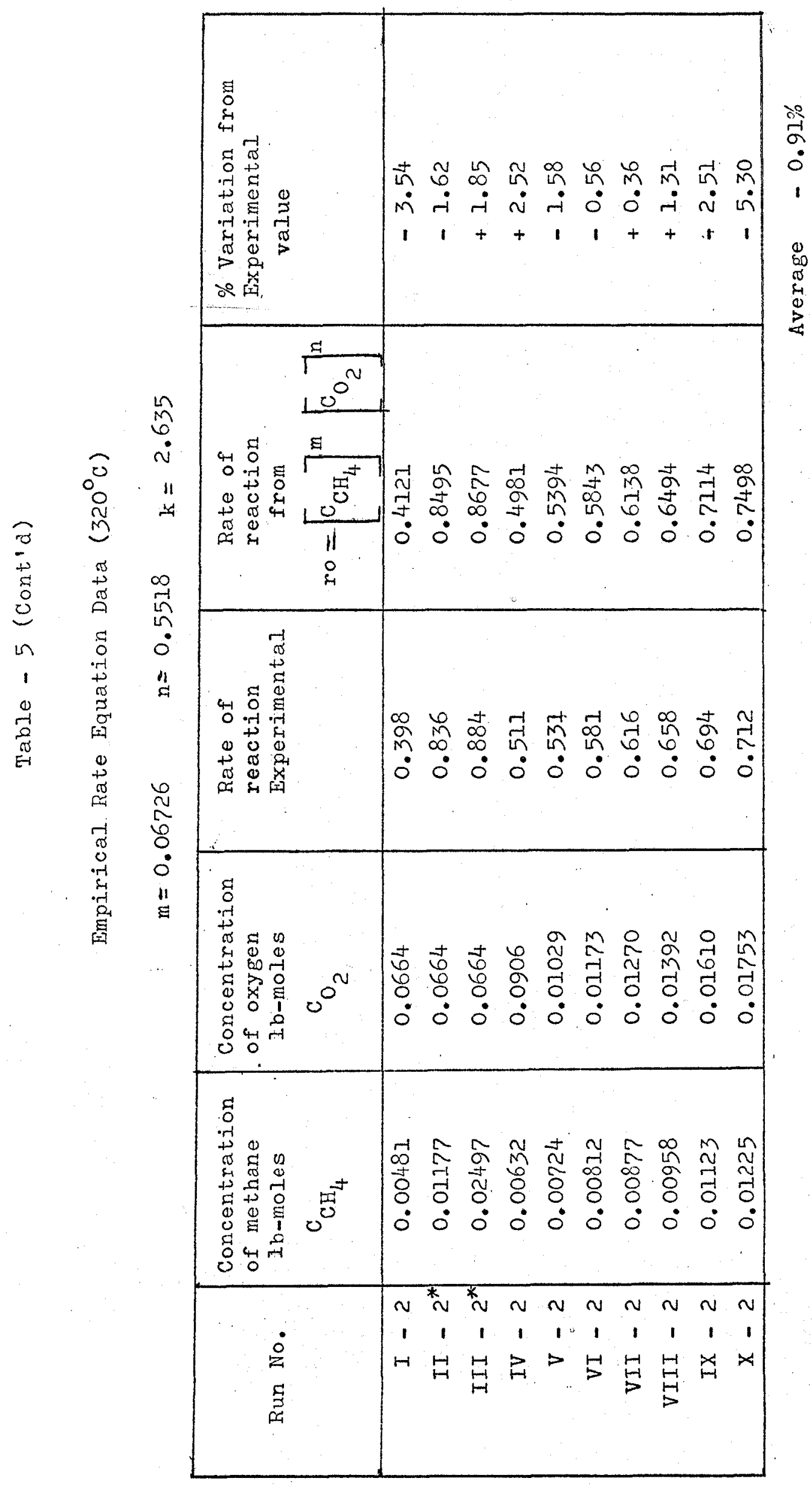




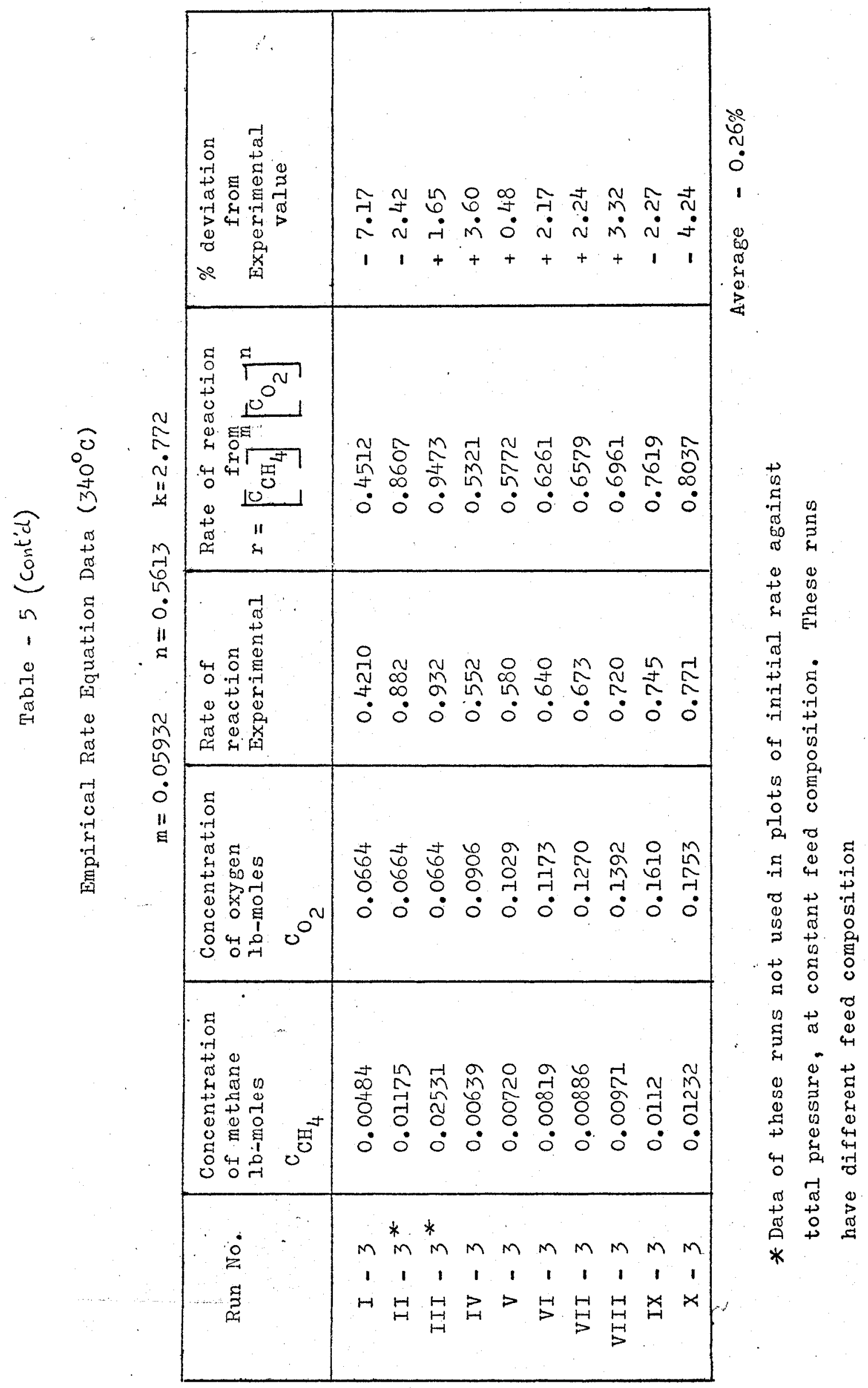




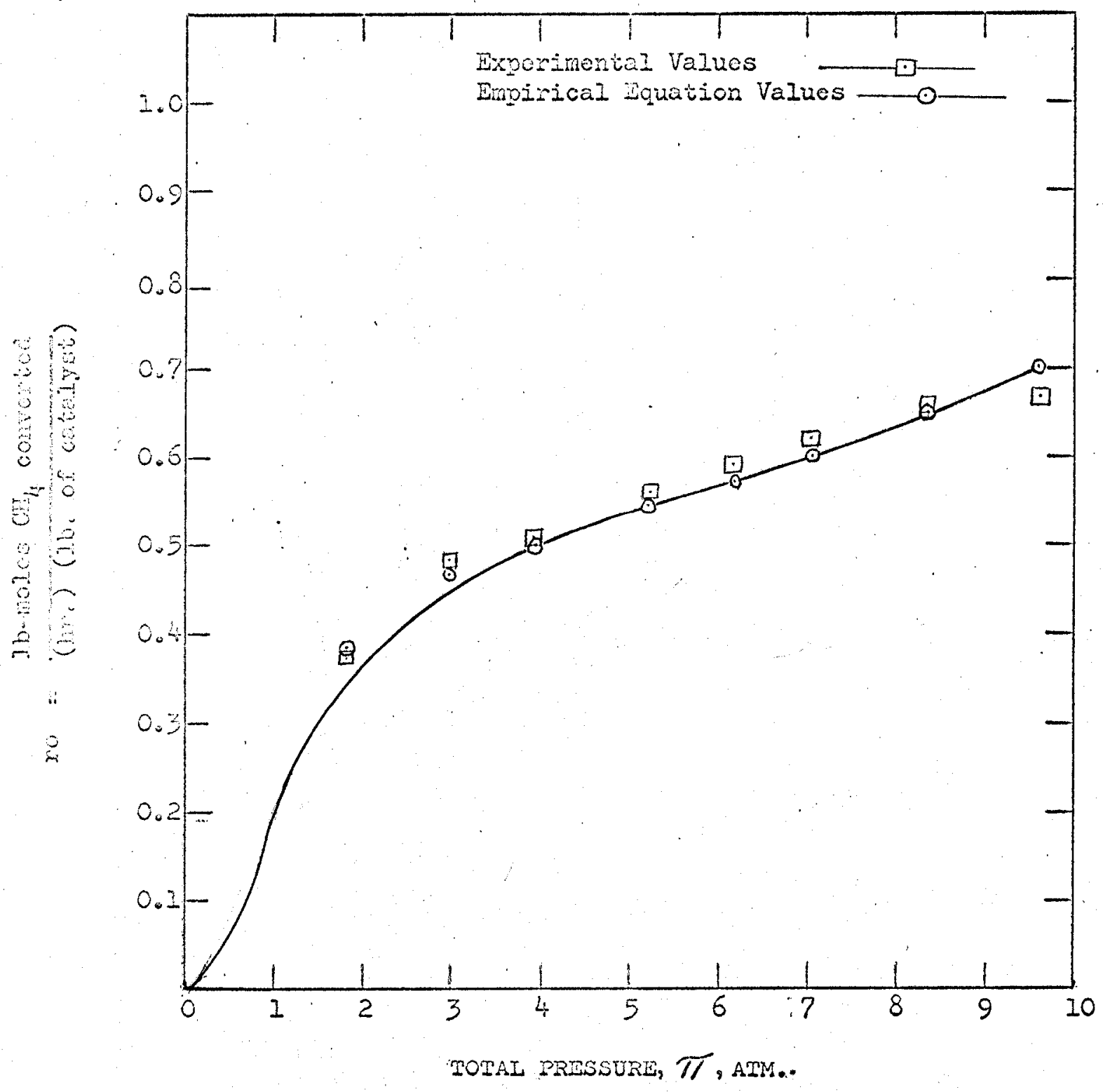

Fig. 12 INITIAL RATE OF REACTION FROM EMPIRICAL EQUATION, $300^{\circ} \mathrm{C}$ 


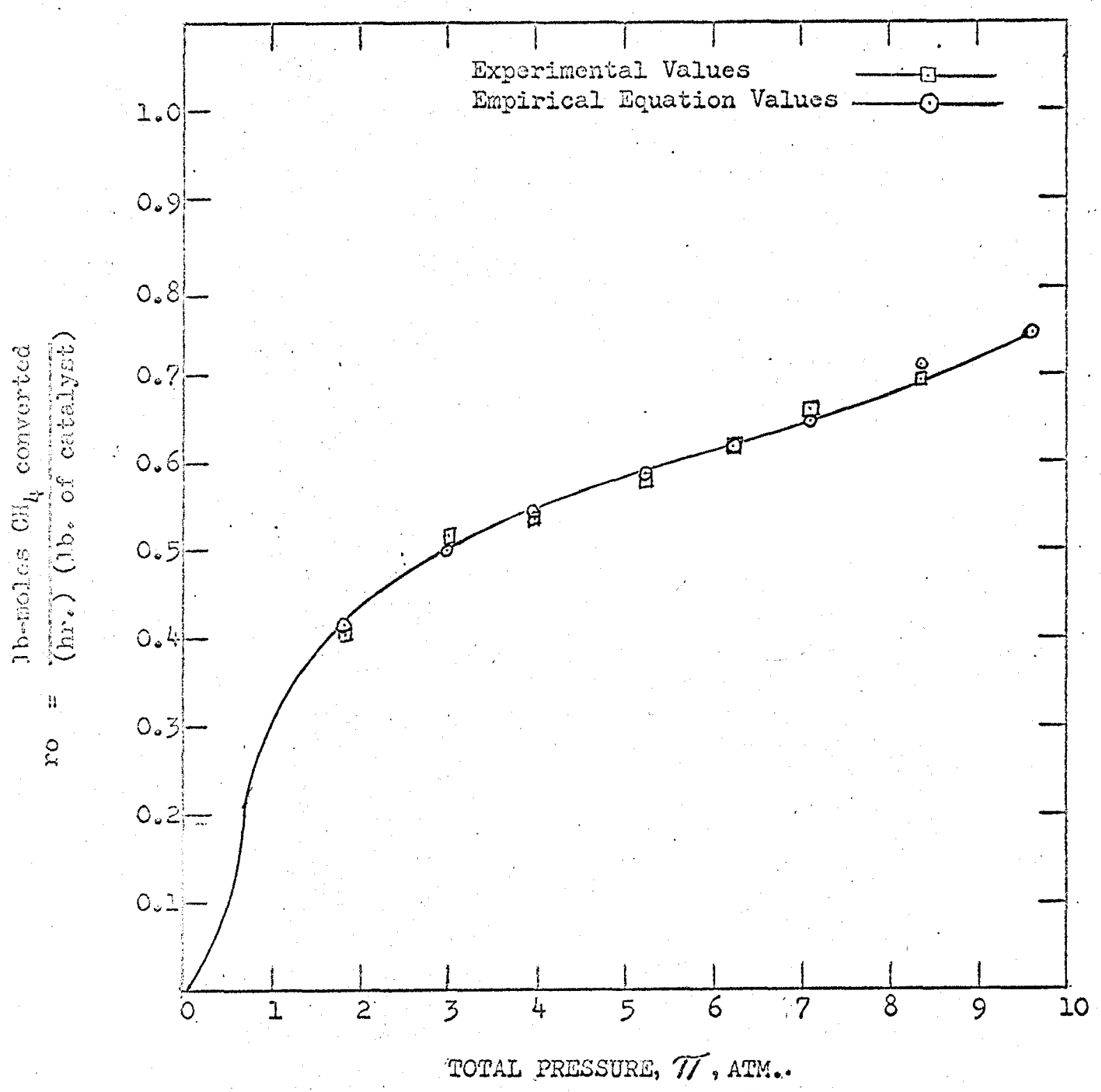

Fig. 13 INITIAL RATE OF REACIION FROM EMPIRICAL EQUATION, $320^{\circ} \mathrm{C}$ 


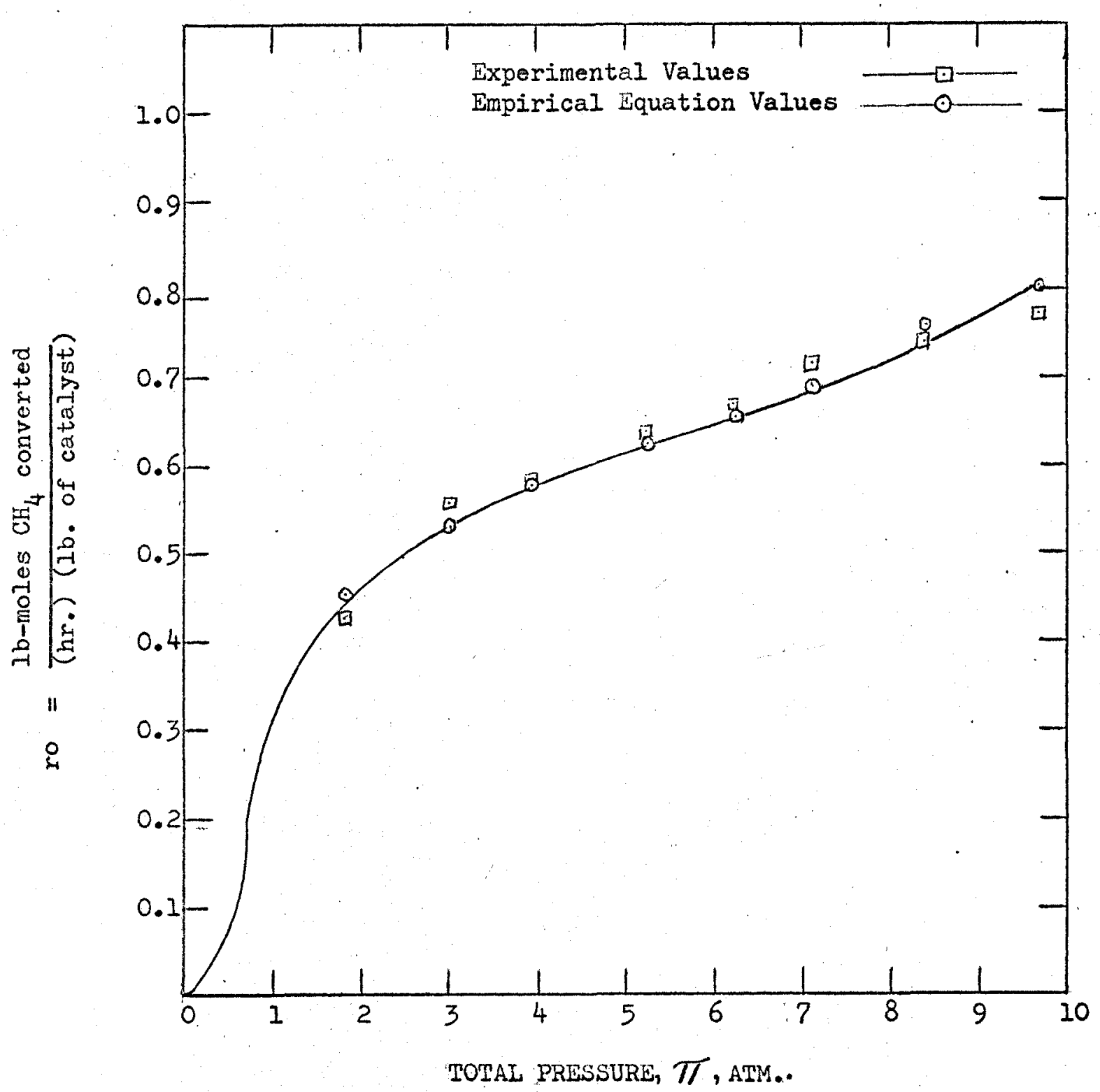

Fig. 14 INITIAL RATE OF REACTION FROM EMPIRICAL EQUATION, $340^{\circ} \mathrm{C}$ 
The mechanism, for the catalytic oxidation of methane has been established experimentally by applying the inital rate approach.

The plots of initial rate against total pressure gave useful qualitative information and thus some implausible mechanisms could be rejected. The determination of linearised regression coefficients and application of the criteria of best fit was then used to reject mechanisms showing wide variation from experimental data. Negative coefficients for some rate mechanisms also helped to eliminate them as possible mechanisms.

The data of initial rates at varying pressures and constant feed composition was not sufficient to establish the controlling mechanism. Plots of initial rate against varying feed composition served as a very useful tool in finding the controlling mechanism. The experimental results showed that there is no shift in mechanism within the range of operating temperature and other operating conditions. The proposed reaction mechanism is as follows:

"Oxygen not dissociated and adsorbed molecularly on dual or single sites, methane adsorbed, carbon dioxide and water adsorbed, surface reaction rate controlling." 
The rate equation based on the mechanism as deduced in the present investigation is only in partial agreement with the mechanistic equation arrived at by Mezaki (19). 


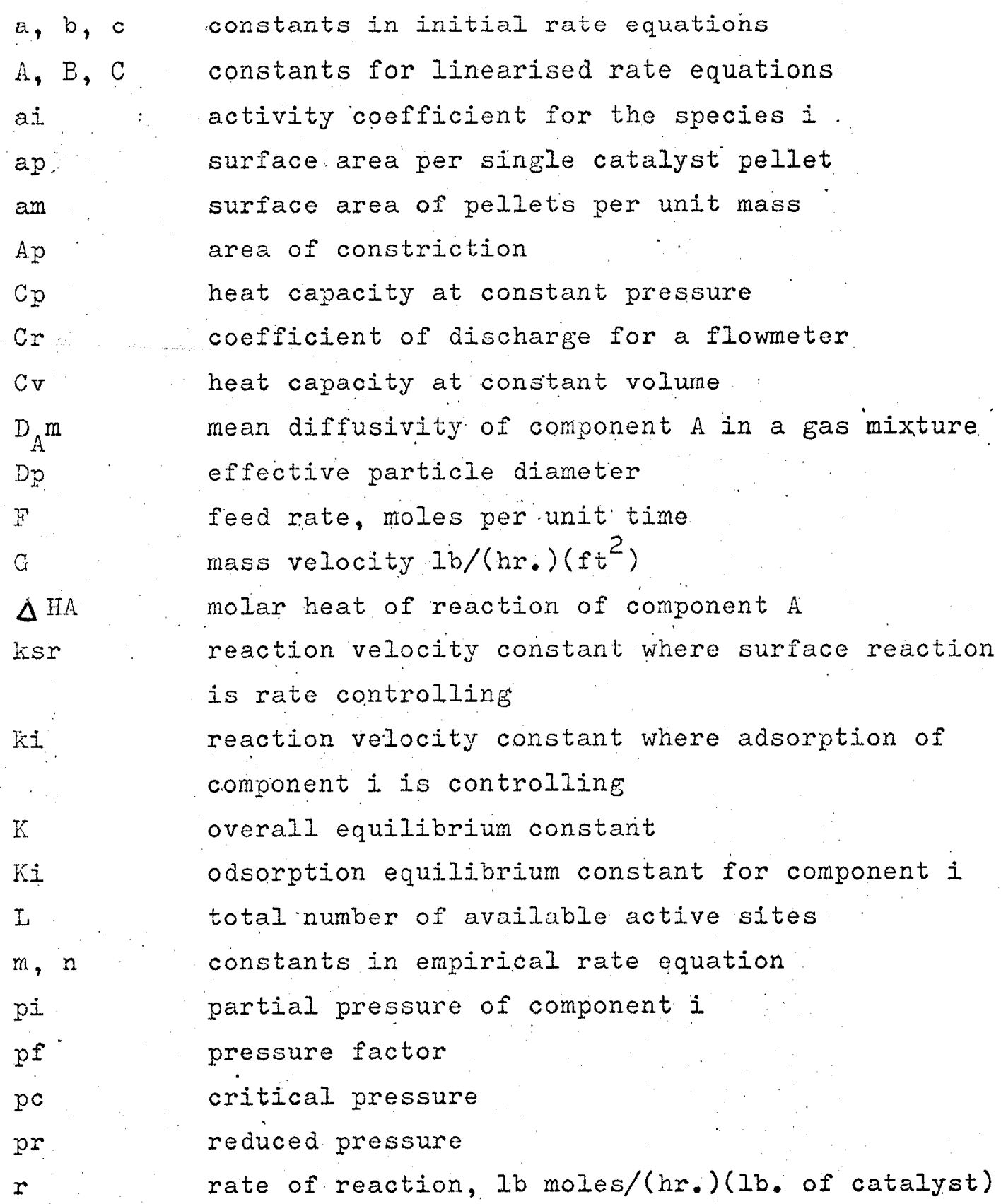


ro

$\mathrm{R}$

$\operatorname{Re}$

$\mathrm{T}$

$t$

Tc

W

W

$X i$

Greek

$\begin{array}{ll}\pi & \text { visocity } \\ \pi & \text { total pressure, atm } \\ \rho & \text { density } \\ \alpha, \alpha & \text { constants }\end{array}$

gas constant

Reynolds number

absolute temperature

temperature, $\mathrm{C}^{\circ}$

flow rate, $\mathrm{lb} . / \mathrm{hr}$.

mass of catalyst initial rate of reaction' referred to methane

critical temperature, $\mathrm{K}^{\circ}$

fraction of $i$ converted

Reproduced with permission of the copyright owner. Further reproduction prohibited without permission. 


\section{BIBIIOGRAPHY}

(1) Yocom, John E., Chemical Engineering, page 104, July 23, 1962.

(2) Faith, W.I., "Air Pollution Control", Wiley and sons Inc., N.Y., 1959.

(3) Lamb, A.B., et. a.., Ind. and Eng. Chem., 12, 213 (1920).

(4) Yant, W.P. and Hawk, C.O., J. Am. Chem. Soc. 49, 1454 (1927).

(5) Cannon, W.A., and Welling, C.E., Ind. and Eng. Chem. Product Research and Development, 1, No. 3. 152 (1962).

(6) Automobile Manufacturers Association, Exhaust System Task Group, Reprint 173, August 1957.

(7) Anderson, R.B., et. aI., Ind. and Eng. Chem., 53, 809 (196I).

(8) Enmet, P.H., Catalysis, Vol. VII, Reinhold Publishing Corporation, 1960.

(9) Henry, G., Phil. Mag., 65, 269 (1825).

(10) Campbell, J.R., and Thomas, G., J. Soc. Chem. Ind., 49, 432 (1930).

(11) Wheeler, T.S., Rec. Trav. Chim. 50, 874 (1931).

(12) Arneil, A., J. Soc. Chem. Ind., 53, 899 (1934).

(13) Araki, S., Japan Analyst, 2, 365 (1953).

(14) Thompson, G.P., et. al. J. Air Pollution Control Assoc., 10, 275 (1960).

(15) Kazarnovskya, I.K. and Dykhno, N.M., Kislorod 12, No. 2, 28 (1959).

(16) Cohn, J.G.E. and Haley, A.J., Can. Patent 597, 459, Nay 3 (1940). (17) Rosenbaum, E.J. et. al., Anal. Chem. 31, 1006 (1959). 
(18) Mezaki, Reiji, "Kinetics of Catalytic Oxidation of Methane", Ph. D Thesis, University of Wisconsin, Chem. Engg. Deptt., Jan., 1963.

(19) Mezaki, Reiji and Watson Charles C., Ind. and Engg. Chem. Process Design and Development, 5, No. 1, 62 (1966).

(20) Thaller, I.H. and George Thodos, A.E. Ch. E. Journal, 6,369 (1960).

(21) Mathur, G.P., "Initial Rate Approach to the Kinetics of Heterogenous Catalytic Reaction", Ph. D. Thesis, Northwestren University, Evanston, June1965.

(22) Hougen, O.A. and Watson K.M., "Chemical Process Principles", part III, John Wïley and Sons...: N.I-, 1950.

(23) Yang K.H. and Hougen, O.A., Chem. Eng. Prog., 46, 156 (1950).

(24) Brown, G.G., et. al., "Unit Operations" John Wiley and Sons, New York, (1950).

(25) Hougen, O.A., Ind. and Eng. Chem., 53, 509 (1961).

(26) Neville Adam M. and Kennedy John B., "Basic Statistical

Methods for Engineers and Scientists". International

Textbook Co., Scranton (Pa.), 1964. 


\section{APPENDIX I}

Tables $6,7,8,9,10$ and 11 . 


$$
\text { Table } 6^{(-6)}
$$

Composition of Auto Exhaust Gases under Different
Operating Conditions - I
$\begin{array}{lll}\text { Operating Condition } & \text { Hydrocarbons (\%) } & \text { Carbon Monoxide (\%) } \\ \text { Idling } & 0.05-0.1 & 4.6 \\ \text { Accelrating } & 0.005-0.05 & 0.6 \\ \text { Cruising } & 0.02-0.03 & 1.4 \\ \text { Decelerating } & 0.4-1.2 & 2.4\end{array}$




$$
\text { Table } 7^{(6)}
$$

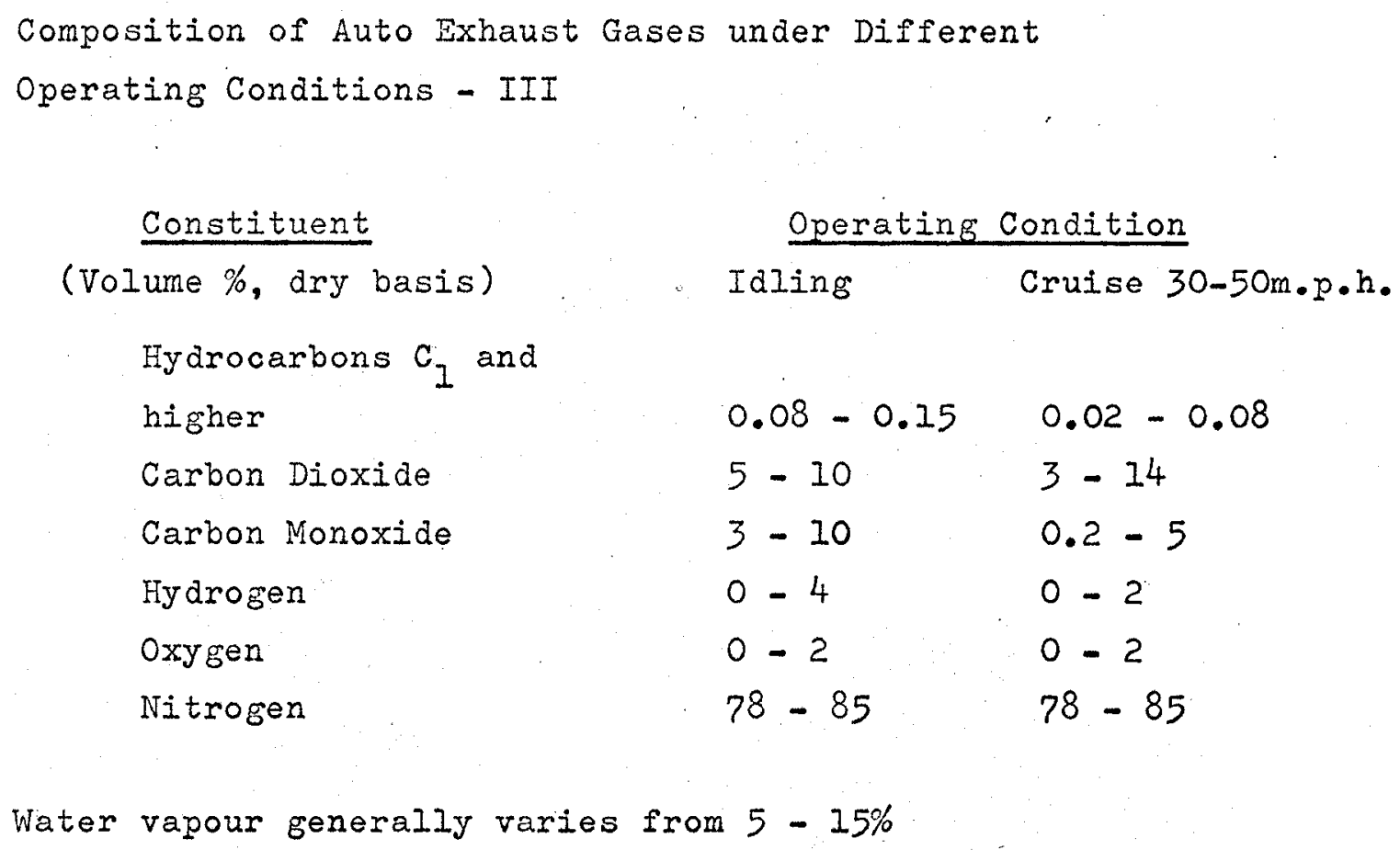




$$
\text { Table } 8^{(6)}
$$

Composition of Auto Exhaust Gases under Different Operating Conditions - II

\section{Constituent}

Nethane
Ethane
Ethylene
Acetylene
Propylene and n-Butane
Butene

Car Condition $30 \mathrm{~m} \cdot \mathrm{p} \cdot \mathrm{h}$.
Concentration p.p.m.

$$
\begin{aligned}
& 63-292 \\
& 15-28 \\
& 114-130 \\
& 41-196 \\
& 35-83 \\
& 0-61
\end{aligned}
$$




\section{Table 9} of Methane (13)

Space Velocity $\left(\mathrm{hr}^{-1}\right)$

Conversion (\%)

$\begin{array}{rr}4,000 & 100 \\ 6,000 & 100 \\ 8,000 & 92 \\ 10,000 & 88 \\ 20,000 & 61\end{array}$


Table 10

The Analysis of C.P. Grade Methane

\section{Constituent}

Methane

Ethane

Carbon Dioxide

Nitrogen

Propane

Oxygen
Percentage

99.05

0.12

0.20

0.60

0.03

50 p.p.m. 
Table 11

Operating Data for Chromatographic Analysis

Column Bath Temperature

Injector Bath Temperature

Detector Bath Temperature

Detector Filament Current

Helium Gas Flow-rate $60^{\circ} \mathrm{C}$

$110^{\circ} \mathrm{C}$

$110^{\circ} \mathrm{C}$

250 milliammeters

0.25 cc. per second 
APPENDIX II

Calibration Curves 


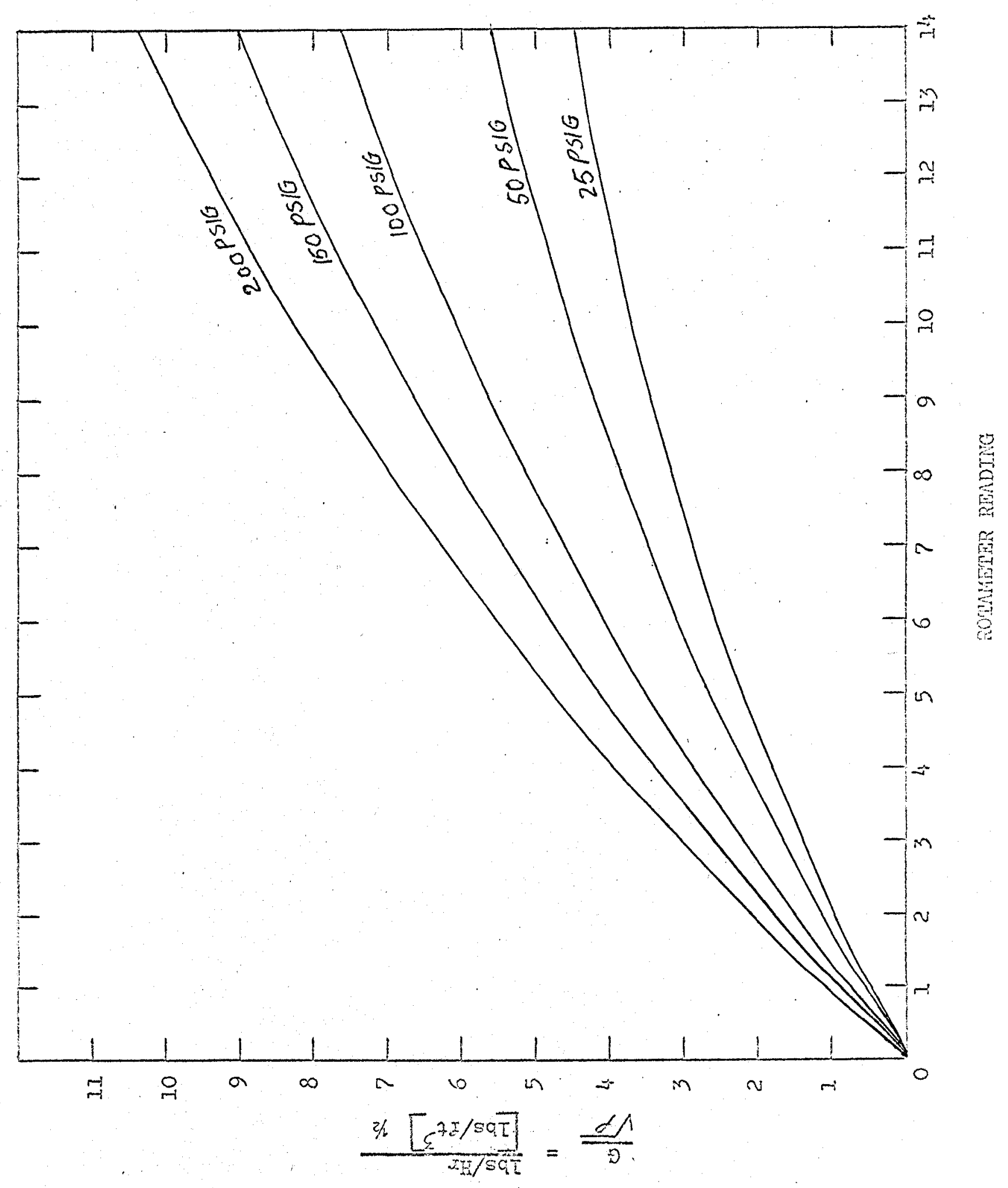

TiE. 15 CAIIBRATION CURVES FOR OXYGEN ROTAMETER 


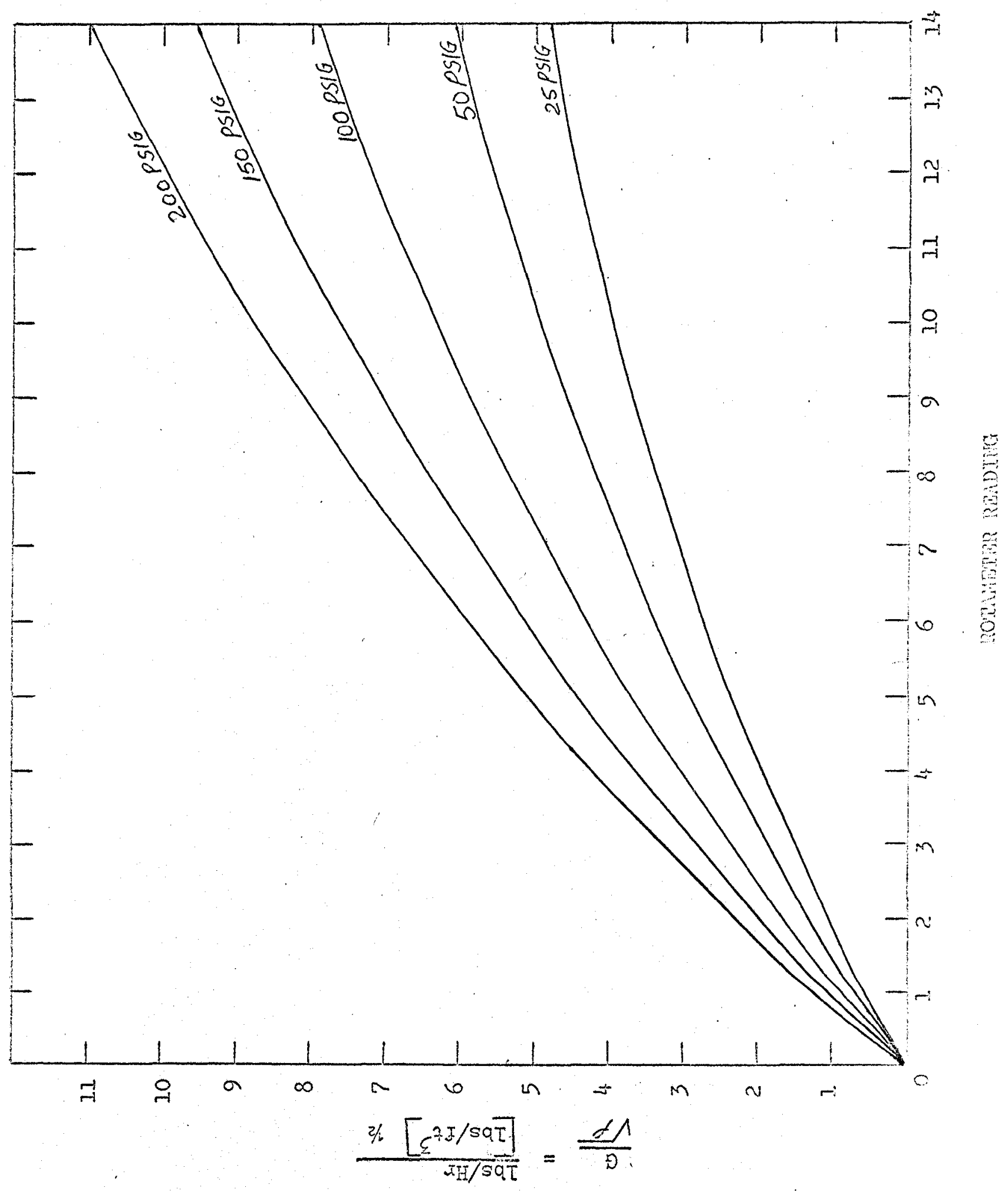

Fig. 16 CALIBRATION CURVES FOR METHATE ROTAMETER 


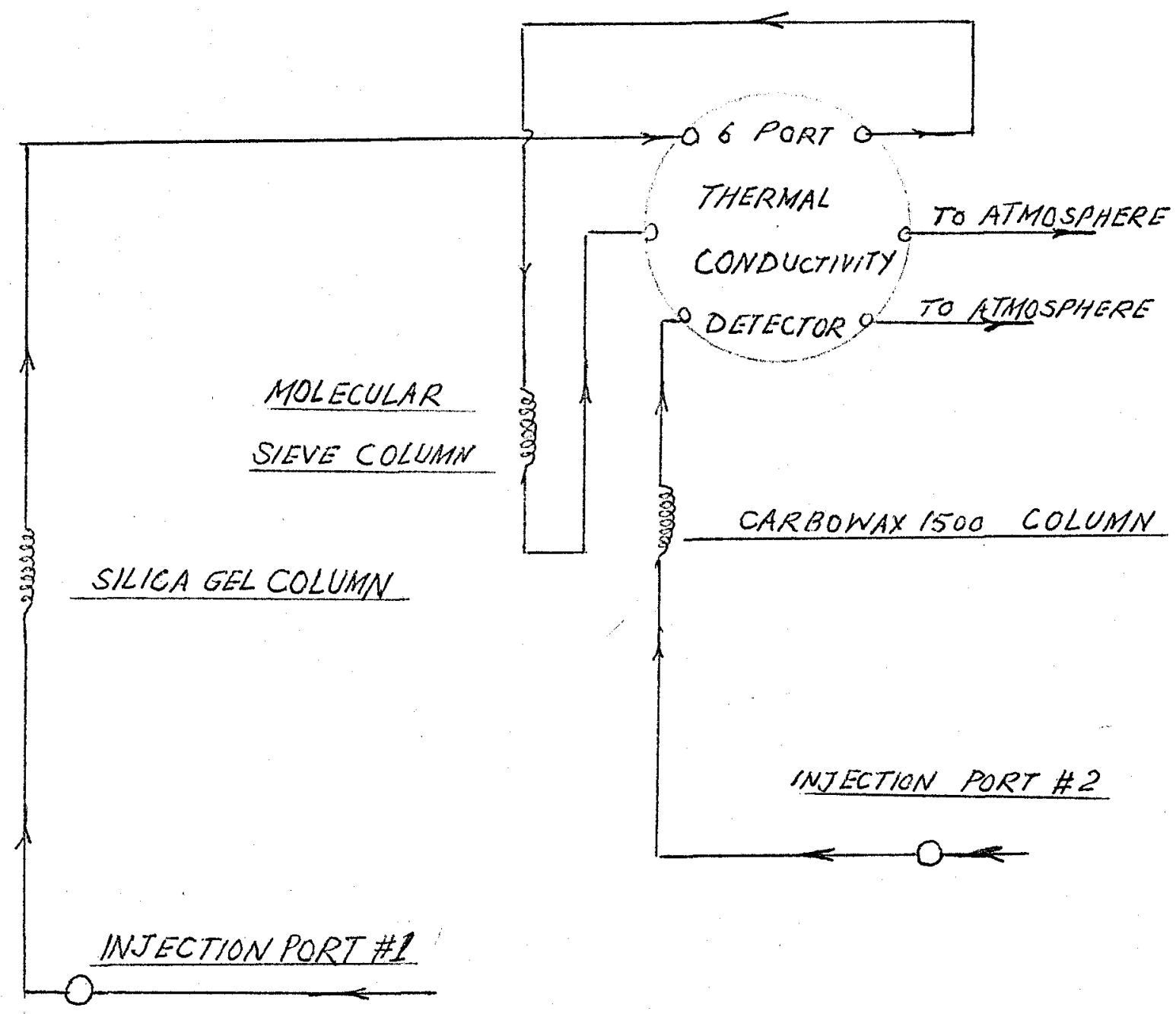

FIG.17 ARRANGEMENT OF COLUMNS FOR G-PORT DETECTOR 


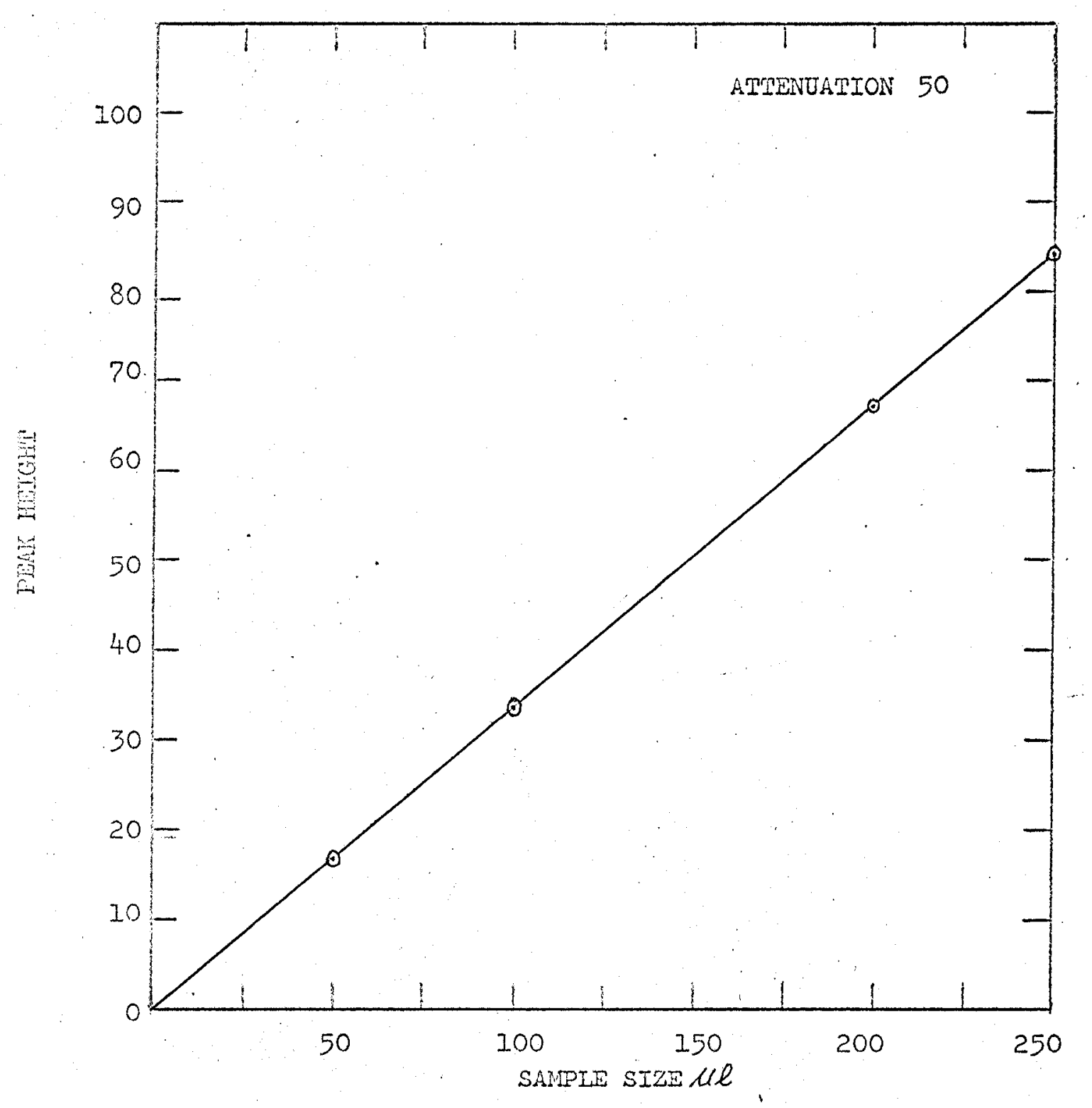

Tig. 18 CHROMATOGRAPHIC CALIBRATION FOR CARBON DIOXIDE 


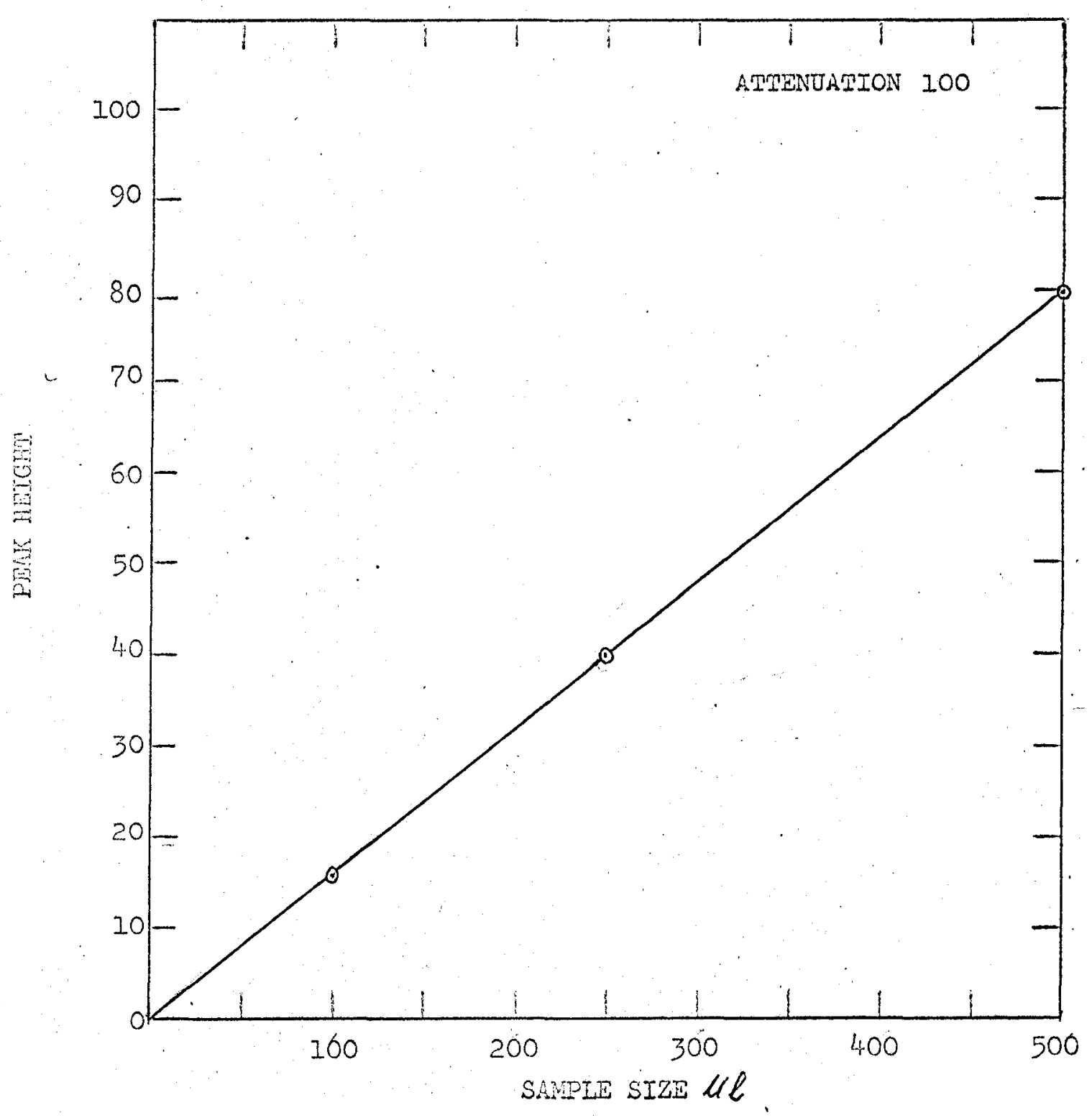

Fig. I9 CHROMATOGRAPHIC CAIIBRATION FOR OXYGEN 


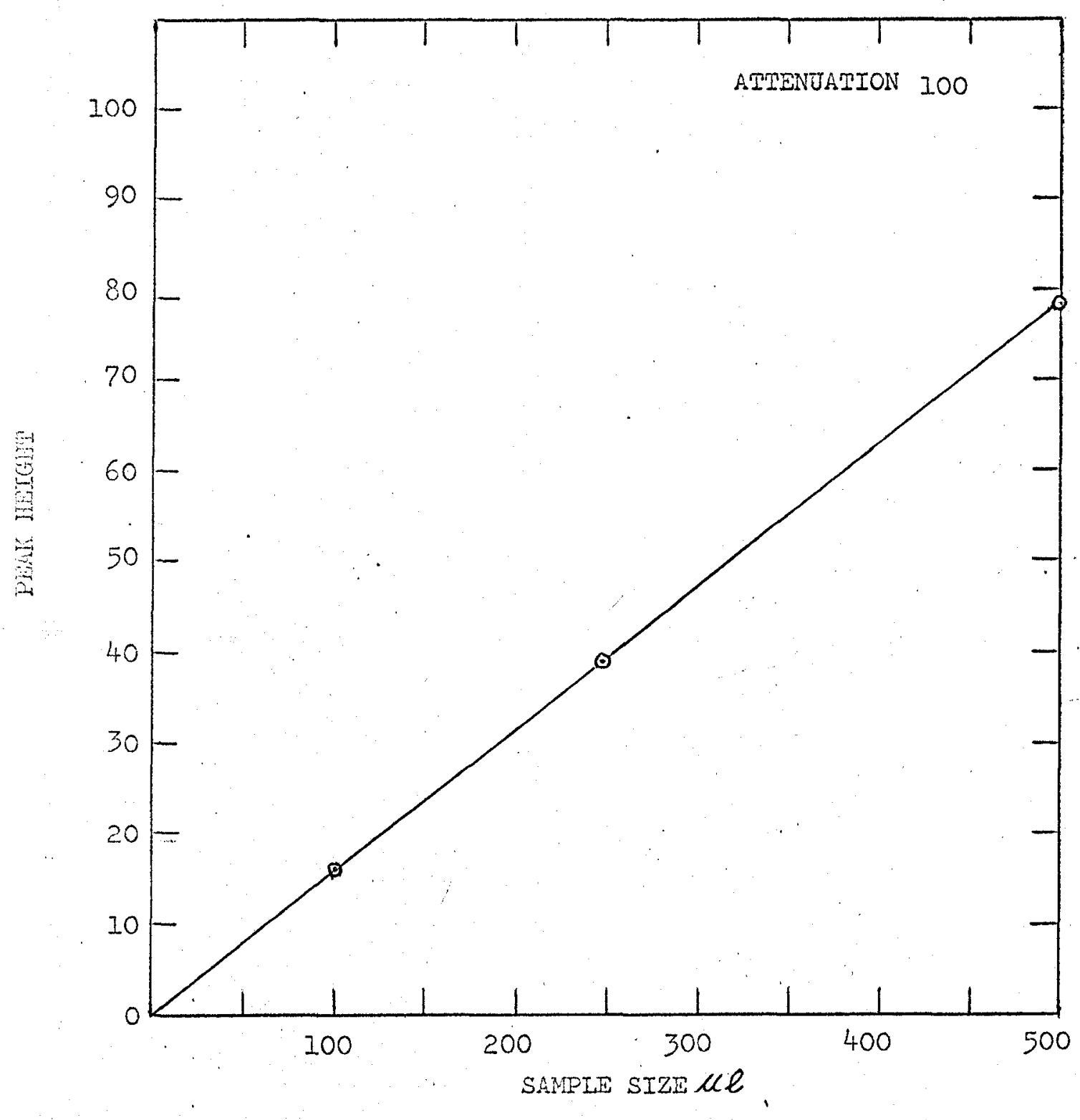

Fig. 20 CHROMATOGRAPHIC CAIIBRATION FOR NITROGEN 


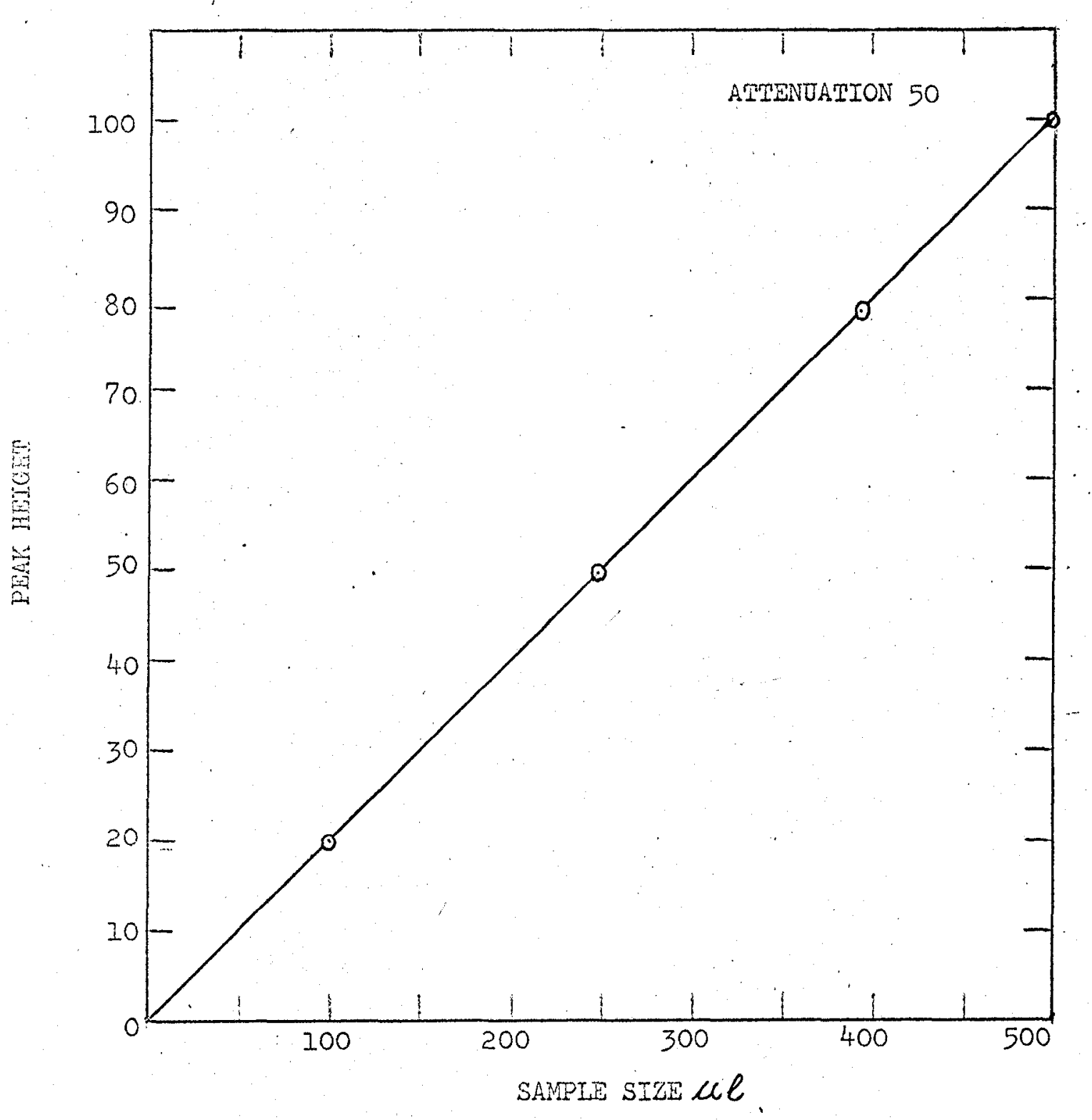

Fig. 21 CHROMATOGRAPHIC CALIBRATIOH FOR METHANE 


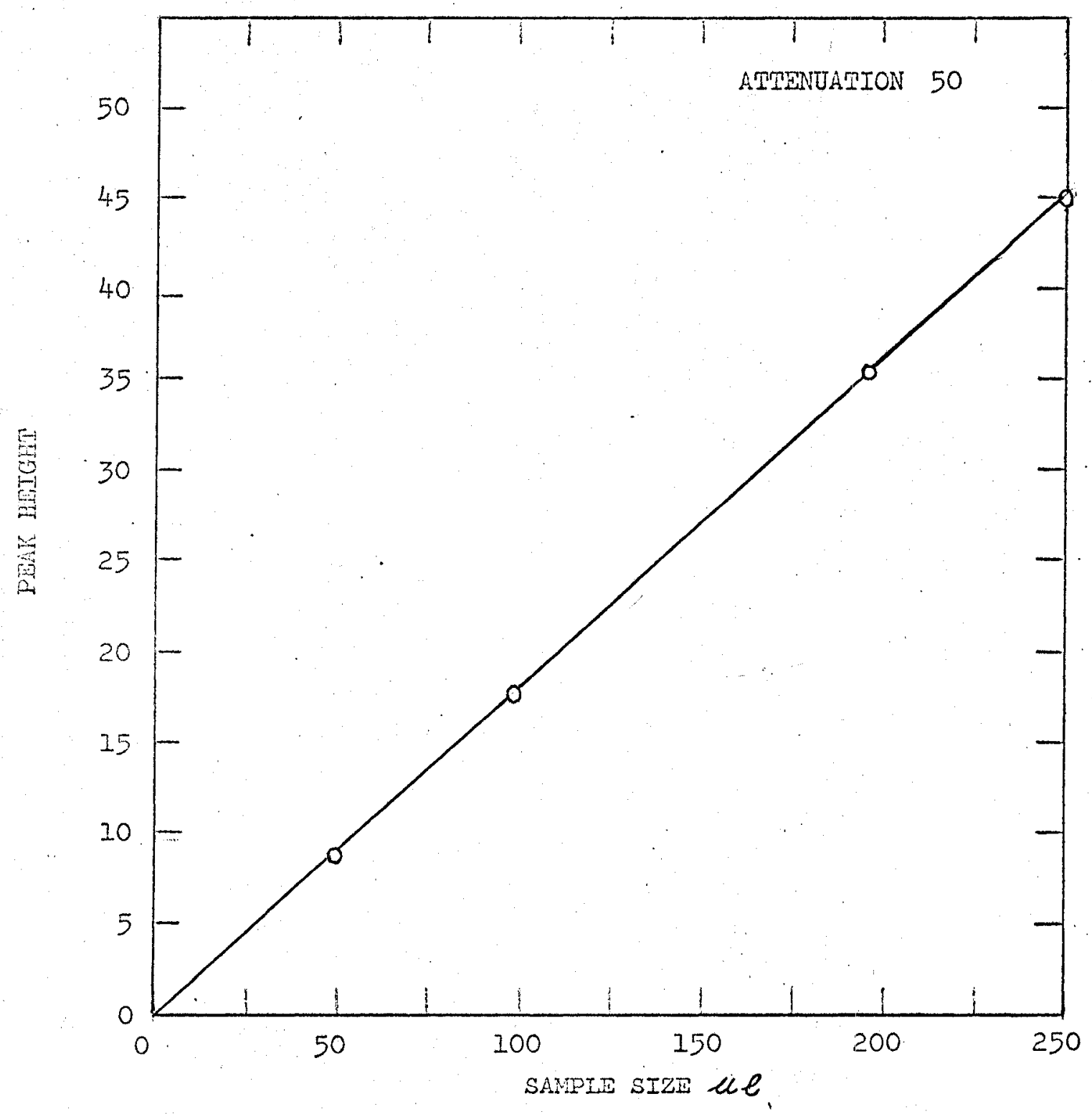

Fig. 22 CHROMATOGRAPHIC CAIIBRATION FOR CARBON MONOXIDE 
APPENDIX III

Sample Calculation of Initial Rate

from Experimental Data

\section{UNIVERSITY OF WINDSOR IIPRARY}

81 


\section{APPENDIX III}

The sample calculation is illustrated for run $I-1$, at $1.817 \mathrm{Atm}$, and $300^{\circ} \mathrm{C}$

OXYGEN ROTAMETER

$$
\begin{aligned}
\begin{array}{l}
\text { Rotameter reading } \\
\text { Upstream pressure } \\
\text { Temperature }
\end{array} & =40 \mathrm{psig} \\
& =25^{\circ} \mathrm{C}
\end{aligned}
$$

Product Analysis

$$
\begin{aligned}
& \text { Carbon Dioxide peak height }=24.2 \text { (Attenuation 2) } \\
& \text { Oxygen peak height }=76.1 \text { (Attenuation 100) } \\
& \text { Nitrogen peak height }=0.8 \quad \text { (Attenuation 100) } \\
& \text { Methane peak height }=31.4 \text { (Attenuation 10) }
\end{aligned}
$$

Volumes of indiviual gases in products

$$
\begin{aligned}
\text { Carbon dioxide } & =24.2 \times \frac{250}{84 \times 25}=2.985 \mu l \\
& =76.1 \times \frac{500}{81}=470 \mu \mathrm{Ml} \\
\text { Oxygen } & =0.8 \times \frac{500}{78}=5.08 \mu \mathrm{Ml} \\
\text { Nitrogen } & =31.4 \times \frac{500}{100 \times 5}=31.4 \mu l \\
\text { Methane } & =3 \ell
\end{aligned}
$$




$$
\text { Water vapour }=2 \times 2.985=5.970 . \quad M B
$$

$\overline{\text { Total } 515.435 \mu \ell}$

Composition of Gases in product:

$$
\begin{aligned}
\text { Carbon Dioxide } & =\frac{2.985}{515.435} \times 100=0.579 \% \\
& =\frac{31.4}{515.435} \times 100=6.09 \% \\
\text { Methane } & =\frac{0.579}{(0.579+6.09)} \times 100=8.66 \%
\end{aligned}
$$

As methane Rotameter was at very low rotameter reading, its feed rate was not calculated on rotameter reading basis, but on percentage of methane in feed gas

Methane in feed gas $=6.669 \%$

Methane gas feed rate

$$
=0.0664 \times \frac{6.669}{93.331}=0.474 \times 10^{-2} \quad 1 \mathrm{~b} \text {-moles } / \mathrm{hr} .
$$

Rate of reaction is given by:

$$
\begin{aligned}
r_{0} & =\frac{\text { (Feed rate of methane) (\% conversion) }}{\text { (Weight of catalyst) } \times 100} \\
& =\frac{0.474 \times 10^{-2} \times 8.66}{1: 1 \times 10^{-3} \times 100} \\
& =0.373 \frac{(1 \mathrm{~b} \text { moles methane) }}{(\mathrm{hr} .)(1 \mathrm{~b} . \text { of catalyst) }}
\end{aligned}
$$




\section{APPENDIX IV}

Sample Calculation for Heat and Mass Transfer Effects 
Yang and Hougen (22) have detailed the equations for calculating heat and mass transfer effects.

The pressure drop $\Delta P$ for any component $A$ from the main gas stream to the gas-solid interface is given by the expression

$$
\frac{\Delta p_{A}}{p_{A}}=\frac{1}{\alpha}\left(\frac{\sqrt{a_{p} r_{A} M_{m} p_{f}}}{p_{A} \mu^{a_{m}}}\right)\left(\frac{\mu}{D_{A m}}\right)\left({\sqrt{a_{p} G}}^{\mu}\right)^{n-1}
$$

The equation proposed for the temperature differential across the stagnant gas film from the catalyst surface to the main gas stream is:

$\frac{\Delta T}{T}=\frac{1}{\alpha}\left[\frac{r_{A} \Delta H A \sqrt{a_{p}}}{a_{m} \cdot \mu \cdot C_{p}^{T}}\right]\left[\frac{C_{p} \mu}{k}\right]_{F}^{2 / 3}\left[\frac{\sqrt{a_{p}}}{\mu}\right]^{n-1}$

Values of constants $\alpha, \alpha^{\prime}$ and $n$ depend on Reynolds number

The result of run I-1, will be used to illustrate the method of estimating various quantities that appear in above expressions. For this run, the overall mass balance is shown below:

$$
\begin{aligned}
& \text { Ib-moles/hr Ib-moles/hr }
\end{aligned}
$$

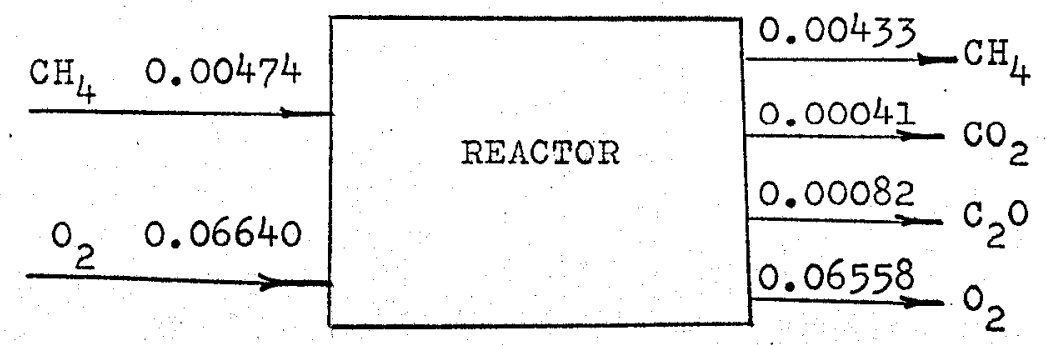




\section{Partial Pressures}

Inlet

$$
\begin{aligned}
& \mathrm{p}_{\mathrm{CH}_{4}}=\frac{0.00474}{0.0714} \times 1.817=0.1210 \mathrm{~atm} \\
& \mathrm{p}_{2}=\frac{0.0664}{0.07114} \times 1.817=1.6960 \mathrm{~atm}
\end{aligned}
$$

Outlet

$$
\begin{aligned}
& \mathrm{p}_{\mathrm{CO}_{2}}=\frac{0.00041}{0.07114} \times 1.817=0.01045 \mathrm{~atm} . \\
& \mathrm{p}_{\mathrm{H}_{2} \mathrm{O}}=\frac{0.00082}{0.07114} \times 1.817=0.0209 \mathrm{~atm} \\
& \mathrm{p}_{\mathrm{CH}_{4}}=\frac{0.00433}{0.07114} \times 1.817=0.1105 \mathrm{~atm} . \\
& \mathrm{p}_{\mathrm{O}_{2}}=\frac{0.06558}{0.07114} \times 1.817=1.6755 \mathrm{~atm} .
\end{aligned}
$$

Average

$$
\begin{aligned}
& \mathrm{p}_{\mathrm{CH}_{4}}=0.1157 \text { atm. } \\
& \mathrm{p}_{\mathrm{O}_{2}}=1.6857 \mathrm{~atm} . \\
& \mathrm{p}_{\mathrm{CO}_{2}}=0.00523 \mathrm{~atm} . \\
& \mathrm{p}_{\mathrm{H}_{2} \mathrm{O}}=0.01045 \mathrm{~atm} .
\end{aligned}
$$

\section{Physical Properties}

Critical Temperature

$$
T_{c m}=\sum_{i} X_{i} T_{C i}
$$

$$
\begin{aligned}
\mathrm{T}_{\mathrm{cm}}= & (0.0638)(190.7)+(0.9275)(154.4)+(0.00279)(304.2)+ \\
& (0.00579)(647.4) \\
& =159.97^{\circ} \mathrm{K}
\end{aligned}
$$


Molecular Weight

$$
M m=\sum_{i} X_{i} M_{i}
$$

$\mathrm{Mm}(0.0638)(16)+(0.9275)(32)+(0.00279)(44)+(0.00579)(18)$

$=30.7235$

$\underline{\text { Viscosity }}$

$$
\begin{aligned}
& \mu_{\mathrm{cm}}=\sum_{i} x_{i} \mu_{\mathrm{ci}} \\
& \mu_{\mathrm{m}}=\mu_{\mathrm{cm}} \mu_{\mathrm{rm}} \\
& \mathrm{cm}(0.0638)(159)+(0.9275)(250)+(0.00279)(343)+(0.00579)(495) \\
&= 245.84 \text { micropoise }
\end{aligned}
$$

The value of $\mu_{r m}$ can be read from figure 175 , page 871 , Reference (2I)

$$
\begin{aligned}
\operatorname{Tr} & =573 / 159.97 \quad 3.58 \\
\mathrm{Pr}_{\mathrm{r}} & \cong 0 \\
\mu_{\mathrm{rm}} & =1.2 \\
\mu_{\mathrm{m}} & =(1.2)(245.84)=295.01 \mathrm{micropoise} \\
& =0.0956 \mathrm{Ibs} /(\mathrm{hr} .)\left(\mathrm{ft}_{.}\right)
\end{aligned}
$$

Density

$$
\begin{aligned}
P_{\mathrm{m}} & =\frac{30.7235 \times 1.817}{0.7302 \times 1032} \\
& =0.0741 \mathrm{1bs} / \mathrm{ft}^{3}
\end{aligned}
$$

Diffusivity

$$
\begin{gathered}
\left(1-x_{A}\right) D_{A m}=x_{B} D_{A B}+x_{C} D_{A C}+\cdots-. .-\cdots x_{i} D_{A i} \\
D_{A B}=\frac{0.0043 T^{3 / 2}}{\pi\left(V_{A}^{1 / 3}+v_{B}^{1 / 3}\right)} \sqrt{\frac{1}{M_{A}}+\frac{1}{M_{B}}}
\end{gathered}
$$




$$
\begin{aligned}
& \mathrm{D}_{\mathrm{CH}_{4}}-\mathrm{O}_{2}=\frac{(0.0043)(573)^{3 / 2}}{1.817\left(29.6^{1 / 3}+25.6^{1 / 3}\right)} \sqrt{\frac{1}{16}+\frac{1}{32}} \\
& =0.48 \mathrm{~cm}^{2} / \mathrm{sec} \text {. } \\
& =1.856 \mathrm{ft}^{2} / \mathrm{hr} \text {. } \\
& \mathrm{D}_{\mathrm{CH}_{4}}-\mathrm{CO}_{2}=\frac{(0.0043)(573)^{3 / 2}}{1.817\left(29.6^{1 / 3}+34^{1 / 3}\right)} \sqrt{\frac{1}{16}+\frac{1}{44}} \\
& =0.417 \mathrm{~cm}^{2} / \mathrm{sec} \text {. } \\
& =1.615 \mathrm{ft}^{2} / \mathrm{hr} \text {. } \\
& \mathrm{D}_{\mathrm{CH}_{4}}-\mathrm{H}_{2} \mathrm{O}=\frac{(0.0043)(573)^{3 / 2}}{1.817\left(29.6^{1 / 3}+18.9^{1 / 3}\right)} \sqrt{\frac{1}{16}+\frac{1}{16}} \\
& =0.598 \mathrm{~cm}^{2} / \mathrm{sec} \text {. } \\
& =2.315 \mathrm{ft}^{2} / \mathrm{hr} \text {. } \\
& (1-0.0638) D_{\mathrm{CH}_{4}}-m=(1.856)(0.9275)+(1.615)(0.00279)+ \\
& (2.315)(0.00579) \\
& \mathrm{D}_{\mathrm{CH}_{4}-\mathrm{m}}=1.85 \mathrm{ft}^{2} / \mathrm{hr} .
\end{aligned}
$$

Pressure Film Factor

$$
\begin{aligned}
P_{f} & =\left(\pi+\delta_{A} P_{A}\right)_{m} \\
& =\pi+0=1.817 \mathrm{~atm} .
\end{aligned}
$$

Modified Reynolds Number

$$
\begin{gathered}
N_{r e}^{\prime}=\frac{\sqrt{a p} \cdot G}{\mu} \\
G=F /_{A}=\frac{0.00453 \times 16}{\left(\frac{\pi}{4}\right) \times\left(\frac{1.5}{12}\right)^{2}}=5.91 \mathrm{lbs} /(\mathrm{hr} .)\left(\mathrm{ft}^{2}\right)
\end{gathered}
$$




$$
\begin{aligned}
& D_{p}=(1.5)^{1 / 2} D=(1.5)^{1 / 2}\left(\frac{1}{812}\right)=0.0127 \mathrm{ft} . \\
& a_{p}=\pi D_{p}^{2}=0.000507 \mathrm{ft}^{2}
\end{aligned}
$$

Modified Reynolds Number

$$
\begin{aligned}
N^{\prime} R e=\frac{\left(a_{p}\right)^{1 / 2} G}{\mu} & =\frac{(0.000507)^{1 / 2}(5.91)}{0.0956} \\
& =1.391
\end{aligned}
$$

Schmidt Number

$$
\begin{aligned}
S_{c} & =\frac{\mu}{P_{A m}}=\frac{0.0956}{\left(7.41 \times 10^{-2}\right)(1.85)}=0.698 \\
A_{m} & =120(\text { metre })^{2} / \mathrm{gm} \quad \text { (Suppliers Data) } \\
& =\frac{120 \times(3.28)^{2}}{1 / 453.6}=5.8 \times 10^{5}(\mathrm{ft})^{2} / 1 \mathrm{~b} .
\end{aligned}
$$

\section{Pressure Drop}

The pressure drop for methane from the main gas stream to the gas-solid interface is given as

$$
\begin{aligned}
& \frac{\Delta p_{A}}{p_{A}}=\frac{1}{\alpha}\left[\frac{\sqrt{a}_{p} r_{A} M_{m} p_{f}}{p_{A} \mu a_{m}}\right]\left[\frac{\mu}{P D_{A m}}\right]_{f}\left[\frac{\sqrt{a p G}}{\mu}\right]^{n-1} \\
& \quad \text { for N're } 6620, \quad \alpha=2.44 \text { and } n=0.51 \\
& \therefore \frac{\Delta p}{p}=\frac{1}{2.44}\left[\frac{(0.000507)^{1 / 2}(0.373)(30.7235)(1.817)}{(0.1157)(0.0956)\left(5.8 \times 10^{5}\right)}\right](0.698)^{2 / 3}(1.391)^{-0.5}
\end{aligned}
$$




$$
\begin{aligned}
& \frac{\Delta p}{p}=2.01 \times 10^{-3} \\
& \Delta P=2.01 \times 10^{-3} \times 0.1157=2.33 \times 10^{-4} \mathrm{~atm} .
\end{aligned}
$$

\section{Specific Heat}

$$
\begin{aligned}
C_{p m} & =\sum_{i} x_{i} C_{p_{i}} \\
& =(0.0638)(12.32)+(0.9275)(7.68)+(0.00279)(11.2)+ \\
& \therefore(0.00579)(3.96) \\
& =7.957 \mathrm{Btu} /(1 \mathrm{~b}-\text { mole })\left(\mathrm{R}^{0}\right) \\
& =7.957 \mathrm{Cal} /(\mathrm{gm}-\mathrm{mole})\left(\mathrm{K}^{0}\right)
\end{aligned}
$$

PrandtI Number

$$
\operatorname{Pr}=\frac{{ }_{p} \mu}{k}
$$

A relation recommended by Hougen and Watson (21), is given on page 990, equation (51).

$$
\begin{gathered}
\frac{{ }_{p} \mu}{k}=\frac{4}{\left[9-5 \frac{\mathrm{Cv}}{C p}\right]} \\
{\left[\frac{c_{p} \mu}{k}\right]^{2 / 3}=\left[\frac{4}{9-\left(5 \times \frac{1}{13 \cdot 1}\right)}\right]^{2 / 3}=0.844}
\end{gathered}
$$

Heat of Reaction

$$
\Delta \mathrm{Hr}=-19 \mathrm{I} \mathrm{K} \cdot \mathrm{Cal} / \mathrm{g}-\mathrm{mole} \text { at } 500^{\circ} \mathrm{K}
$$




\section{Temperature Drop}

The temperature differential $\Delta \mathrm{T}$ across the stagnant gas film from the catalyst surface to the main gas stream is

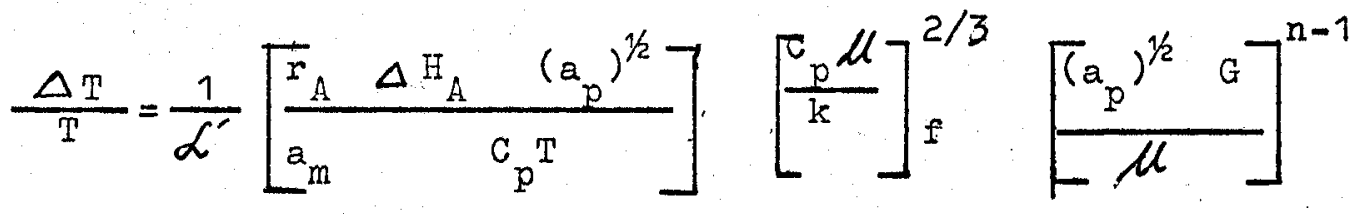

$$
\begin{aligned}
& \text { For } N^{\prime} \text { re }<20 \quad \alpha^{\prime}=2.62 \quad n=0.51 \\
& \therefore \frac{\Delta T}{T}=\frac{1}{2.62}\left[\frac{0.373 \times 1.91 \times 10^{5} \times 2.255 \times 10^{-2}}{5.8 \times 10^{5} \times 0.0956 \times\left(\frac{7.957}{30.7235}\right) \times 573}\right](0.844)(1.391)^{1-0.51} \\
& =1.345 \times 10^{-4} \\
& \Delta T=1.345 \times 10^{-4} \times 573=0.077^{\circ} \mathrm{C}
\end{aligned}
$$

It is evident, that mass transfer and heat transfer effects are quite negligible. For other runs, the mass and heat transfer contributions were found to be of the same order of magnitude as this particular run. 


\section{APPENDIX V}

Computer Programmes and Results 
C C O. P. AHUJA DIMENSION X(10), SIGY 10$)$.SIGYY 10$), X Y(10) . A(10), B(10) . P(10$ $1 R(10), Y(10,10)$

1 READ 2, $(P(K), K=1,8),(R(K), K=1,8)$

$C=8$

$F=1 . / 3$

DO $3 K=1,8$

$X(K)=P(K)$

$Y(1, K)=P(K) / \operatorname{SQRTF}(R(K))$

$Y(2, K)=P(K) / R(K) * * F$

$Y(3, K)=(P(K) * * 1.5) / \operatorname{SQRTF}(R(K))$

$Y(4, K)=(P(K) * * 3 \cdot) / R(K)$

$Y(5, K)=P(K) / R(K)$

$Y(6, K)=(\operatorname{SQRTF}(P(K))) / R(K) * * .25$

$Y(7, K)=(P(K) * * .75) / R(K) * * .25$

$3 Y(8, K)=P(K) / R(K)$

$S I G X=0$

$S I G X X=0$

DO $4 J=1,8$

$\operatorname{SIGY}(J)=0$

$4 X Y(J)=0$

DO $5 \mathrm{~J}=1.8$

DO $5 K=1,8$

$S I G Y(J)=S I G Y(J)+Y(J \cdot K)$

$5 X Y(J)=X Y(J)+X(K) * Y(J, K)$

DO $6 K=1,8$

$S I G X=S I G X+X(K)$

$6 S I G X X=S I G X X+X(K) * X(K)$

DO $7 \mathrm{~J}=1,8$

$A(J)=(S I G X X * S I G Y(J)-S I G X * X Y(J)) /(C * S I G X X-S I G X * S I G X)$

$7 B(J)=$ (C*XY $(J)-S I G X * S I G Y(J)) /(C * S I G X X-S I G X * S I G X)$

PUNCH 10

DO $9 \mathrm{~J}=1,8$

9 PUNCH $8, J, A(J), B(J)$

2 FORMAT $(8 F B \cdot 3 /(8 F 8 \cdot 3))$

10 FORMAT ( $5 X, 1 \mathrm{HN}, 15 \mathrm{X}, 1 \mathrm{HA}, 20 \mathrm{X}, 1 \mathrm{HB} / \mathrm{H})$

8 FORMAT $(5 X, 11,2(10 X, F 12.6))$

GO TO 1 END

$\begin{array}{rrrrrrrr}1817 & 2975 & 3925 & 5220 & 6240 & 7130 & 8410 & 97 \\ 373 & 481 & 503 & 559 & 594 & 624 & 655 & 671 \\ 1817 & 2975 & 3925 & 5220 & 6240 & 7130 & 8410 & 97 \\ 398 & 511 & 531 & 581 & 616 & 658 & 694 & 712 \\ 1817 & 2975 & 3925 & 5220 & 6240 & 7130 & 8410 & 97 \\ 421 & 552 & 580 & 640 & 673 & 720 & 745 & 771\end{array}$


O. P. AHUJA

REGRESSION COEFFICIENTS FOR THE MECHANISM EQUATIONS NO. 1
TEMPRATURE 300 DEGREES $C$

N

1
2
3
4
5
6
7
8

TEMPRATURE 320 DEGREES C

$N$

1

2

3

4

5

6

7

8

TEMPRATURE

$N$

1
2
3
4
5
6
7
8
A

$$
\begin{array}{r}
1.034149 \\
.622627 \\
-4.980518 \\
-471.924620 \\
2.818439 \\
1.448114 \\
1.218984 \\
2.818439
\end{array}
$$

A

1.018676 .619577

$-4 \cdot 797862$

$-443.534080$

2.692498

1.429209

1.205102

2.692498

340 DEGREES $C$

A

. 973950

.599482

$-4.642242$

$-411 \cdot 557960$

2.484799

1.402137

1.180958

2.484799
B

1.119909

1.082035

4.172677

164.676080

1.208295

.214024

.511810

1.208295

B

. 1.088979

1.061949

4.055110

155.399770

1.143425

. 211230

.504798

1.143425

$B$

$$
\begin{array}{r}
1.045676 \\
1.033754 \\
3.898043 \\
143.724510 \\
1.052355 \\
.206615 \\
.494457 \\
1.052355
\end{array}
$$




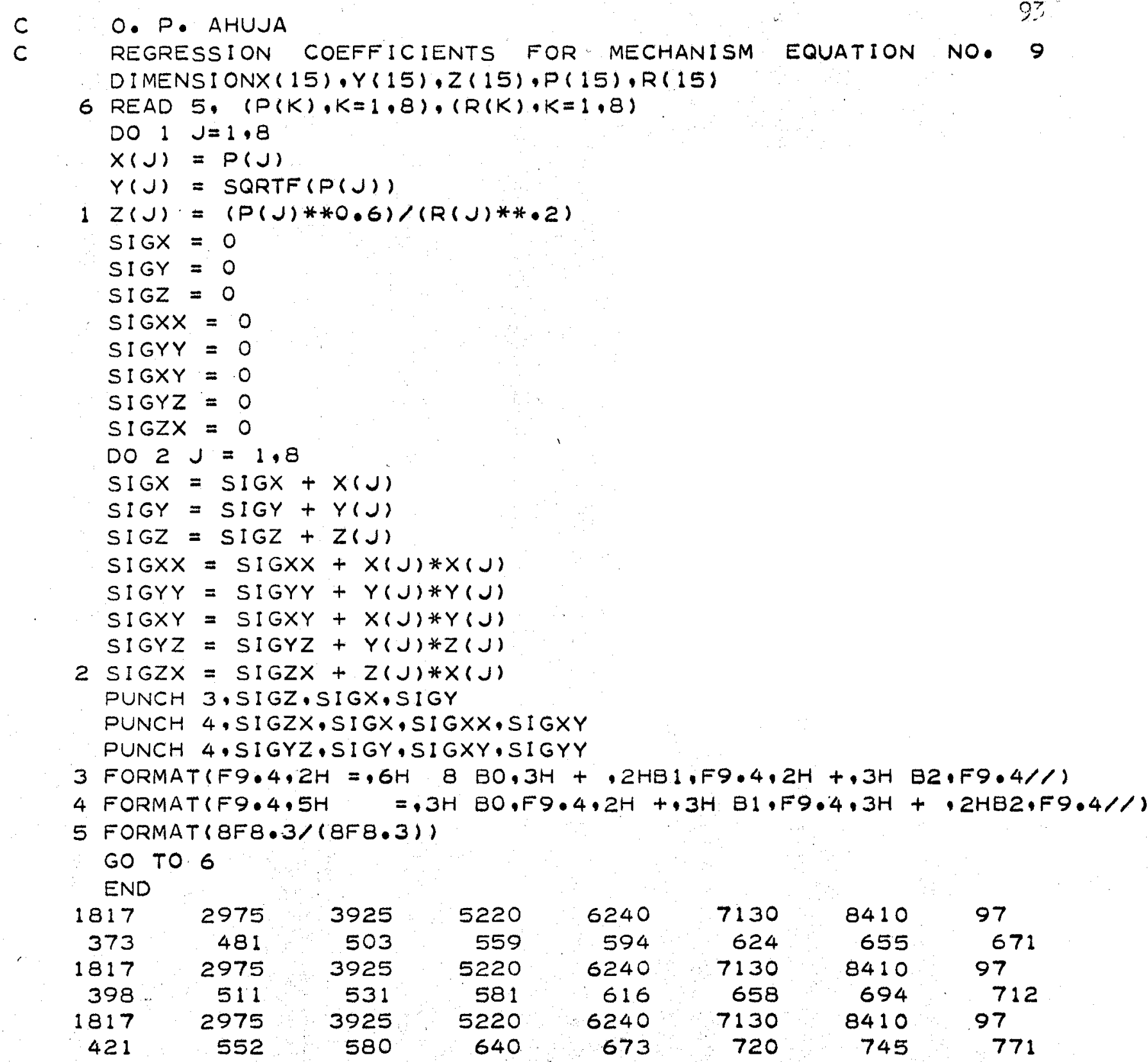




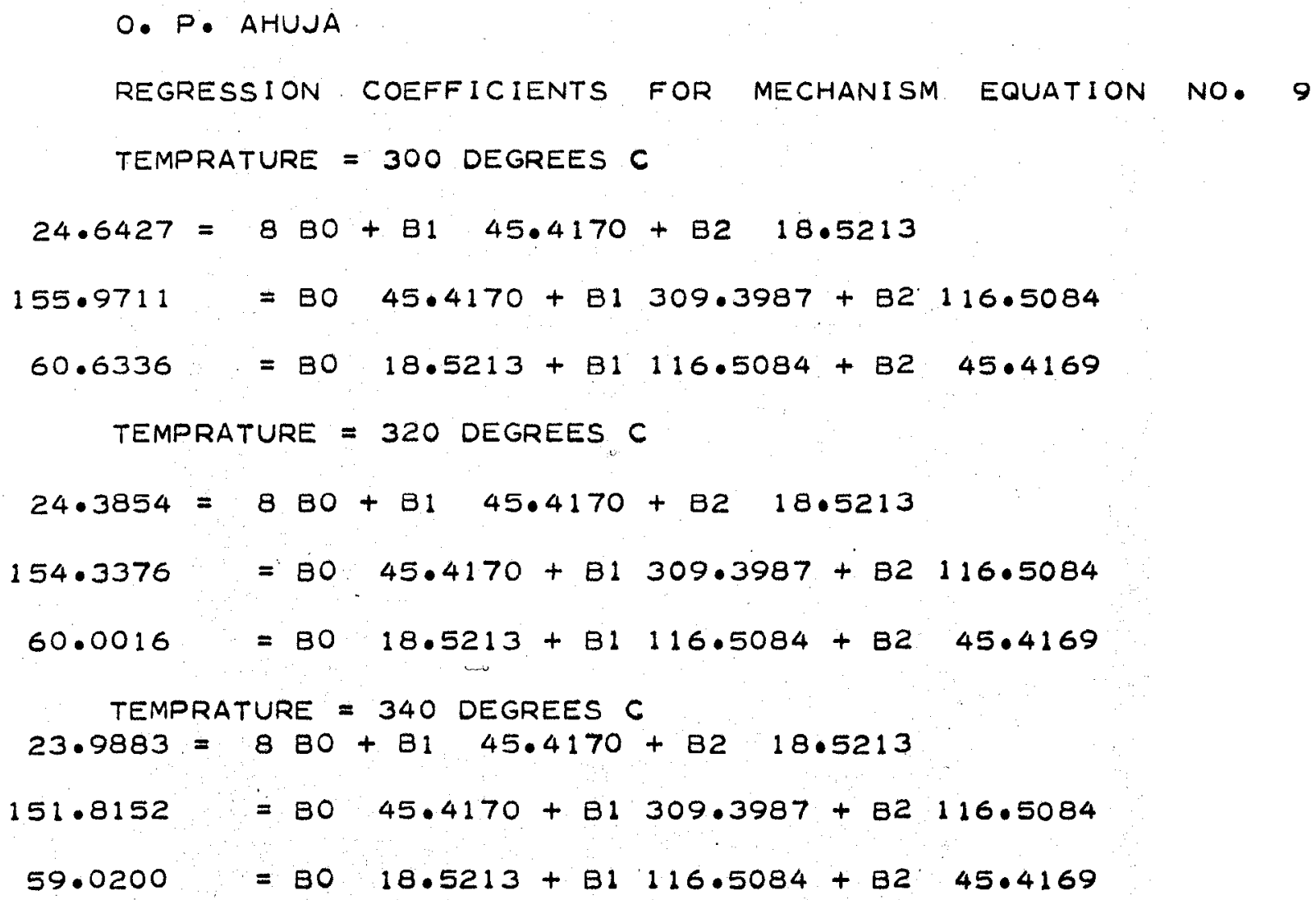


C O.P. AHUJA

- COEFFICIENTS FOR THE EMPIRICAL RATE EQUATION DIMENSION $X(15), Y(15), Z(15), A(15), B(15), R(15)$

$6 \operatorname{READ} 5,(A(J), J=1,10),(B(J), J=1,10),(R(J), J=1,10)$

DO $1 J=1,10$

$X(J)=\operatorname{LOGF}(A(J))$

$Y(J)=\operatorname{LOGF}(B(J))$

$1 Z(J)=\operatorname{LOGF}(R(J))$

$S I G X=0$.

SIGY $=0$

$S I G Z=0$

SIGXX $=0$

SIGYY $=0$

SIGXY $=0$

SIGYZ $=0$

SIGZX $=0$

DO $2 J=1.10$

$S I G X=S I G X+X(J)$

SIGY $=S I G Y+Y(J)$

$S I G Z=S I G Z+Z(J)$

SIGXX $=$ SIGXX + $X(J) * X(J)$

SIGYY $=$ SIGYY + Y $(J) * Y(J)$

SIGXY $=$ SIGXY + X(J)*Y(J)

SIGYZ = SIGYZ + Y (J)*Z(J)

2 SIGZX = SIGZX + Z(J)*X(J)

PUNCH 3,SIGZ,SIGX,SIGY

PUNCH 4, SIGZX, SIGX, SIGXX,SIGXY

PUNCH 4.SIGYZ,SIGY, SIGXY, SIGYY

3 FORMAT(F9.4,2H $=, 6 \mathrm{H} 10 \mathrm{BO}, 3 \mathrm{H}+, 2 \mathrm{HB} 1, \mathrm{F9} .4,2 \mathrm{H}+, 3 \mathrm{H} \mathrm{B2,F9.4//)}$

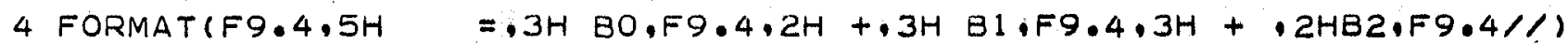

5 FORMAT $(10 F 6.6 /(10 F 6.4) /(10 F 6.3))$

GO TO 6

END

$\begin{array}{cccccccccc}4740 & 6280 & 7125 & 8160 & 8800 & 9610 & 11171 & 12310 & 11793 & 251 \\ 664 & 906 & 1029 & 1173 & 1270 & 1392 & 1610 & 1753 & 664 & 664 \\ 373 & 481 & 503 & 559 & 594 & 624 & 655 & 671 & 796 & 842 \\ 481 & 632 & 724 & 812 & 877 & 958 & 1123 & 1225 & 1177 & 2497 \\ 664 & 906 & 1029 & 1173 & 1270 & 1392 & 1610 & 1753 & 664 & 664 \\ 398 & 511 & 531 & 581 & 616 & 658 & 694 & 712 & 836 & 884 \\ 484 & 639 & 72 & 819 & 886 & 971 & 112 & 1232 & 1175 & 2531 \\ 664 & 906 & 1029 & 1173 & 1270 & 1392 & 1610 & 1753 & 664 & 664 \\ 421 & 552 & 580 & 640 & 673 & 720 & 745 & 771 & 882 & 932\end{array}$




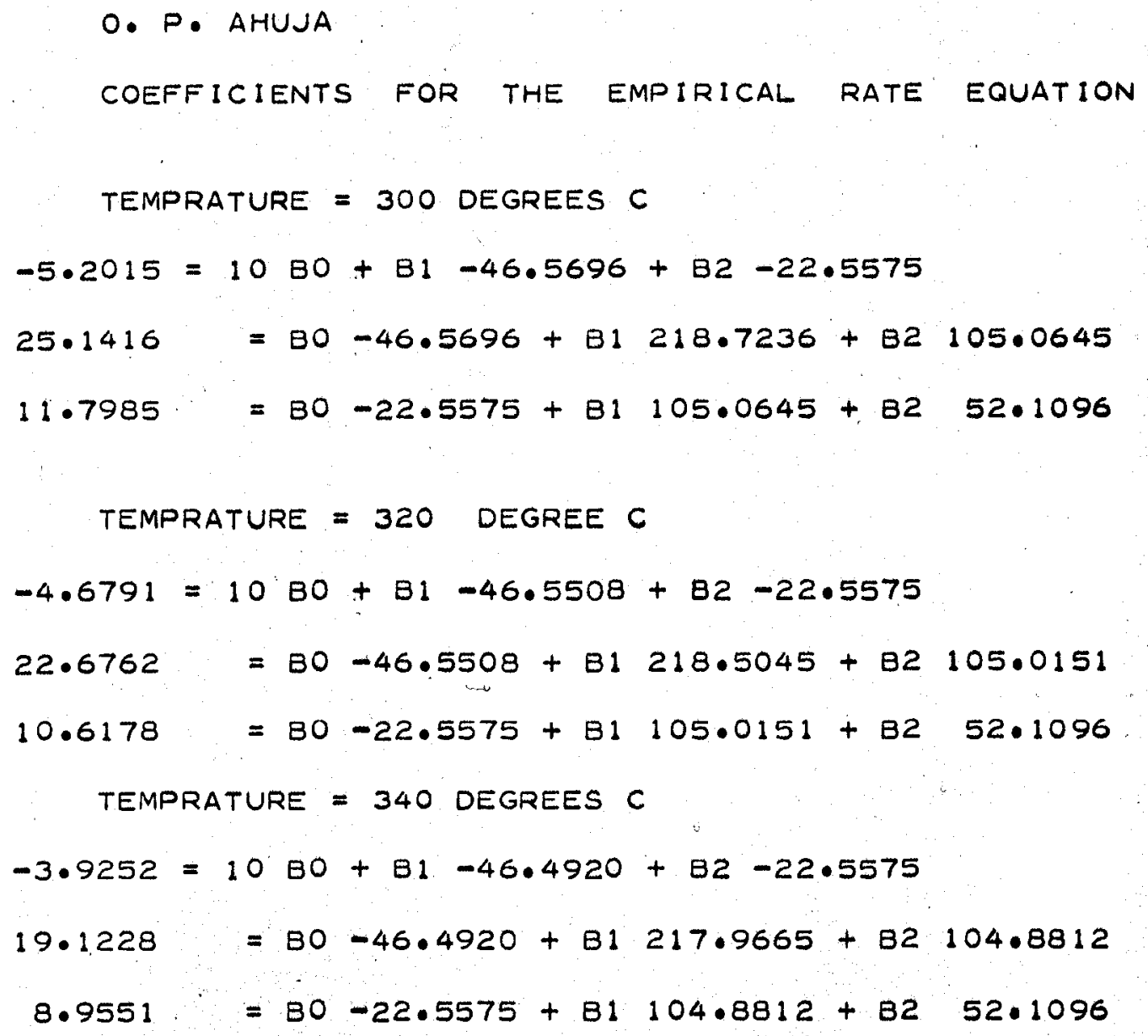


VITA AUCTORIS

1937 Born Om Parkash Ahuja on June 8, 1937, in Bhera, Surcodha. India.

1953 Completed science matriculation at Arya High School, Panipat, India..

1957 Graduated in science, D.S. College, Karnal, India.

1961 Graduated in Chemical Engineering, Indian Institute of Technology, Kharagpur, India.

1961-64 Employed in Design and Development section of DCM Chemical Works, New Delhi, India.

1964 Accepted into the Graduate School of University of Windsor as Candidate for the degree of M. A. Sc. in Chemical Engineering.

1966 Working as project Engineer, Canadian Celanese, Drummondville (Quebec). 